Linköping Studies in Science and Technology

Dissertation No. 2062

\title{
A techno-economic system approach for the energy renovation of residential districts built before 1945
}

\section{Vlatko Milić}

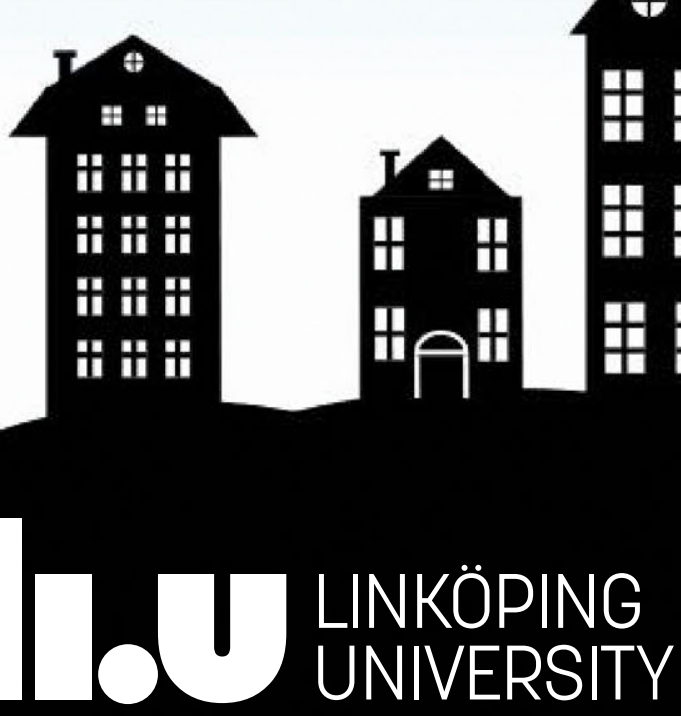



Linköping Studies in Science and Technology

Dissertation No. 2062

\title{
A techno-economic system approach for the energy renovation of residential districts built before 1945
}

\author{
Vlatko Milić
}

I.U UNNEDERSS

Division of Energy Systems

Department of Management and Engineering

Linköping University, Sweden

Linköping 2021 
(c) EY-NC This work is licensed under a Creative Commons AttributionNonCommercial 4.0 International License.

https://creativecommons.org/licenses/by-nc/4.0/

(C) Vlatko Milić, 2021

Linköping Studies in Science and Technology

Dissertation No. 2062

ISBN: 978-91-7929-874-6

ISSN: 0345-7524

Distributed by:

Linköping University

Department of Management and Engineering

SE-581 83 Linköping

Sweden

Phone: +46(0)13-28 1000

Printed by:

LiU-Tryck, Linköping, Sweden, 2021.

Cover design: Vlatko Milić 


\section{Abstract}

A key factor in the quest for sustainable development worldwide is reducing the energy use and greenhouse gas emissions from residential buildings. The residential and service sector represent 39\% of the final energy use in Sweden. The housing stock in Sweden is fairly old with approximately $25 \%$ of the residential buildings built before 1945 , many of which possess heritage values. Considering the generally poorer thermal performance in older buildings compared to newer ones, it is important to investigate the technoeconomic energy efficiency potential in this part of the built environment.

The aim of this thesis is to develop a bottom-up approach and to analyze energy renovation of residential districts built before 1945 from a system perspective with regard to targets of life cycle costs (LCC), energy use and preservation of building heritage values. The developed approach includes a combination of economic and environmental impacts from a building owner and energy utility point of view. The approach includes analysis on four different levels, i.e., building level, cluster level, district level and city level.

The results show that the developed approach is successful in integrating targets of LCC and energy use, as well as preservation of heritage values, during techno-economic energy renovation. By a further development of the change-point model, data related to building thermal power characteristics, such as $Q_{\text {total }}$ and balance temperature, can be calculated and used for analysis of a residential district. Moreover, the cluster with the initial poorest thermal performance, i.e., the single-family houses in stone, account for the highest decrease in specific energy use (70-78\%) and LCC (34-37\%) during energy renovation at LCC optimum. The corresponding figures for the buildings with the best thermal performance initially, i.e., the cluster with multi-family buildings in wood, are $23-24 \%$ and $14 \%$, respectively. Furthermore, it is concluded that the cost-effective energy efficiency potential is highly correlated with initial building properties and preservation requirements, which significantly affects the stone buildings. This is because insulation on the inside of the external walls is cost-effective in these buildings, but not in the wooden buildings, which consequently decreases the energy savings potential from $46-69 \%$ in a balanced energy renovation scenario to $8-30 \%$ in a restricted energy renovation scenario.

The findings also show that the environmental performance of the building district is closely linked with the selected energy system boundary. This can be exemplified by $\mathrm{CO}_{2}$ emissions of $0.7-1.1 \mathrm{~kg} \mathrm{CO} \mathrm{Cq}_{2} /\left(\mathrm{m}^{2} \cdot\right.$ year $)$ at LCC optimum for multi-family 
buildings when considering biomass an unlimited resource, compared to $28.9-40.0 \mathrm{~kg}$ $\mathrm{CO}_{2}$ eq. $/\left(\mathrm{m}^{2}\right.$ year $)$ when considering biomass a limited resource with condensing coal power plants as the marginal user. Furthermore, on a city level it is concluded that the environmental performance of the district heating (DH) system is improved as a result of techno-economic energy renovation of a district, and that the net income is decreased $(8 \%)$ despite a lower system cost (12-13\%) due to less DH sold to end users. The global $\mathrm{CO}_{2}$ emissions are decreased by 3,545-3,737 tonnes/year and the primary energy use is decreased by $5.0-5.2 \mathrm{GWh} /$ year.

Apart from the developed bottom-up approach for analysis of the energy renovation of residential districts built before 1945, this thesis has provided valuable results to the research community, building sector and authorities in terms of (1) the further development of the change-point model, which enables time-effective analysis of the thermal performance of residential districts; (2) the environmental benefits with technoeconomic energy renovation of residential districts from a DH producer perspective and (3) the need to develop packages of EEMs that are profitable for both $\mathrm{DH}$ producers and end users of $\mathrm{DH}$. 


\section{SAMMANFATTNING}

En nyckel till hållbar utveckling globalt är minskad energianvändning och lägre utsläpp av växthusgaser från bostäder. I Sverige står bostads- och servicesektorn för 39 \% av den slutliga energianvändningen. Bostadsbeståndet i Sverige är relativt gammalt eftersom cirka $25 \%$ av bostadshusen är byggda före 1945, varav många med historiskt värde. Med tanke på generellt sämre termiska prestanda i äldre byggnader jämfört med nyare, är det viktigt att undersöka den teknisk-ekonomiska energieffektivitetspotentialen i denna del av den byggda miljön.

Syftet med denna avhandling är att utveckla en bottom-up-strategi utifrån ett systemperspektiv och att analysera energirenovering av bostadsdistrikt byggda före 1945 med hänsyn till mål för livscykelkostnader (LCC), energianvändning och bevarande av historiska värden. Strategin inkluderar en kombination av ekonomi och miljöpåverkan ur två perspektiv: bostadsägarnas och fjärrvärmebolagets. Fyra nivåer är inkluderade i analysen, det vill säga byggnadsnivå, klusternivå, distriktsnivå och stadsnivå.

Resultaten visar att den utvecklade strategin är framgångsrik när det gäller att integrera mål för LCC och energianvändning samt för bevarande av historiska värden under teknisk-ekonomisk energirenovering. Genom en vidareutveckling av effektsignaturen kan data kopplade till byggnadens termiska effektegenskaper, såsom $Q_{\text {total }}$ och balanstemperatur, beräknas och användas för analys av ett bostadsområde. Vidare står klustret med den ursprungligen sämsta termiska prestandan, det vill säga enfamiljshusen i sten, för den största minskningen i specifik energianvändning (70-78\%) och LCC (34-37 \%) vid energirenovering enligt LCC-optimum. Motsvarande siffror för byggnaderna med ursprungligen bäst termisk prestanda, det vill säga klustret med flerfamiljshus i trä, är 23-24\% respektive $14 \%$. Resultaten visar också att den kostnadseffektiva energieffektivitetspotentialen är starkt kopplad till ursprungliga byggnadsegenskaper och bevarandekrav av historiska värden, vilket väsentligt påverkar stenbyggnaderna. Detta beror på att isolering på insidan av ytterväggarna är kostnadseffektivt i dessa byggnader, men inte i träbyggnaderna, vilket följaktligen minskar energibesparingspotentialen från 46-69 \% i ett balanserat energirenoveringsscenario till 8-30\% i ett begränsat energirenoveringsscenario med hårdare krav på bevarande.

Vidare är bostadsdistriktets miljöprestanda nära kopplad till den valda energisystemgränsen. Detta kan exemplifieras med $\mathrm{CO}_{2}$-utsläpp på 0,7-1,1 kg $\mathrm{CO}_{2}$ 
ekv. $/\left(\mathrm{m}^{2}\right.$ ·år $)$ vid LCC-optimum för flerfamiljshus, när man betraktar biomassa som en

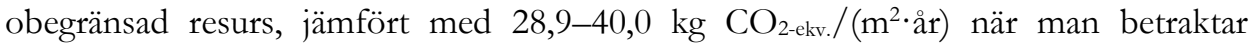
biomassa som en begränsad resurs med kolkondenskraft som den marginella användaren av biomassa. På stadsnivå visar resultaten att fjärrvärmebolagets miljöprestanda förbättrades till följd av teknisk-ekonomisk energirenovering av ett bostadsdistrikt, och att nettointäkterna minskade med $8 \%$ trots en $12-13 \%$ lägre systemkostnad på grund av mindre mängd såld fjärrvärme till kunderna. De globala koldioxidutsläppen minskade med 3 545-3 737 ton/år och den primära energianvändningen minskade med 5,0-5,2 GWh/år.

Utöver den utvecklade bottom-up-strategin för analys av energirenovering av bostadsdistrikt byggda före 1945, bidrar denna avhandling med värdefulla resultat till forskningssamhället, byggnadssektorn och myndigheterna när det gäller (1) vidareutvecklingen av effektsignaturen som möjliggör tidseffektiv analys av den termiska prestandan i bostadsdistrikt, (2) miljöfördelarna med teknisk-ekonomisk energirenovering av bostadsdistrikt ur fjärrvärmebolagets perspektiv (3) och behovet av att utveckla energieffektiviseringsåtgärder som är lönsamma för både producenter och slutanvändare av fjärrvärme. 
Mojoj dragoj mami,

koja više nije s nama 


\section{LIST OF APPENDED PAPERS}

\section{Paper I}

Vlatko Milić, Klas Ekelöw, Bahram Moshfegh

On the performance of LCC optimization software OPERA-MILP by comparison with building energy simulation software IDA ICE

Building and Environment, 128 (2018), 305-319

\section{Paper II}

Vlatko Milić, Klas Ekelöw, Maria Andersson, Bahram Moshfegh

Evaluation of energy renovation strategies for 12 historic building types using LCC optimization

Energy and Buildings, 197 (2019), 156-170

\section{Paper III}

Petra Eriksson, Vlatko Milić, Tor Broström

Balancing preservation and energy efficiency in building stocks

International Journal of Building Pathology and Adaption, 38 (2019), 356-373

\section{Paper IV}

Vlatko Milić, Shahnaz Amiri, Bahram Moshfegh

A systematic approach to predict the economic and environmental effects of the cost-optimal energy renovation of a historic building district on the district heating system

Energies, 2020, 13(1)

\section{Paper V}

Vlatko Milić, Patrik Rohdin, Bahram Moshfegh

Further development of the change-point model-Differentiating thermal power characteristics for a residential district in a cold climate

Energy and Buildings, 231 (2021), 110639 


\section{ACKNOWLEDGEMENTS}

My research would not have been possible without the financial support from the Swedish Energy Agency. Therefore, I would like to acknowledge them for enabling my $\mathrm{PhD}$ studies.

There are several people that have supported me during my research that I would like to acknowledge.

First, I would like to express my deepest gratitude to my main supervisor, Professor Bahram Moshfegh, for introducing me to the amazing world of science. I am forever thankful for your never-ending support, guidance and inspiration during my research.

I would like to pay my special regards to my co-supervisor, Associate Professor Patrik Rohdin, for our fruitful discussions regarding numerous questions related to my research topic. You continuously provided encouragement and were always willing and enthusiastic to help in any way you could throughout my $\mathrm{PhD}$ studies. I would also like to thank my co-supervisor, Klas Ekelöw, PhD, who supported me in the beginning of my research. Thanks to my co-supervisor, Maria Andersson, PhD, for your valuable comments on my research. I would also like to acknowledge Professor emeritus StigInge Gustafsson for your invaluable support with the OPERA-MILP software. I wish to show my gratitude to Linn Liu, PhD, whose support guided me in the right direction in the start of my research. Thank you for all our discussions on all kinds of topics, and your good sense of humor.

I wish to show my gratitude to the Swedish Meteorological and Hydrological Institute, Tekniska Verken and Gotlands Energi AB. Thank you for sharing your data. My research would not have been possible without your contribution. I would also like to thank Professor Tor Broström, PhD student Petra Eriksson and Anna Donarelli for our invaluable collaboration during my $\mathrm{PhD}$ studies. Your expertise and guidance within heritage values has truly improved my thesis. I would like to acknowledge Shahnaz. Amiri, $\mathrm{PhD}$, for contributing her expertise in energy system optimization during my research. Thanks to Ralf Kilian, PhD, and colleagues at the Fraunhofer Institute for Building Physics in Holzkirchen, Germany, for opening the doors for me as a guest researcher. Financial support was received from "Bengt Ingeströms stipendiefond" which made my visit possible.

I would like to thank all my colleagues at the Division of Energy Systems, and especially thanks to Elisabeth Larsson for always being helpful and kind. I could not have asked for 
better colleagues. We have helped each other grow as individuals and researchers, and also shared a lot of laughter during our coffee breaks.

Finally, I would like to thank my family and friends for your support during the years of my PhD studies. Ett särskilt tack till Hagny och Ralph för all er omtanke under åren. Hvala mojoj obitelji i rodbini, sestri Antoneli, zetu Josipu i Ankici, na vašoj ljubavi i što stojite uz mene. Zauvijek sam zahvalan što vas imam u žvotu. Najveće hvala dugujem svom tati Ivici. Cijeli moj život si se borio svim snagama kako ništa ne bi nedostajalo, kako meni, tako i mojoj sestri. Uvijek si nas stavljao ispred sebe. Bez tebe ne bih bio ono što jesam danas. 


\section{LIST OF ABBREVIATIONS}

\begin{tabular}{|c|c|}
\hline $\mathrm{ACH}$ & Air changes per hour \\
\hline BBR & Swedish building regulations \\
\hline BES & Building energy simulation \\
\hline $\mathrm{BXX}$ & Building number XX \\
\hline $\mathrm{CHP}$ & Combined heat and power \\
\hline DG & Double-glazed windows \\
\hline $\mathrm{DH}$ & District heating \\
\hline DTPC & Differentiating thermal power characteristics \\
\hline EEMs & Energy efficiency measures \\
\hline ER & Electric radiator \\
\hline GHP & Groundwater heat pump \\
\hline GIS & Geographic information system \\
\hline $\mathrm{HOBs}$ & Heat-only boilers \\
\hline HTW & Hot tap water \\
\hline HVAC & Heating, ventilation and air conditioning \\
\hline HWC & Hot water circulation \\
\hline $\mathrm{IHG}$ & Internal heat generation \\
\hline LCC & Life cycle costs \\
\hline MODEST & $\begin{array}{l}\text { Model for Optimization of Dynamic Energy Systems with Time- } \\
\text { dependent components and boundary conditions }\end{array}$ \\
\hline NPV & Net present value \\
\hline OPERA-MILP & $\begin{array}{l}\text { Optimal Energy Retrofits Advisory-Mixed Integer Linear } \\
\text { Program }\end{array}$ \\
\hline SEK & Swedish kronor \\
\hline
\end{tabular}


TG+L.E.

WB
Triple-glazed windows with low emission glass

Wood boiler 


\section{NOMENCLATURE}

\begin{tabular}{|c|c|}
\hline$A$ & Area $\left(\mathrm{m}^{2}\right)$ \\
\hline C & Cost (SEK) \\
\hline$C_{p}$ & Specific heat capacity $\left(\mathrm{J} /\left(\mathrm{kg} \cdot{ }^{\circ} \mathrm{C}\right)\right)$ \\
\hline$d$ & Discount rate $(\%)$ \\
\hline$E$ & Energy (Wh) \\
\hline$L C C_{\text {energy cost }}$ & Energy cost (SEK) \\
\hline$L C C_{\text {investment cost }}$ & Investment cost for EEMs (SEK) \\
\hline$L C C_{\text {maintenance cost }}$ & Maintenance cost (SEK) \\
\hline$L C C_{\text {total }}$ & Total LCC of a building (SEK) \\
\hline$P$ & Power (W) \\
\hline qinfiltration & Infiltration air flow rate $\left(\mathrm{m}^{3} / \mathrm{s}\right)$ \\
\hline qventilation & Ventilation air flow rate $\left(\mathrm{m}^{3} / \mathrm{s}\right)$ \\
\hline$Q_{\text {infiltration }}$ & Infiltration losses $\left(\mathrm{W} /{ }^{\circ} \mathrm{C}\right)$ \\
\hline$Q_{\text {total }}$ & Total specific heat losses $\left(\mathrm{W} /{ }^{\circ} \mathrm{C}\right)$ \\
\hline$Q_{\text {transmission }}$ & Transmission losses $\left(\mathrm{W} /{ }^{\circ} \mathrm{C}\right)$ \\
\hline$Q_{\text {ventilation }}$ & Ventilation losses $\left(\mathrm{W} /{ }^{\circ} \mathrm{C}\right)$ \\
\hline$s$ & Number of years $(-)$ \\
\hline$t$ & Time period (h) \\
\hline$T_{\text {balance }}$ & Balance temperature $\left({ }^{\circ} \mathrm{C}\right)$ \\
\hline$T_{\text {in }}$ & Indoor temperature $\left({ }^{\circ} \mathrm{C}\right)$ \\
\hline$T_{\text {ODT }}$ & Outdoor design temperature $\left({ }^{\circ} \mathrm{C}\right)$ \\
\hline$T_{\text {out }}$ & Outdoor temperature $\left({ }^{\circ} \mathrm{C}\right)$ \\
\hline$U$ & Overall heat transfer coefficient $\left(\mathrm{W} /\left(\mathrm{m}^{\left.2 \cdot{ }^{\circ} \mathrm{C}\right)}\right)\right.$ \\
\hline
\end{tabular}




$\begin{array}{ll}\varrho & \text { Density }\left(\mathrm{kg} / \mathrm{m}^{3}\right) \\ \tau & \text { Time constant }(\mathrm{h}) \\ \eta & \text { Efficiency }(-) \\ \Psi & \text { Degree hours }\left({ }^{\circ} \mathrm{C} \cdot \mathrm{h}\right)\end{array}$




\section{TABle of CONTENTS}

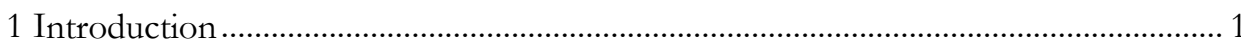

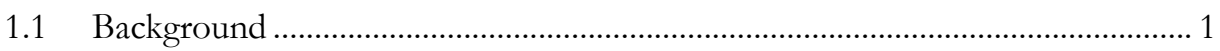

1.2 Motivation of research....................................................................................... 4

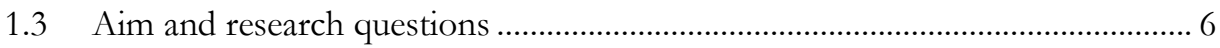

1.4 Description of research journey and methodological approach......................... 7

1.5 Overview of papers and co-author statement .............................................. 9

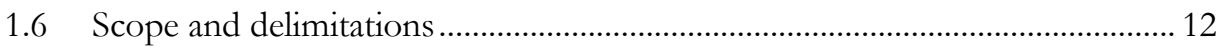

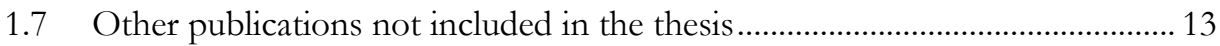

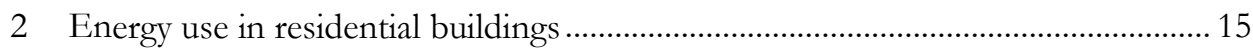

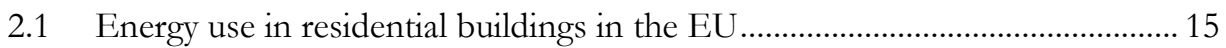

2.2 Energy use in Swedish residential buildings.................................................. 17

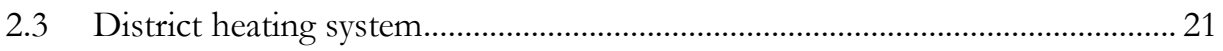

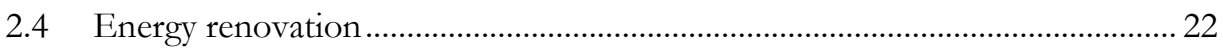

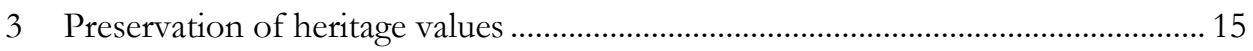

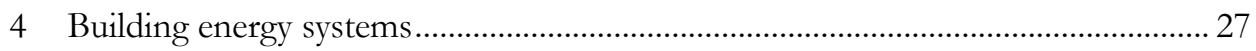

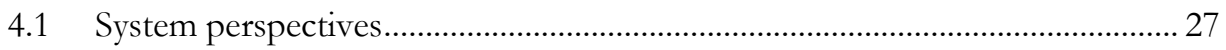

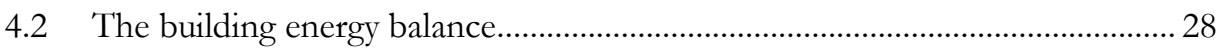

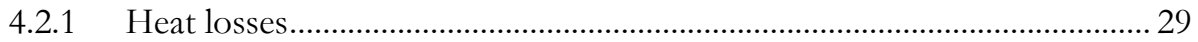

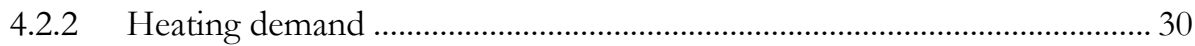

4.2.3 Power demand and heating system ......................................................... 31

4.3 Modeling energy use in the residential building sector.................................... 31 


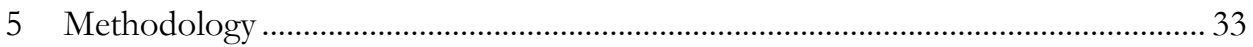

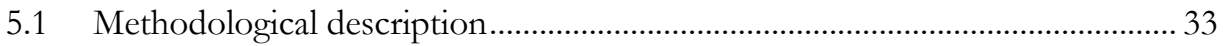

5.1.1 Building level.............................................................................................. 34

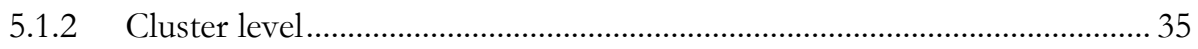

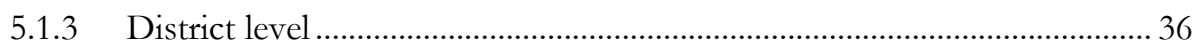

5.1.4 City level .............................................................................................. 37

5.2 Methods and tools....................................................................................... 37

5.2.1 Bottom-up approach................................................................................... 37

5.2.2 Building energy simulation ....................................................................... 40

5.2.3 Change-point modeling ............................................................................... 41

5.2.4 Life cycle cost analysis and optimization..................................................... 46

5.2.5 Environmental assessment $-\mathrm{CO}_{2}$ emissions and primary energy use ..... 50

5.2.6 Local energy system analysis and optimization .......................................... 53

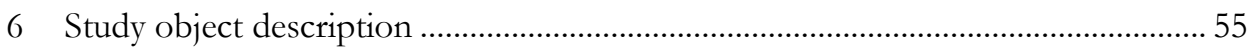

6.1 Building types and district heating system in Visby ……………....................... 55

6.2 Residential district in Linköping ........................................................................ 59

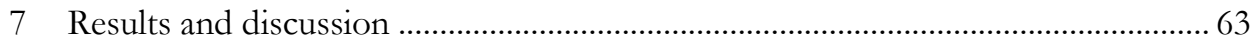

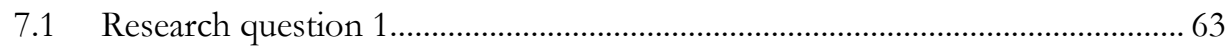

7.1.1 Cost-effective packages of EEMs on a residential district.......................... 64

7.2 Research question 2..................................................................................... 71

7.3 Research question 3..................................................................................... 76

7.3.1 $\mathrm{CO}_{2}$ emissions and primary energy use ………………………………….... 76 


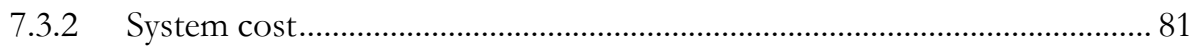

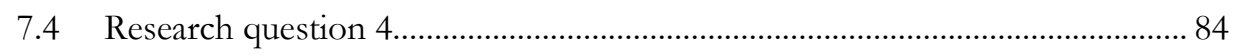

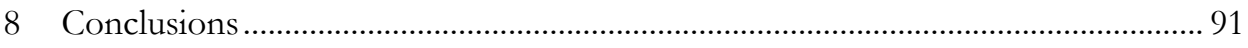

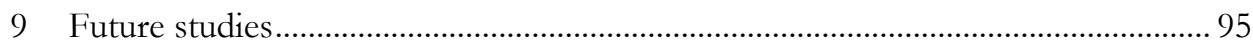

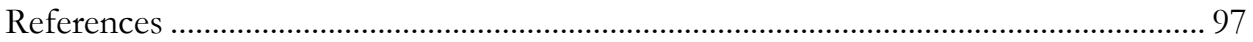




\section{INTRODUCTION}

This chapter first describes the research area of the thesis. Then the aim and research questions are presented, as well as a description of my research journey and methodological approach. Following this, an overview of the appended papers, scope and delimitations, and other publications not included in the thesis, are presented.

\subsection{BACKGROUND}

Housing is a vital human need, and key for socio-cultural growth and the development of a country [1]. Additionally, on a national level housing is an important economic asset. To achieve desirable indoor temperatures in buildings and hence a sound indoor environment, there is a need for energy supply. Globally, the built environment was responsible for $36 \%$ of final energy use and $39 \%$ of $\mathrm{CO}_{2}$ emissions in 2018 [2]. The corresponding figures within the European Union (EU) are $40 \%$ and $36 \%$, respectively [3]. Within the EU, the existing building stock is identified as the single sector with the highest energy savings potential [4] with almost $75 \%$ of the buildings being energy inefficient [3]. Based on figures from 2017, the final energy use in households is 3,293 TWh (27\%) in the EU [5]. In a Northern European climate, heat supply to buildings is often highly resource demanding. Space heating corresponds to the major part of the total energy supply [6]. Therefore, good building thermal performance is crucial for decreasing life cycle costs (LCC), especially when considering the long life cycle of buildings.

The 2030 Climate \& Energy Framework includes an energy efficiency target of minimum $32.5 \%$ by 2030 compared to 1990 levels and a reduction in $\mathrm{CO}_{2}$ emissions by $40 \%$ [7]. The amended Energy Performance of Buildings Directive (EPBD) $(2018 / 844 / \mathrm{EU})$ targets a highly energy efficient and decarbonized building stock by 2050 [8]. The Swedish climate policy framework targets reductions in greenhouse gas emissions of $63 \%$ by 2030 compared to 1990 , and also states that by 2045 at the latest national greenhouse gas emissions should be net zero [9]. Moreover, a 50\% increase in energy efficiency is targeted by 2030 compared to 2005. Hence, frameworks exist both nationally and on the EU level for improving the thermal performance of the current building stock and decreasing associated greenhouse gas emissions, which consequently place high demands on the research community, building sector and policy makers. 
The housing stock within the EU is relatively old with approximately $20 \%$ of the residential buildings built before $1945^{1}$ [10]. Of this part of the built environment, many buildings are historic. The same tendencies can be seen in Sweden with circa $25 \%$ of the residential buildings built before 1945 [10], which are the focus in this thesis. From an energy savings perspective nationally in Sweden, this segment of the building stock is important due to generally poorer thermal performance in older buildings compared to newer ones [11]. Even though only a small number of buildings built before 1945 are classified as listed (approximately 2,500 in Sweden [12]), these buildings often possess heritage values that cannot be distorted as a result of renovation, which is pointed out by the European Commission [8]. Nationally, legislation connected to the preservation of heritage values is addressed in the Swedish Planning \& Building Act $(1987: 10)^{2}$ [13] and by the Historic Environment Act (1988:950) [14]. Hence, many buildings built before 1945 have commonly been exempted from requirements on energy efficiency due to the complexity during renovations in developing energy efficiency measures (EEMs) that simultaneously preserve heritage values [15]. This requires solutions based on knowledge and integration between multiple disciplines, i.e., cross-disciplinarity. However, considering the overall high energy efficiency potential in the older housing stock, and the ambitious energy and climate targets both in the EU and Sweden, energy efficiency improvements are also required in this part of the building stock. To generate techno-economic packages of feasible EEMs in buildings built before 1945, it is necessary to use a system approach. This enables a better understanding of the studied system and the underlying complexity of implementing EEMs in buildings built before 1945.

Building renovation is a broad term covering a large range of actions in a building [16]. This can for example be renovation of building elements or various types of maintenance. Improving building thermal performance and hence lowering the energy use is often referred to as "energy renovation." The term does not have a widely accepted definition in the EU in terms of renovation depth and the resulting energy savings. The connection between final energy savings and varying degrees of energy renovations has, however, been used by the Buildings Performance Institute Europe [17]. Energy efficiency improvements resulting in final energy savings between $0-30 \%$, $30-60 \%$ and $60-90 \%$ correspond to minor, moderate and deep energy renovation, respectively. To achieve the abovementioned targets in EU of a decarbonized building

\footnotetext{
${ }^{1}$ The title of the thesis refers to buildings built before 1945 since the term is more recognized within the research field. However, buildings constructed in 1945 are also included in this research.

${ }^{2}$ Replaced the Swedish Planning \& Building Act (1987:10) in 2/5/2011.
} 
stock by 2050, an increase in deep renovation of the current building stock to nearly zero-energy buildings is pointed out as a key factor [8]. An average annual renovation rate of $3 \%$ is needed to fulfill the set objectives, which places high demands on national authorities and the building sector within the EU, especially when considering the significantly lower renovation pace today of approximately 1.2\% [18]. Ambitious energy targets for buildings undergoing renovation to decrease the environmental impact from the building sector is also realized on a national level in Sweden. When a building undergoes renovation, the same energy requirements are strived for as in newly constructed buildings according to Swedish building regulations (BBR) [19]. Moreover, there are other incentives apart from improved building thermal performance and associated improved environmental performance from performed energy renovation, such as economic benefits [20], as well as increased living standard and better indoor environment [21].

District heating (DH) accounts for $52 \%$ of the heating supply to one- and two-dwelling buildings ${ }^{3}$ and multi-family buildings in Sweden [22]. It is especially the heating supply to multi-family buildings that is characterized by $\mathrm{DH}$ which corresponds to more than $90 \%$ of the total heated area and energy use [23], explained by the urban location of most multi-family buildings, making them appropriate for connection to DH networks. Twelve percent of the heating supply to one- and two-dwelling buildings occurs via $\mathrm{DH}$. Private owners correspond to $95 \%$ of one- and two-dwelling buildings [24] while the form of ownership for multi-family buildings is more varied. Member-owned buildings account for $43 \%$, privately owned $31 \%$ and municipally owned $26 \%$. A Swedish study investigating how building owners work with renovations showed that the main reasons for building renovation are technical aspects, i.e., the various building elements must be renovated or replaced due to poor technical status [25]. Other high-ranking reasons include high energy use, as well as high operation and maintenance costs. In addition, it was shown that the heritage values are in many cases not considered at all. This is despite the fact that the Swedish Planning and Building Act (2010:900) states that changes to a building must be carried out carefully, considering the character-defining elements of the building in terms of the technical, historical, cultural-historical, environmental and aesthetic values [13]. Energy renovation of buildings built before 1945 creates cross-disciplinary challenges for improving the thermal performance of the building stock in a cost-effective manner while preserving heritage values. The complexity of the task is increased when considering the need to model entire residential districts. Moreover, improvement in building thermal performance is directly

${ }^{3}$ Detached, semi-detached and terraced one- and two-dwelling buildings. 
linked with the magnitude of the heat load in a DH system, especially when investigating entire residential districts, which consequently affects the economic and environmental performance of the $\mathrm{DH}$ system. The large proportion of residential buildings connected to DH systems in Sweden stresses the importance of assessing building energy renovation effects on the local DH systems.

\subsection{MOTIVATION OF RESEARCH}

As described in the previous section, the built environment accounts for a significant part of total energy use both nationally in Sweden and on a global level, which is also the case for greenhouse gas emissions connected to global warming. In order to decrease the environmental impact from the building sector, authorities have identified the existing building stock as a key sector. This is in particular the case for the building stock built before 1945 due to often poorer thermal performance in older buildings compared to newer ones [11]. To promote an increased pace of energy renovation from a building owner perspective, there is a need for developing economically viable EEMs in various types of buildings. This puts demands on national governments for implementing profitable EEMs in the building stock. In addition, in Sweden it is shown that from a building owner perspective, techno-economic factors are a main priority during renovation along with energy efficiency [25]. For predictions of the optimal techno-economic level of a building, an LCC optimization tool is required. However, in order to ensure a high reliability of the predicted energy use by the LCC optimization tool, the predictions need to be validated with more advanced building simulation tools.

It is important to be aware that many buildings built before 1945 possess heritage values that cannot be distorted during renovations. The Swedish Planning and Building Act (2010:900) states that the character-defining elements of a building need to be taken into account when changing a building [13]. Buildings which are particularly valuable from a historical, cultural-historical, environmental, or aesthetic point of view have enhanced protection and cannot be distorted. However, these buildings constitute an insignificant proportion of the total heated area of the building stock built before 1945, which can be exemplified by the fact that only around 2,500 buildings are classified as listed in Sweden [12]. Consequently, it is the large quantity of buildings built before 1945 without enhanced protection against distortion, which are of interest to investigate in terms of techno-economic energy efficiency potential. In order to enable investigation of a residential district, it is possible to apply a bottom-up approach using representative buildings. By doing so, prediction of the cost-effective energy efficiency potential is made possible on a cluster level and district level. A question that arises when investigating techno-economic energy renovation of residential districts built 
before 1945, which has not been in focus in the scientific community, is the impact on the environmental and economic performance of the connected DH system. By improving building thermal performance, the heat demand will be decreased in the $\mathrm{DH}$ system, which is counterproductive for the DH supplier due to less DH sold to customers. However, implemented energy renovation measures could also be beneficial for the DH supplier by reducing the use of costly peak load plants during wintertime. Therefore, prediction of the economic and environmental effects on a DH system from building energy renovation are complex considering varying local conditions, such as fuel mix, heat-only production boiler or combined heat and power (CHP) plant. Moreover, it is necessary to achieve a holistic picture of the relationship between techno-economic EEMs in a residential district and the local DH system. This task can be facilitated by applying a system approach, which contributes to a better understanding of the various components within the system.

A fundamental issue of assessing the energy efficiency potential in the building stock built before 1945 is the lack of data describing the thermal performance of entire residential districts. By generating performance indicators based on temperaturedependent heat losses, authorities can be supported in identifying buildings with poor thermal performance. Presently in Sweden, existing data on building thermal performance on a larger number of buildings is found in the National Energy Audit Program for Buildings (GRIPEN) in which specific energy use, i.e., $\mathrm{kWh} /\left(\mathrm{m}^{2} \cdot\right.$ year), is used as a performance indicator for hundreds of thousands of buildings. The main downside with GRIPEN includes non-dynamic data and describing thermal performance as total energy use supplied to a building, which means that there is no differentiation between performance indicators. There are databases with more detailed descriptions of a building's thermal performance, which is mainly found in BETSI on a national level in Sweden [11]. The negative aspect of these databases is the small quantity of buildings built in 1945 or before included to enable predictions of the current thermal performance at a residential district level. For example, BETSI includes 60 multi-family buildings and 115 one- or two-dwelling buildings built in 1945 or before. However, possibilities exist for predicting building temperature-dependent heat losses in a time-effective manner for entire residential districts. By using actual heating supply data in combination with outdoor temperature, a building's change-point model can be developed and thermal power characteristics can be studied, such as specific heat losses and balance temperature, which consequently provides more information compared to specific energy use. This kind of data is valuable for identifying buildings with poor thermal performance in a residential district and can be used for categorizing buildings depending on thermal power characteristics. 
To date, a number of scientific investigations have been performed investigating the economic aspects from energy renovation of buildings built before 1945 together with an associated evaluation of the environmental performance. However, prior research mainly deals with the renovation of single buildings. Consequently, there is a need to shift focus to a cluster level and district level. By mapping the thermal performance in buildings within a residential district, hotspots in terms of energy efficiency potential are possible to identify. In addition, the impact from techno-economic EEMs on the energy-related expenditures during the building life cycle can be analyzed. Furthermore, combining a bottom-up approach based on representative residential buildings extrapolated to a cluster level and district level with an analysis of the local energy system, allows for investigation of the economic and environmental performance on a city level. Lastly, a shift to research on cluster, district and city level can support the quest for a sustainable transformation of the built environment built before 1945 with regards to economic and environmental performance in order to achieve national and EU climate targets.

\subsection{AIM AND RESEARCH QUESTIONS}

The aim of this thesis is to develop a bottom-up approach and to analyze energy renovation of residential districts built before 1945 from a system perspective with regard to targets of LCC, energy use and preservation of building heritage values. The impacts will be further analyzed in terms of economic and environmental performance, both from a building owner and energy utility perspective.

The following research questions (RQs) are answered to fulfill the aim.

RQ1. How can a bottom-up approach be used to analyze packages of cost-effective EEMs on a residential district built before 1945 ?

RQ2. How can preservation of building heritage values be integrated in the proposed bottom-up approach when analyzing packages of cost-effective EEMs on a residential district built before 1945?

RQ3. How can local energy system analysis and optimization be combined with the bottom-up approach on a district level to analyze $\mathrm{CO}_{2}$ emissions, primary energy use and system costs on a city level?

RQ4. How can the bottom-up approach be combined with a change-point model for analysis of a residential district built before 1945 ? 


\subsection{DESCRIPTION OF RESEARCH JOURNEY AND METHODOLOGICAL APPROACH}

This thesis is the result of two research projects. When I started my $\mathrm{PhD}$, I was working within the interdisciplinary research project "Potential and policies for energy efficiency in Swedish buildings built before 1945 (Stage II) - Energy systems analysis" in which the overall aim was to develop an interdisciplinary approach for analysis of the energy savings potential in Swedish buildings built before 1945. The research project included further development of a tool for techno-economic assessment of energy savings potential and a statistical assessment of the cost-effective energy savings potential in the Swedish building stock built before 1945. The project was performed in collaboration between the division of Energy Systems at Linköping University and the Department of Art History/Building Conservation at Uppsala University. My own research was mainly oriented towards investigating the potential with cost-effective packages of EEMs for various building types built before 1945 using the techno-economic LCC optimization software OPERA-MILP. Since the energy calculations in OPERA-MILP are performed using a quasi-steady-state approach it was important to ensure reliable accuracy in the calculations of OPERA-MILP. This was performed by comparison with building energy simulation (BES) software IDA ICE, which was presented in Paper I. Prior to and in connection with Paper I, I collected extensive data in order to enable simulation and optimization procedures. Based on an inventory and categorization of the building district built before 1945 in Visby, Sweden, the data collection consisted of building construction data and input data for the techno-economic optimization. This was performed in total for 12 building types, which are different in terms of construction and layout. The collected input data laid the foundation for Papers I-IV. In Paper II, an evaluation of cost-effective packages of EEMs is performed for the abovementioned building types. The evaluation includes overall three key elements: LCC, packages of cost-effective EEMs, and environmental performance in the form of $\mathrm{CO}_{2}$ emissions and primary energy use. In order to demonstrate the replicability of optimizing single building types to a higher number of buildings, general tendencies in terms of selected renovation measures were identified on a cluster level. In Paper III, an interdisciplinary step-by-step method is presented for implementing cost-effective packages of EEMs in the residential district built before 1945 in Visby based on building categorization, definition of restriction levels for various energy renovation scenarios and LCC optimization. While Papers I-III focus to a large extent on optimization procedures and cost-effective packages of EEMs for single buildings, clusters of buildings and entire districts, Paper IV suggests a systematic approach for prediction of the effects from techno-economic LCC optimization of a residential district built before 
1945 on the local DH system. This includes both economic figures and environmental performance.

The second research project I was involved in was "Categorization of the Swedish stock of historic valuable buildings." This research was a continuation project of the abovementioned project "Potential and policies for energy efficiency in Swedish buildings built before 1945 (Stage II) - Energy systems analysis". This project aimed to address the issue of lacking or poor information in the existing register of buildings with heritage values. Moreover, the research also included the development of a statistical model for quantification of thermal power characteristics in residential districts. My part of this project consisted of collecting heating supply data for a residential district built before 1945 and local climate data in the form of outdoor temperature, and thereafter development of the abovementioned statistical model. Paper V was based on development of the statistical model.

A bottom-up approach has been used for analyzing the energy renovation of a residential district. This is allowed through mapping and collection of geographic information system (GIS) data for an entire district, which can consequently generate building types representative of the studied district through building categorization. Hence, it is possible to study energy use, power demand, LCC, primary energy use, $\mathrm{CO}_{2}$ emissions and cost-effective packages of EEMs at building level by modeling, simulation and optimization procedures of the generated building types. Input data consist of construction data generated by the building categorization, as well as climate data and economic data for building LCC. Through the mapping and data collection of the entire residential district, the corresponding results can be generated for a larger set of buildings. This is performed by considering the number of buildings represented by each cluster and the entire district. Cluster level corresponds to different building types representative of similar buildings with regard to building size and type of building structure, and district level corresponds to the entire residential district consisting of all clusters.

Moreover, by collection of heat load data and operational data for the DH system to which the studied district is connected, together with the use of energy system analysis and optimization, it is possible to generate results in terms of system cost, optimal DH production, $\mathrm{CO}_{2}$ emissions and primary energy use of the DH system, titled "city level" in this research. A schematic of the methodological approach is given in Figure 1. 


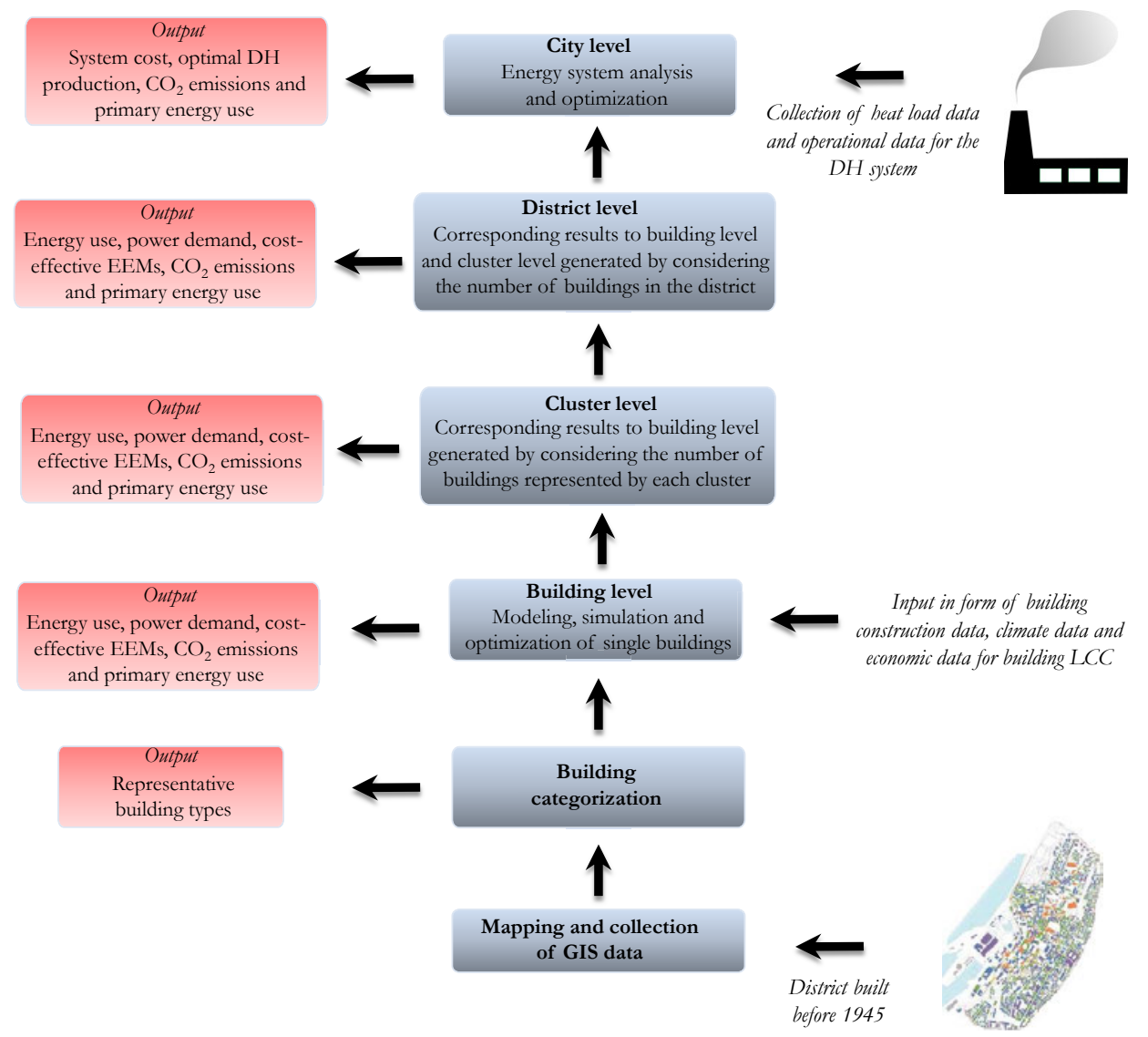

Figure 1: Schematic of the bottom-up approach used in this research.

\subsection{OVERVIEW OF PAPERS AND CO-AUTHOR STATEMENT}

This thesis is based on the work presented in five papers, which are listed below, together with a brief co-author statement. Moreover, the connection between the appended papers and the RQs is summarized at the end of this section.

\section{Paper I}

Vlatko Milić, Klas Ekelöw, Bahram Moshfegh.

On the performance of LCC optimization software OPERA-MILP by comparison with building energy simulation software IDA ICE

Building and Environment, 128 (2018), 305-319 
The aim of this paper was to investigate the performance of the techno-economic LCC optimization software OPERA-MILP by comparison with dynamic BES IDA ICE. The aim was fulfilled through quantification of differences in building power demand and energy use between the two software programs, as well as the consequential impact on LCC. Three building types built before 1945 with typically good, intermediate and poor thermal insulation of the building envelope for the city of Visby were selected as the study object. The analysis of the performance of OPERA-MILP was strengthened by assessing the impact on the results both before and after cost-effective energy renovation, as well as investigating different climate zones. The paper was written by the author of this thesis. Valuable guidance from Klas Ekelöw and Bahram Moshfegh helped to explore the differences between the two software programs. The co-authors also contributed valuable insights concerning the content of the paper.

\section{Paper II}

Vlatko Milić, Klas Ekelöw, Maria Andersson, Bahram Moshfegh

Evaluation of energy renovation strategies for 12 historic building types using LCC optimization

Energy and Buildings, 197 (2019), 156-170

This paper presents an evaluation of cost-effective packages of EEMs using the LCC optimization software OPERA-MILP described in Paper I. The evaluation is performed based on preset targets depending on LCC (LCC optimum) and energy use (decrease by $50 \%$ compared to status quo) where the environmental performance is also investigated in terms of primary energy use and $\mathrm{CO}_{2}$ emissions. Twelve building types, representing 920 buildings and typical of the residential district built before 1945 in Visby, Sweden, were used as the study object. The thesis author was responsible for the performed optimizations and writing the paper. Klas Ekelöw and Bahram Moshfegh were involved in the evaluation of the results, and also contributed valuable comments on the content of the paper together with Maria Andersson.

\section{Paper III}

Petra Eriksson, Vlatko Milić, Tor Broström

\section{Balancing preservation and energy efficiency in building stocks}

International Journal of Building Pathology and Adaption, 38 (2019), 356-373

This paper builds on the development of a step-by-step method for generating costeffective EEMs while preserving heritage values in a residential district built before 1945. The method includes categorization of a residential district, definition of restriction levels for various energy renovation scenarios and LCC optimization of the 
twelve building types, which are also investigated in Paper II. The thesis author was responsible for the LCC optimizations. Moreover, the thesis author provided valuable knowledge in the analysis and discussion of the results and contributed to the writing of the paper.

\section{Paper IV}

Vlatko Milić, Shahnaz Amiri, Bahram Moshfegh

\section{A systematic approach to predict economic and environmental effects of the cost-optimal energy renovation of a historic building district on the district heating system}

Energies, 2020, 13(1)

This paper presents a systematic approach based on building categorization, LCC optimization, BES and energy system optimization procedures, for prediction of the economic and environmental performance of a DH system when performing energy renovation of a residential district built before 1945. The same building types used in Paper II and Paper III were used as the study object. To assess the impact from different packages of energy renovation measures on the DH system in Visby, the optimizations were performed based on the lowest possible LCC and energy targets according to Swedish building regulations, BBR. Shahnaz Amiri was responsible for the optimizations performed in energy system optimization software MODEST and helped with writing the paper connected to the MODEST results. Bahram Moshfegh helped the thesis author to shape the results and discussion section, and contributed valuable comments.

\section{Paper V}

Vlatko Milić, Patrik Rohdin, Bahram Moshfegh

Further development of the change-point model-Differentiating thermal power characteristics for a residential district in a cold climate

Energy and Buildings, 231 (2021), 110639

In this paper, a residential district with 73 multi-family buildings built between 1908 and 1945, is selected as the study object. The district is located in Linköping, Sweden, and connected to the DH network. The paper presents a development of the change-point model for prediction of building thermal power characteristics in the form of specific heat losses, energy use for hot water circulation (HWC) and hot tap water (HTW), as well as balance temperature. The key contribution of the model is the differentiation of building thermal power characteristics using heating supply data and local climate data in the form of outdoor temperature. Patrik Rohdin and Bahram Moshfegh contributed 
valuable insights during the development of the change-point model and helped with valuable comments during the writing of the paper.

The connection between the respective paper and the research questions from section 1.2 is shown in Table 1.

Table 1: Connection between appended papers and research questions.

\begin{tabular}{l|c|c|c|c|c}
\hline $\begin{array}{l}\text { Research } \\
\text { question }\end{array}$ & Paper I & Paper II & Paper III & Paper IV & Paper V \\
\hline RQ1 & $\times$ & $\times$ & $\times$ & $\times$ & \\
RQ2 & $\times$ & $\times$ & $\times$ & $\times$ & \\
RQ3 & & $\times$ & & $\times$ & \\
RQ4 & & & & & \\
\hline
\end{tabular}

\subsection{SCOPE AND DELIMITATIONS}

In this thesis, the term "energy efficiency measures" (EEMs) is used to describe measures with the purpose of decreasing the heat demand related to the thermal performance of the building envelope, i.e., the space heating demand, as well as for the building heating supply system. The term "techno-economic energy renovation" describes techno-economic EEMs that decrease the space heating demand based on a life cycle perspective, including the selection of a cost-optimal heating supply system. Associated values connected to the cultural-historical, technical, aesthetic or environmental elements of a building are referred to as "heritage values." Comfort cooling is not considered in any of the appended papers since it is not common in residential buildings located in a Northern European climate.

The papers included in this thesis are based on two study districts consisting of residential buildings that are constructed in 1945 or earlier. DH is to a large extent in the focus of the research since $\mathrm{DH}$ is the most common heating supply system in 
residential buildings in Sweden, and both study districts are located within a $\mathrm{DH}$ network. In Papers I-IV, a categorization of the residential district built before 1945 in Visby, Sweden, is used as the study object. The categorization is based on an inventory of 1048 buildings, which resulted in 12 building types representative of 920 buildings after eliminating outliers in the form of diverging buildings concerning heated volumes outside the standard deviation. Even though DH is central in the thesis, other heating supply systems are also considered in the techno-economic optimizations. This is in order to investigate the economic and environmental effects of a potential change in heating supply system. Almost all the data related to costs for EEMs are calculated using only the Swedish database Wikells [26] consisting of up-to-date market costs. The database is based on general market costs without any consideration of potential higher renovation costs for buildings with heritage values. Fixed fuel prices are used over the studied time period based on current prices. Thermal comfort and occupant activities, such as opening windows for airing, are not included in the analysis in Papers I-V. In Paper IV, the present DH load is used for the entire analysis period of 50 years. This means that neither potential EEMs in the remaining buildings connected to the DH network nor expansion of the $\mathrm{DH}$ network due to future new constructions in Visby are taken into account.

In Paper V, 73 multi-family buildings in the district of Vasastaden located in Linköping, Sweden, are used as the study object. Local climate data in the form of outdoor temperature has been collected from the Swedish Meteorological and Hydrological Institute (SMHI) from a weather station located at Malmslätt, which is approximately 8 $\mathrm{km}$ west of Vasastaden. Heating supply data has been collected from the energy company Tekniska Verken AB. No consideration is taken for variations in indoor temperature and internal heat generation (IHG), but assumptions are made connected to these parameters based on standard values.

\subsection{OTHER PUBLICATIONS NOT INCLUDED IN THE THESIS}

In addition to the five papers presented above, the thesis author has also contributed to the following publications:

Bahram Moshfegh, Patrik Rohdin, Vlatko Milić, Anna Donarelli, Petra Eriksson, Tor Broström

A method to assess the potential for and consequences of energy retrofits in Swedish historic district

The $3^{\text {rd }}$ International Conference on Energy Efficiency in Historic Buildings, Visby, Sweden, 2018 
Patrik Rohdin, Vlatko Milić, Max Wahlqvist, Bahram Moshfegh

On the use of change-point models to describe the energy performance of historic buildings

The $3^{\text {rd }}$ International Conference on Energy Efficiency in Historic Buildings, Visby, Sweden, 2018 


\section{ENERGY USE IN RESIDENTIAL BUILDINGS}

This chapter presents energy use in residential buildings within the EU and on a national level in Sweden. District heating systems are described in a cold climate with emphasis on their role in the Swedish energy system, followed by a description of the significance from improving building thermal performance.

The energy use in residential buildings located in a Northern European climate derives to a large extent from a high space heating demand due to low outdoor temperatures and a long heating season. A building's energy use is directly linked with the building thermal performance, but also geographic location and user behavior, such as desired indoor temperature. By increasing building energy efficiency and hence lowering energy use, it is possible to decrease residential buildings' contribution to global warming and resource exploitation.

\subsection{ENERGY USE IN RESIDENTIAL BUILDINGS IN THE EU}

The final energy use in the EU has been steadily around 12,000 TWh from 1990 to 2017 as presented in Figure 2. In 2017, the residential and service sector corresponded to $42 \%$ of the total final energy use [27]. The two other largest sectors, industry and transport, corresponded to $25 \%$ and $31 \%$ of total final energy use, respectively. The fuel supply in the EU is dominated by oil and petroleum products, natural gas and electricity, which can be seen in Figure 3. The tendency from 1990 to 2017 shows a decrease in the use of solid fossil fuels by more than $70 \%$ and increase in renewables and biofuels by circa $160 \%$.

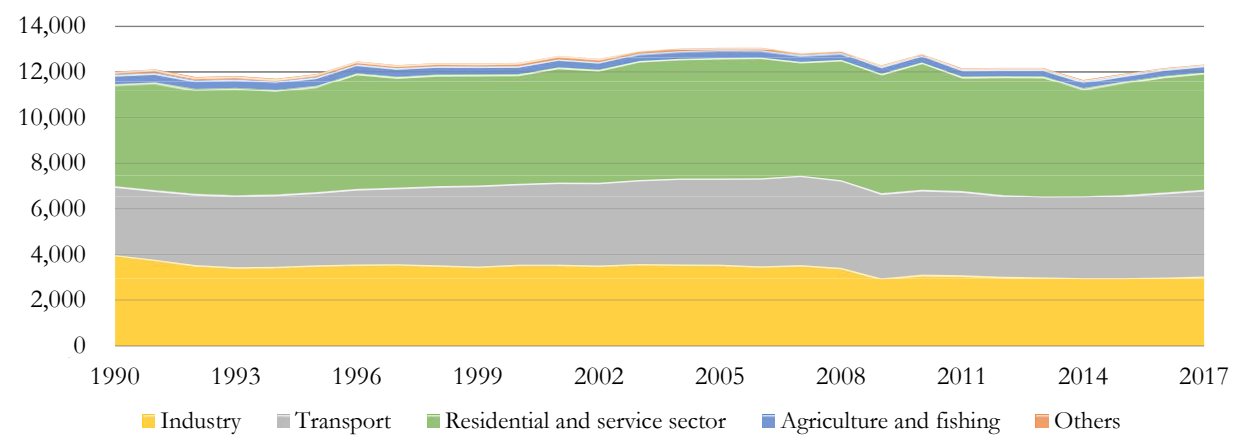

Figure 2: Final energy use (TWh) in the EU by sector [27]. 


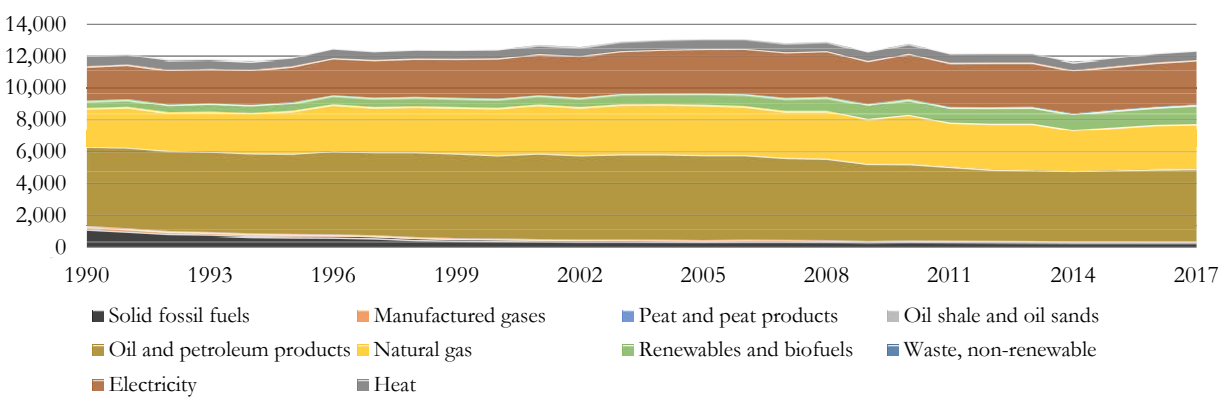

Figure 3: Final energy use (TWh) in the EU by fuel [27].

The final energy use in the residential sector in the EU is covered to a large extent by natural gas (36.0\%) and electricity (24.1\%) [28]. Renewables and waste account for $17.5 \%$, oil and petroleum products $11.2 \%$, derived heat $7.6 \%$ and coal products $3.3 \%$. Sixty-four percent of the total energy use in the residential sector derives from the energy use for space heating. However, there are large national differences in the proportion of total energy use for space heating due to varying climate conditions. The major part of the final energy use for space heating is covered by natural gas $(43.0 \%)$ and renewables and waste (23.4\%) [28], as can be seen in Figure 4. Oil and petroleum products correspond to $14.0 \%$, derived heat $9.5 \%$, electricity $5.4 \%$ and solid fossil fuels $4.8 \%$. This shows that there is a long way to a decarbonized building stock in the EU by 2050 , as well as a possibility for reducing the environmental effects connected to the energy use for space heating demand through building energy renovation.

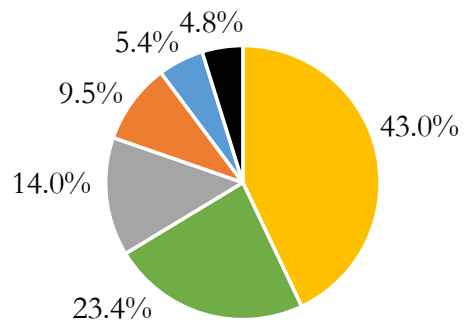

$$
\begin{array}{ll}
\square \text { Natural gas } & \text { Renewables and waste } \\
\square \text { Oil and petroleum products } & \square \text { Derived heat } \\
\square \text { Electricity } & \text { - Solid fossil fuels }
\end{array}
$$

Figure 4: Share of fuels in final energy use for space beating in the EU based on figures from 2017 [28]. 


\subsection{ENERGY USE IN SWEDISH RESIDENTIAL BUILDINGS}

The total final energy use is 378 TWh in Sweden of which 146 TWh (39\%) is used in the building and service sector [29]. The final energy in the Swedish residential and service sector from 1970 to 2017 is shown in Figure 5. Oil has been the main fuel historically due to low prices. This started changing in 1973 because of the oil crisis. In 2017, oil represented $8 \%$ of the final energy use in the residential and service sector compared to $72 \%$ in 1970 . The final energy use in 2017 was dominated by electricity $(50 \%)$ and $\mathrm{DH}(31 \%)$. Hence, considering the overall reduction in oil as main fuel in the residential and service sectors, including many residential buildings built before 1945 , the next step to reduce the environmental impact from these buildings is increased energy efficiency.

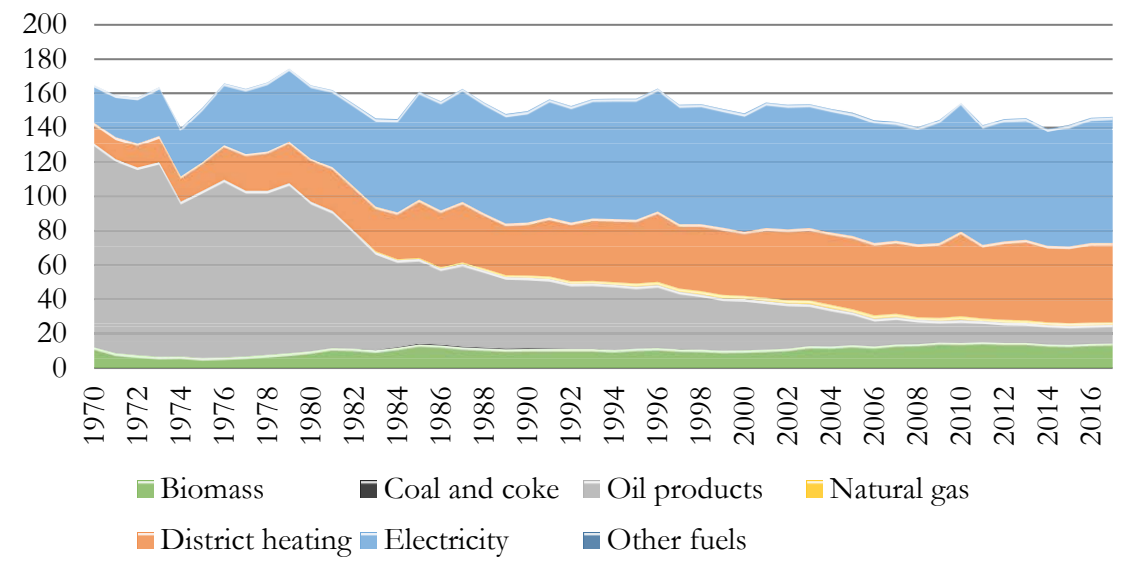

Figure 5: Final energy use (TWh) in the Swedish residential and service sector between 1970 and 2017 [29].

The building stock in Sweden is rather old as in the rest of the EU resulting in associated building renovation needs. In fact, $35 \%$ of the total heated area ${ }^{4}$ of multi-family buildings is built in 1960 or before [23]. The corresponding figure for the building stock built in 1945 or before is approximately 19\%. As mentioned in section 1.1, improving the thermal performance in the current building stock is crucial for reaching the set energy and climate targets of a highly-energy efficient and decarbonized building stock in the union by 2050. This is especially the case for buildings built before 1945 due to

${ }^{4}$ Floor area heated to more than $10{ }^{\circ} \mathrm{C}$ according to BBR. 
the generally poorer thermal performance of older buildings compared to newer ones. The owners of one- and two-dwelling buildings are very homogeneous with private owners accounting for $95 \%$ [24]. The form of ownership for multi-family buildings is more heterogenous with co-operatively owned buildings representing $43 \%$, private owners $31 \%$ and public housing companies $26 \%$.

The energy use divided by energy carrier for space heating and HTW, and total heated area for one- and two-dwelling buildings and multi-family buildings can be seen in Figure $6^{5}$ with a timeline from 1983 to 2016. Data for both one- and two-dwelling buildings and multi-family buildings is presented at the top of the figure, one- and twodwelling buildings in the center and multi-family buildings at the bottom. The most common energy carrier in Swedish residential buildings today is DH corresponding to a $50 \%$ share of total energy use, or in total $29.5 \mathrm{TWh}$. Oil was the most common energy carrier in 1983 for all three categories of buildings. The use of oil has steadily decreased from $32.8 \mathrm{TWh}(43 \%)$ in 1983 to $0.6 \mathrm{TWh}(1 \%)$ in 2016. Moreover, as can be observed in Figure 6, the energy use has decreased over time for all three categories of buildings, while the total heated area has increased. This tendency suggests poorer thermal performance in older buildings and increased thermal performance of the newer residential building stock. In any way, the expansion of DH for space heating and HTW stresses the importance of working with potential energy renovation in residential buildings connected to $\mathrm{DH}$ networks.

The latest available figures (from 2018) show that total energy use for space heating and HTW use in Swedish multi-family buildings is 28 TWh of which DH accounts for 25 TWh [23]. The corresponding figures for one- and two-dwelling buildings are $32 \mathrm{TWh}$ and $6 \mathrm{TWh}$, respectively, corresponding to a share of $18 \%$ of total energy use supplied via $\mathrm{DH}$ [30]. The average specific energy use for space heating and HTW usage is 143 $\mathrm{kWh} /\left(\mathrm{m}^{2} \cdot\right.$ year) and $125 \mathrm{kWh} /\left(\mathrm{m}^{2} \cdot\right.$ year) (temperature-corrected figures) for multifamily buildings and one- and two-dwelling buildings supplied with heat via $\mathrm{DH}$ for 2018, respectively. The specific energy use has decreased steadily the latest years. This can be exemplified by an average specific energy use of $159 \mathrm{kWh} /\left(\mathrm{m}^{2} \cdot\right.$ year $)$ and 137 $\mathrm{kWh} /\left(\mathrm{m}^{2}\right.$.year) in 2009 for multi-family buildings and one- and two-dwelling buildings, respectively.

\footnotetext{
${ }^{5}$ Values on the heated area for 2015 are missing. Therefore, approximations are made based on figures from 2014 and 2016.
} 


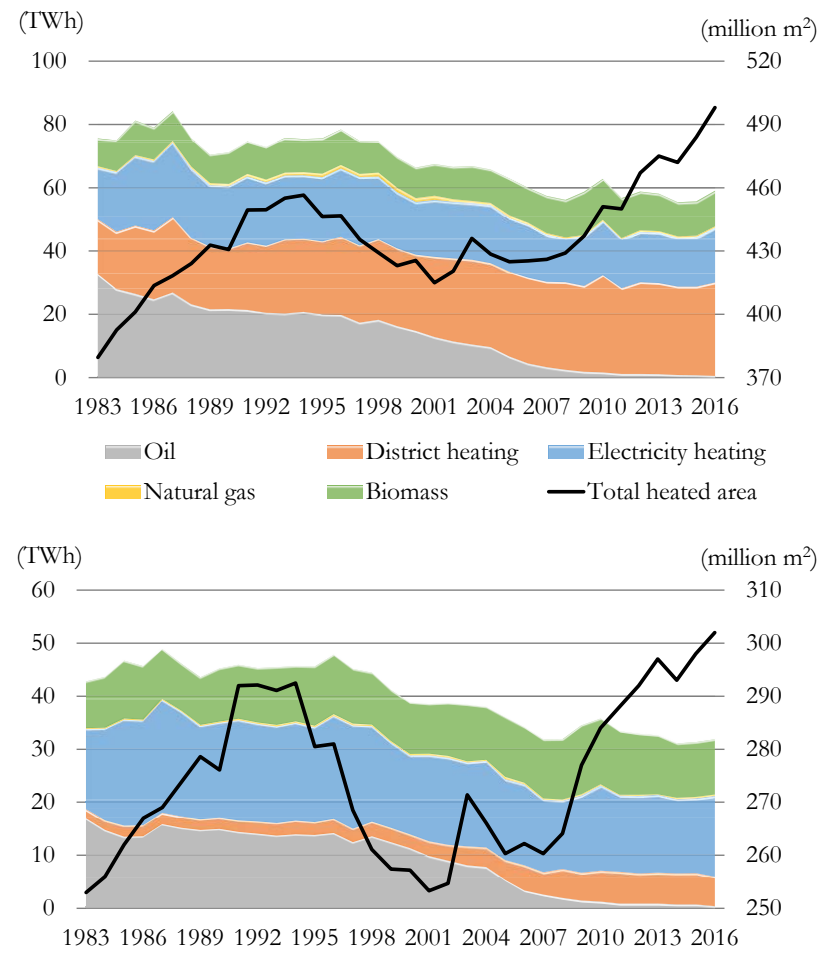

198319861989199219951998200120042007201020132016

$$
\begin{aligned}
& \text { Oil District heating Electricity heating } \\
& \text { Natural gas Biomass - Total heated area }
\end{aligned}
$$

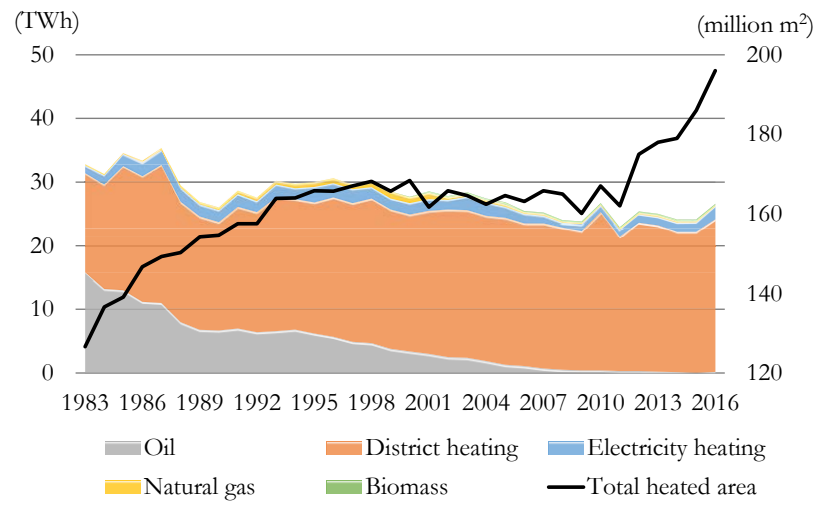

Figure 6: Energy use for space heating and HTW and total heated area for one-and two-dwelling buildings and multi-family buildings at the top, one-and two-dwelling buildings in the center and multi-family buildings at the bottom [23, 30]. 
When comparing the specific energy use for buildings constructed in different time periods, there is a clear correlation between newer buildings and lower specific energy use, as can be seen in Figure 7, confirming the abovementioned tendency of increased thermal performance in newer residential buildings. One- and two-dwelling buildings built between 2011 and 2017 have $61 \mathrm{kWh} /\left(\mathrm{m}^{2}\right.$.year) (52\%) lower energy use compared to buildings built in 1940 or before. Multi-family buildings built between 2011 and 2018 have $55 \mathrm{kWh} /\left(\mathrm{m}^{2}\right.$.year) (38\%) lower energy use in comparison with the building stock built in 1940 or before. Hence, considering the overall significantly higher energy use in older buildings, there is a large energy efficiency potential in Swedish residential buildings built before 1945 .
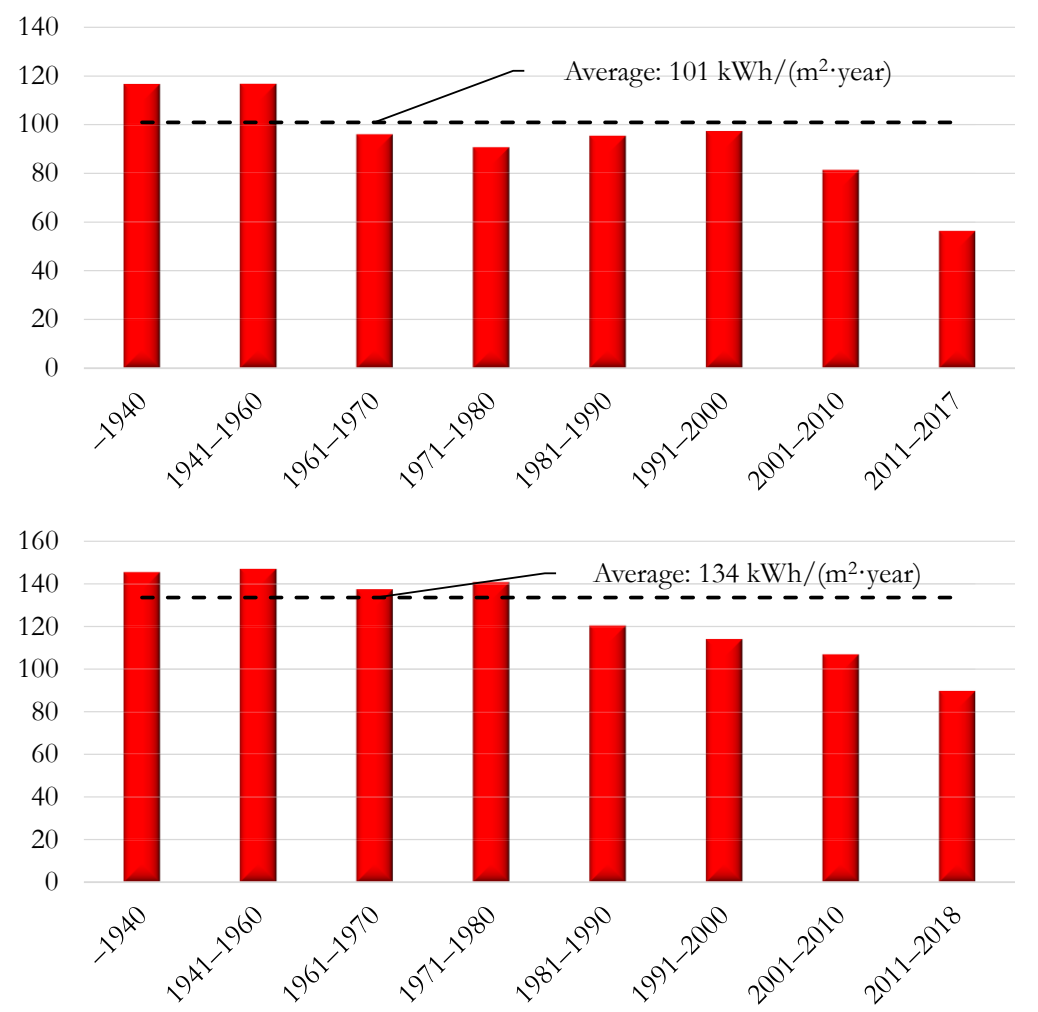

Figure 7: Specific energy use (kWh/ ( $\mathrm{m}^{2}$-year)) for space beating and HTW use during 2018 for one- and two-dwelling buildings (at the top) and multi-family buildings (at the bottom) divided by construction year [23, 30]. 


\subsection{DISTRICT HEATING SYSTEM}

With growing global population, efficient resource use is vital for achieving sustainable development. In a Northern European climate, heat supply to buildings is often highly resource demanding. Large-scale heat production enables efficient resource use together with economic viability. DH is a heat distribution system where heat is produced in a central plant and distributed in pipes in the local energy system. DH was first commercially introduced in the United States in the late 19th century and in Europe in the early 20th century [31]. It is commonly used to supply heat for space heating, HTW, as well as industrial processes [31]. The main users are residential buildings and industries. Fuels used in various DH plants vary from biomass, household waste and waste heat from industrial processes to electricity and fossil fuels. It is common to cogenerate the production of heat with power production, i.e., combined heat and power plants (CHP). Benefits from DH include the possibility to use different fuels, use of waste that would otherwise be deposited, cogeneration with power production and also a high supply security. On a global level it has been estimated that around 80,000 DH systems exist [31]. The corresponding figure is 6,000 in Europe [32]. The operation of a DH system is affected by a number of time-dependent factors, such as changing fuel prices, technology development and $\mathrm{CO}_{2}$-tax on fossil fuels [33]. In addition, considering that the profitability and environmental performance of a $\mathrm{DH}$ system is directly associated with the buildings' energy use in the DH network it is important to be aware of other influencing factors, which include larger populations living in cities, building energy renovation rate of the current building stock, construction of new buildings and warmer outdoor temperatures in the future due to global warming.

DH is the most common way of heating residential buildings in Sweden [22]. Of the DH produced today, 90\% (51 TWh) derives from renewable fuels and recycled energy [34], as presented in Figure 8. The supplied fuel for DH has increased from 30 TWh in 1980 to 57 TWh in 2018. The share of fossil fuels has steadily decreased since the 1980 s. Fossil fuel covered $90 \%$ of the $\mathrm{DH}$ production in 1980 compared to less than $5 \%$ in 2018. In order to enable a fossil fuel-free DH production in the future there is a need to energy renovate the building stock since the vast majority of fossil fuels are today already replaced by renewable energy and recycled energy in production of $\mathrm{DH}$. 


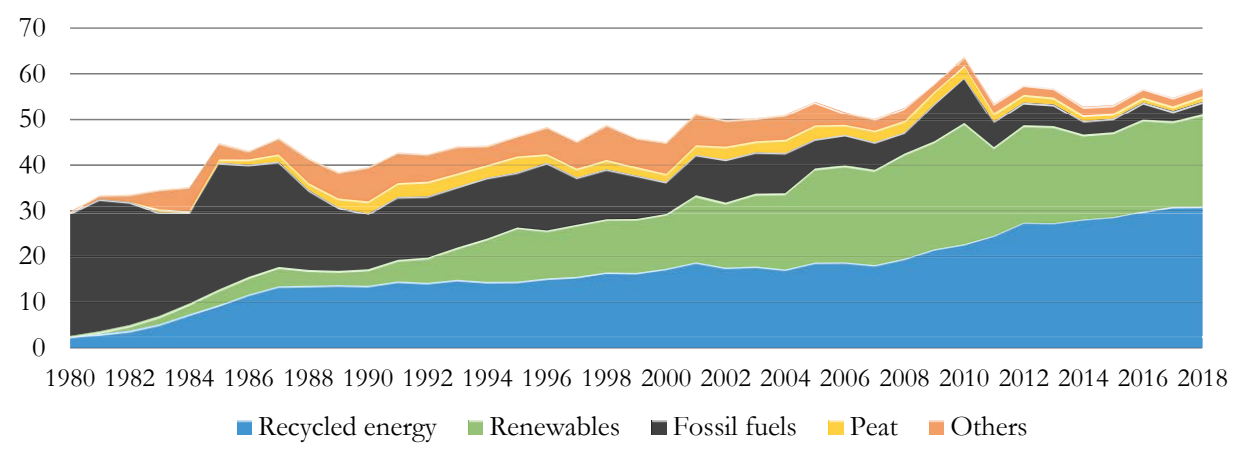

Figure 8: Supplied fuel (TWh) for production of DH from 1980 to 2018 [34].

\subsection{ENERGY RENOVATION}

Energy renovation (often synonymous with refurbishment and retrofitting) is related to improving the thermal performance of a building and consequently lowering the energy use. The reason for performing building energy renovation is often associated with high utility bills and consequently as a tool for reducing energy-related expenditures, which has therefore been a central element within the research community on energy renovation, as can be seen in e.g. [35-39]. Similar tendencies are shown in a study by Thuvander et al. [25] investigating causes for building renovation from a building owner perspective within a Swedish context, in which high expenditures connected to operation and maintenance cost ranked high, together with high energy use and need for upgrade of building elements due to technical problems.

EEMs decreasing the space heating demand are often connected with some type of insulation of the building envelope in buildings built before 1945 [15]. This includes insulation of the external walls, floor, crawl space, attic space and roof. Weatherstripping, replacement of windows and change to a new heating system are examples of other relevant EEMs in these buildings. Common EEMs which have not been in focus in this thesis are installation of solar panels and adjustment of the control system by e.g. lowering the indoor temperature. Since many older buildings are naturally ventilated, installation of mechanical ventilation with heat recovery can also be used as a measure to reduce heat losses. Due to the unique character of each EEM, it is important to be aware of the effects on the heritage values (addressed in the following chapter) and building physical properties, such as potential moisture problems. It should be noted that suitable packages of EEMs are dependent on climate conditions and vary from building to building depending on thermal performance, which has also been pointed out by [40, 41]. 
When altering a building in Sweden, the same energy requirements are strived for as in new construction according to BBR [19]. However, the requirements are adapted with regard to the extent of the alteration and building conditions. The energy requirements vary depending on heating system, as well as geographic location since Sweden is an oblong country with an approximate distance of $1,600 \mathrm{~km}$ from the north to the south. 


\section{Preservation of heritage Values}

This chapter describes preservation of heritage values during building energy renovation with a focus on buildings built before 1945.

Improving building thermal performance is often a complex task due to numerous requirements such as profitability and preservation of building hygrothermal performance. The degree of complexity is increased when considering the heritage values in buildings built before 1945. The preservation of heritage is important for ensuring diversity in the cultural environment for present and future generations [42]. Regulations on preservation of the built cultural environment have been around since 1931 in Sweden, and have undergone several changes since then [43]. The definition of cultural heritage has historically been somewhat ambiguous. The Swedish National Heritage Board states today that cultural-historical value should be defined as follows [44]:

Cultural-historical value consists in the possibilities that material and intangible phenomena can provide in terms of acquiring and communicating knowledge about and understanding of different events and contexts - and thereby people's living conditions at different times, including the conditions that exist today.

There are different degrees of protection for the preservation of a building's heritage values depending on the unique status in terms of heritage values for each building. Listed buildings, which show how Swedish society has changed over time, are covered by the highest degree of protection. The preservation of listed buildings is handled in the Historic Environment Act (1988:950) [14]. The listing is not restricted to single buildings, but also to sites that can include a larger number of buildings and various types of land areas. Just over 2,500 buildings are today classed as listed in Sweden [12], of which 11\% are governmentally listed buildings which are regulated in act 2013:558. Decisions on the listing of buildings are made by the various county administrative boards $^{6}$. The administrative boards also state what the specific protection consists of and how the building is to be maintained. All listed buildings and sites are found in a register managed by the Swedish National Heritage Board.

More general legislation exists for the preservation of areas with cultural significance. Cultural environments in Sweden are protected by the Swedish Environmental Code

${ }^{6}$ With the exception of government buildings. The Swedish Government decides whether a government building is to be listed or not after a request from the Swedish National Heritage Board. 
(1998:808) which states that valuable environments shall be cared for due to the protection value of nature [45]. The entire built environment is encompassed by the Swedish Planning and Building Act (2010:900) which protects buildings with heritage values [13]. The act states that any changes to a building must be performed carefully with consideration for technical, historical, cultural-historical, environmental and aesthetic values. In addition, buildings that are particularly valuable in terms of the abovementioned values, have an enhanced protection and the specific values must be preserved. Municipalities can apply the legislation in the local development plan in order to protect and preserve buildings with heritage values. The legislation can be relevant for other actors working with heritage values, such as consultant companies and in various types of education.

The Swedish Planning and Building Act (2010:900) is incorporated in requirements from BBR when altering a building [19]. However, as mentioned in section 2.4, the same energy requirements are strived for when an older building undergoes renovation as for new construction [19]. Consequently, improving the thermal performance of buildings built before 1945 is a multifaceted challenge considering the need for preservation of heritage values and the tough energy requirements when a building undergoes renovation. However, despite the fact that any changes to a building must consider character-defining elements, the vast majority of the buildings built before 1945 are not listed and consequently without enhanced protection. Therefore, energy efficiency improvements in this part of the building stock are made possible through EEMs that simultaneously consider character-defining elements. 


\section{BUILDING ENERGY SYSTEMS}

The following chapter presents different system boundaries that have been used during this research, the energy balance of a building, and introduces modeling of energy use in the residential sector with a focus on the bottom-up approach.

\subsection{SYSTEM PERSPECTIVES}

For studies of technical systems, including energy systems, the work by Churchman [46], who is often regarded as the founder of the system approach, a scientific and holistic approach for system planning, is widely referenced. The ideas and views on how a system is set and defined can differ somewhat between researchers and scientists; however, there are some keystones that can be identified as introduced by Churchman in 1968. This includes that the system consists of a number of components that are interconnected and together aim to achieve a specific objective. According to Churchman [46], there are five attributes that need to be considered when assessing the purpose of a system:

- The total system objectives and the performance measures of the whole system corresponds to the real objective of the system with regard to its environment and can be measured in terms of the performance of the whole system

- The system's environment are the fixed constraints outside the system boundary that affect the system. The environment has effects on the system objective but cannot be influenced by the system

- The resources of the system include elements used to operate the system such as people and technology. In comparison to the environment, the resources are not fixed but can change over time

- The components of the system and their activities, objectives and measures of performance correspond to the attributes, or subsystems, within the system boundary which assist the performance measures of the system

- The management of the system is the actions meant for an effective management of the system considering the four abovementioned points

In order to enable assessment of the energy use of a building or a group of buildings, a system boundary needs to be set. Abel and Elmroth [47] state that "if the system boundaries are vague or ill-defined, it is difficult to carry out an analysis founded on indisputable facts or to pursue a meaningful discussion" for investigations of technical systems, especially buildings. When studying a building as a whole, it is common to set 
the system boundary around the building. This is visualized by system boundary A in Figure 9, when including components that are common for buildings located in a Northern European or cold climate (excluding electricity since this thesis focuses on energy efficiency related to space heating demand). The reason for why the figure is specified for cold climate is because comfort cooling is common in residential buildings in warm climates, which is not the case in Northern European climate. It is necessary to study all flows through the system boundary, including heat losses and insolation when studying the energy balance of a building [47], as illustrated by system boundary A. Other system attributes that need to be taken into account are heating supply systems, as well as user behavior. The results on building level from this thesis include LCC before and after techno-economic optimization (including packages of cost-effective EEMs), $\mathrm{CO}_{2}$ emissions, energy use and primary energy use. As shown to the left in Figure 9, by considering the number of buildings represented by each studied building type, it is possible to generate the corresponding results on cluster level and district level. System boundary B illustrates conversion processes outside the building which are used in Paper IV when combining studies on building, cluster, and district level, with local energy system analysis and optimization, which allows for investigation of the performance of the $\mathrm{DH}$ system. In order to enable an objective analysis of the $\mathrm{DH}$ system it is necessary to include all buildings connected to the DH network, and not only the buildings included in the studied district. Generated results include system cost, $\mathrm{CO}_{2}$ emissions, energy use and primary energy use.

\subsection{THE BUILDING ENERGY BALANCE}

Energy in the form of heating and electricity is supplied to buildings for maintaining a set indoor temperature, for hot water circulation (HWC) and hot tap water (HTW) use, as well as for household appliances and facility functions. Heating supplied for space heating, HWC and HTW use corresponds to a large part of the total energy use for buildings located in a cold climate. The space heating demand depends on the outdoor temperature, preset indoor temperature and building thermal performance in terms of specific heat losses and thermal inertia. The supplied heat to a building derives from the heating supply system, which can be e.g. through DH or a wood boiler, as well as heat from insolation and IHG consisting of heat generated from electrical appliances and residents. Heat losses from the building envelope include transmission, ventilation and infiltration. The preset indoor temperature is kept when the supplied heat equals the heat losses. 


\subsubsection{Heat losses}

The temperature-dependent heat losses from a building, i.e., excluding heating for HWC and HTW, originate from transmission, ventilation and infiltration losses. Hence, the total heat loss term, $Q_{\text {total }}$, can be calculated according to Eq. 1. Transmission, ventilation, and infiltration losses are calculated according to Eq. 2-4, respectively.

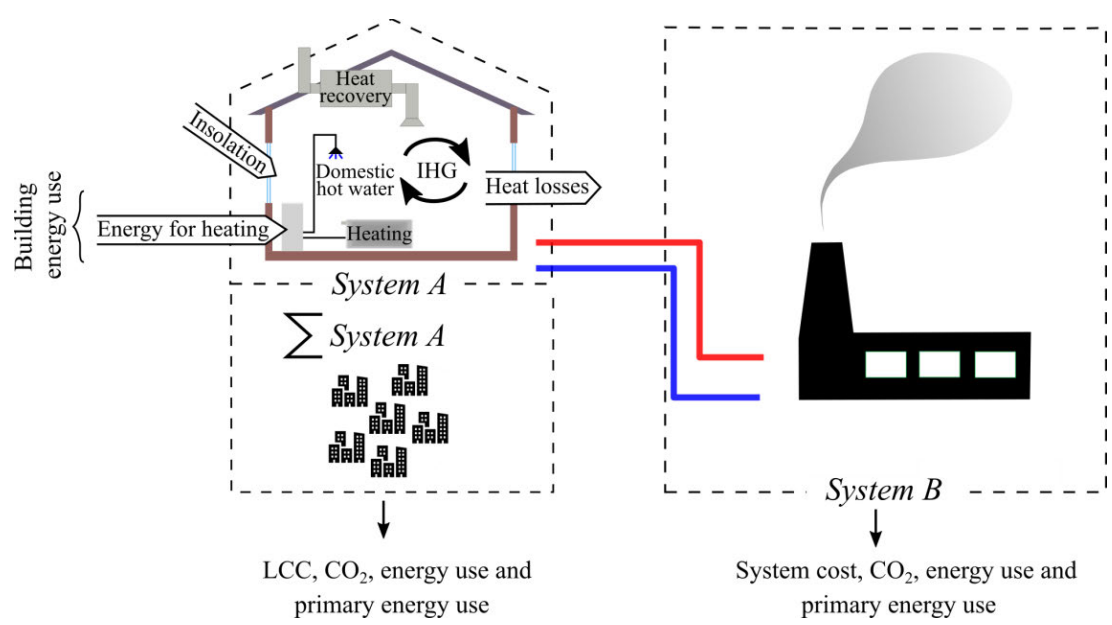

Figure 9: The system boundaries used. System boundary A (inspired from the Swedish National Board of Housing, Building and Planning [48]) consists of the building envelope and system boundary $B$ includes energy conversion processes outside the building.

$$
\begin{array}{cc}
Q_{\text {total }}=Q_{\text {transmission }}+Q_{\text {ventilation }}+Q_{\text {infiltration }} & \text { Eq. } 1 \\
Q_{\text {transmission }}=\sum_{j=1}^{k} U_{j} \cdot A_{j} & \text { Eq. } 2 \\
Q_{\text {ventilation }}=(1-\eta) \cdot q_{\text {ventilation }} \cdot \varrho \cdot C_{p} & \text { Eq. } 3 \\
Q_{\text {infiltration }}=q_{\text {infiltration }} \cdot \varrho \cdot C_{p} & \text { Eq. } 4
\end{array}
$$


In which $Q_{\text {transmission }}\left(\mathrm{W} /{ }^{\circ} \mathrm{C}\right)$ are the heat losses via transmission through the building envelope, $Q_{\text {ventilation }}\left(\mathrm{W} /{ }^{\circ} \mathrm{C}\right)$ are the heat losses from ventilation and $Q_{\text {infiltration }}\left(\mathrm{W} /{ }^{\circ} \mathrm{C}\right)$ are the heat losses from undesired air leakage such as through holes and gaps. $U_{j}$ $\left(\mathrm{W} /\left(\mathrm{m}^{2} \cdot{ }^{\circ} \mathrm{C}\right)\right)$ is the overall heat transfer coefficient of a building element including thermal bridges and $A_{j}\left(\mathrm{~m}^{2}\right)$ is the area of the respective building element. $\eta(-)$ is the efficiency of a potential ventilation heat recovery system, $q_{\text {ventiation }}\left(\mathrm{m}^{3} / \mathrm{s}\right)$ is the ventilation air flow rate, $\varrho\left(\mathrm{kg} / \mathrm{m}^{3}\right)$ is the air density and $C_{p}\left(\mathrm{~J} /\left(\mathrm{kg} \cdot{ }^{\circ} \mathrm{C}\right)\right)$ is the specific heat capacity of air. $q$ infiltration $\left(\mathrm{m}^{3} / \mathrm{s}\right)$ is the infiltration air flow rate caused by mechanical forces, wind pressure and temperature difference between indoors and outdoors. As described above, $Q_{\text {total }}$ describes the sum of the heat loss term for transmission, thermal bridges, infiltration and ventilation, without any influences from occupancy behavior, such as the use of HTW. Hence, the total heat loss term enables an assessment of the building technical performance without any influences from user behavior.

\subsubsection{Heating demand}

The heating demand for a building is directly dependent on the heat loss coefficient and the degree hours for the building, which is the number of hours and degrees by which the outdoor temperature is below the building balance temperature. The balance temperature, also often referred to change-point temperature, corresponds to the outdoor temperate when the IHG and insolation equal the building heat losses, i.e., no heating supply is required to maintain the set indoor temperature. Thus, the degree hours are directly related to building thermal performance, heat gains and the outdoor conditions of the location. In addition to the temperature-dependent heating supply to the building, heating is required for HWC and HTW use. Hence, the heating demand for a building over a longer period of time can be described according to Eq. 5-Eq. 7.

$$
\begin{array}{cc}
E_{\text {heating }}=Q_{\text {total }} \cdot \Psi+\text { HWC }+ \text { HTW } & \text { Eq. } 5 \\
\Psi=\sum_{l=1}^{8760}\left(\left(T_{\text {balance }}-T_{\text {out }}\right) \cdot \Delta t\right) & \text { Eq. } 6 \\
T_{\text {balance }}=T_{\text {in }}-\frac{P_{\text {IHG }}+P_{\text {solar }}}{Q_{\text {total }}} & \text { Eq. } 7
\end{array}
$$


In which $E_{\text {heating }}(\mathrm{Wh})$ represents the heating energy supplied to the building for space heating and heating used for HWC and HTW. $\Psi\left({ }^{\circ} \mathrm{C} \cdot \mathrm{h}\right)$ corresponds to the degree hours, $T_{\text {balance }}\left({ }^{\circ} \mathrm{C}\right)$ is the balance temperature, $T_{\text {out }}\left({ }^{\circ} \mathrm{C}\right)$ is the outdoor temperature and $t(\mathrm{~h})$ is the time period given in number of hours. $T_{\text {in }}\left({ }^{\circ} \mathrm{C}\right)$ equals the preset indoor temperature, $P_{\mathrm{IHG}}(\mathrm{W})$ is the IHG from electrical appliances and residents and $P_{\text {solar }}(\mathrm{W})$ is insolation.

\subsubsection{Power demand and heating system}

The design power, $P_{\text {design }}(\mathrm{W})$, of the heating system is directly related to the heat loss coefficient and the temperature difference between indoors and the outdoor design temperature, see Eq. 8.

$$
P_{\text {design }}=Q_{\text {total }} \cdot\left(T_{\mathrm{in}}-T_{\mathrm{ODT}}\right) \quad \text { Eq. } 8
$$

In which TODT $\left({ }^{\circ} \mathrm{C}\right)$ is the set outdoor design temperature corresponding to the outdoor temperature used for designing the power demand of the heating system at a particular location and building time constant. SMHI has calculated the outdoor design temperature based on reported outdoor temperatures for a building with a certain time constant, which is not below the TоDт more than 30 times during a time period of 30 years (using data between 1981 and 2010). The time constant, $\tau$ (h), of a building is calculated according to Eq. 9.

$$
\tau=\frac{\sum_{m=1}^{n}\left(m_{m} \cdot C p_{m}\right)}{Q_{\text {total }}} \cdot \frac{1}{3600}
$$

In which $\left(m_{m} \times C p_{m}\right)\left(\mathrm{J} /{ }^{\circ} \mathrm{C}\right)$ is the heat capacities for respective construction element and interior. Hence, the time constant is influenced by the heat storing mass and the heat losses from transmission, ventilation and infiltration.

\subsection{MODELING ENERGY USE IN THE RESIDENTIAL BUILDING SECTOR}

The review by Swan and Ugursal [49] on modeling techniques in the residential building sector identifies two main approaches for modeling energy use: top-down and bottom- 
up approaches. The methods have different applications and differ with regard to input data and calculation procedures.

In a top-down approach, no differentiation is made for separate end uses [49]. Examples of end uses include space heating and HTW from building heating supply. Common input data consist of variables such as climate conditions, new construction and demolition rates, and macroeconomic parameters such as employment rates and price indices. Predictions of future energy use are directly correlated with the historical energy use and the input data used in the model. The main advantages include no necessity for detailed data of the various end uses in the residential sector, but only aggregated data. The approach allows for good predictions for small deviations from the status quo behavior of the sector. However, due to the dependence on historical data, non-continuous advances in the studied sector are hard to predict, as is identifying focus areas for improving energy efficiency and hence reducing energy use.

Bottom-up approaches can be divided into two different modeling approaches: statistical models, which are often based on some type of regression technique, and models based on building physics [50]. The statistical models enable prediction of energy use in the residential sector but are restricted in terms of assessment of energy renovation scenarios. Compared to the building physics-based modeling approach, the statistical models are in general easier to develop and use. No requirement for detailed data about the building is also an advantage with this type of modeling approach. The building physics-based approach can model present and future energy use based on the use of building physics data, as well as assumptions and data about building user behavior. The building physics-based bottom-up model is based on representative buildings or building categories which are extrapolated to represent a larger building stock, e.g. district, region or nation, by considering the sample weight of the respective building or building category [49]. Input data commonly consists of building properties in the form of layout, thermal properties, geometries, occupancy behavior, as well as climate data and set indoor temperature. The detailed description of a building is a main advantage of the bottom-up approach which allows for identification of suitable energy efficiency improvements. In addition, there is no need for historical data for calculation of the energy use in the sector since the energy use is extrapolated based on the calculated energy use of the modeled buildings. However, a weakness with the approach is the need for more detailed data compared to the top-down model, and calculations can therefore be rather complex. There is also often a need for many assumptions concerning user behavioral factors, which can be set indoor temperature and use of electrical appliances, which reduces the prediction accuracy of the model [50]. 


\section{Methodology}

This chapter presents a description of the methodological approach used in the research, which includes four levels: building level, cluster level, district level and city level. This is followed by a description of the methods and tools used, i.e., bottom-up approach, building energy simulation, change-point modeling, life cycle cost analysis and optimization, environmental assessment and local energy system analysis and optimization, along with an overview on related research.

\subsection{METHODOLOGICAL DESCRIPTION}

To enable analysis of the energy renovation of residential districts built before 1945 from a system perspective, a bottom-up methodology has been developed in this research. The methodology includes four different levels: building level, cluster level, district level and city level. Each level includes the use of different methods. Changepoint modeling, building categorization, LCC optimization, dynamic BES and environmental assessment through calculations of $\mathrm{CO}_{2}$ emissions and primary energy use are performed on building level. Input data consists of GIS data, building construction data such as $U$-values of building elements, climate data, economic data connected to LCC calculations, emission factors for $\mathrm{CO}_{2}$ and primary energy factors. Through the mapping and data collection of an entire district, which allows for the studied buildings to be divided into various representative building types as well as clusters, the results from the LCC optimization and BES procedures can be generated on cluster level and district level. Cluster level refers to different representative building types, which are similar concerning size and type of building structure. District level corresponds to the entire district, which consists of all clusters. Moreover, by collection of heat load data for the entire building stock connected to the DH network in the city together with operational data for the $\mathrm{DH}$ system, studies on city level are made possible through local energy system analysis and optimization. Papers I-V consist to various extents of studies performed on building level. Papers II-IV include studies on cluster and district level, and Paper $\mathrm{V}$ also includes a study on district level. Paper IV includes a study on city level by analyzing the effects on the local energy system from cost-effective packages of EEMs in a district built before 1945. Different stakeholders are interested in the generated results from the various levels. At building level, the results are mainly targeted for building owners and housing companies, while cluster and district level are connected to municipalities, housing companies and authorities. The study on city level is of interest to municipalities, housing companies, authorities and energy supply companies. A schematic of the connection between the studied levels and methods used, as well as the targeted stakeholders, can be seen in Figure 10. 


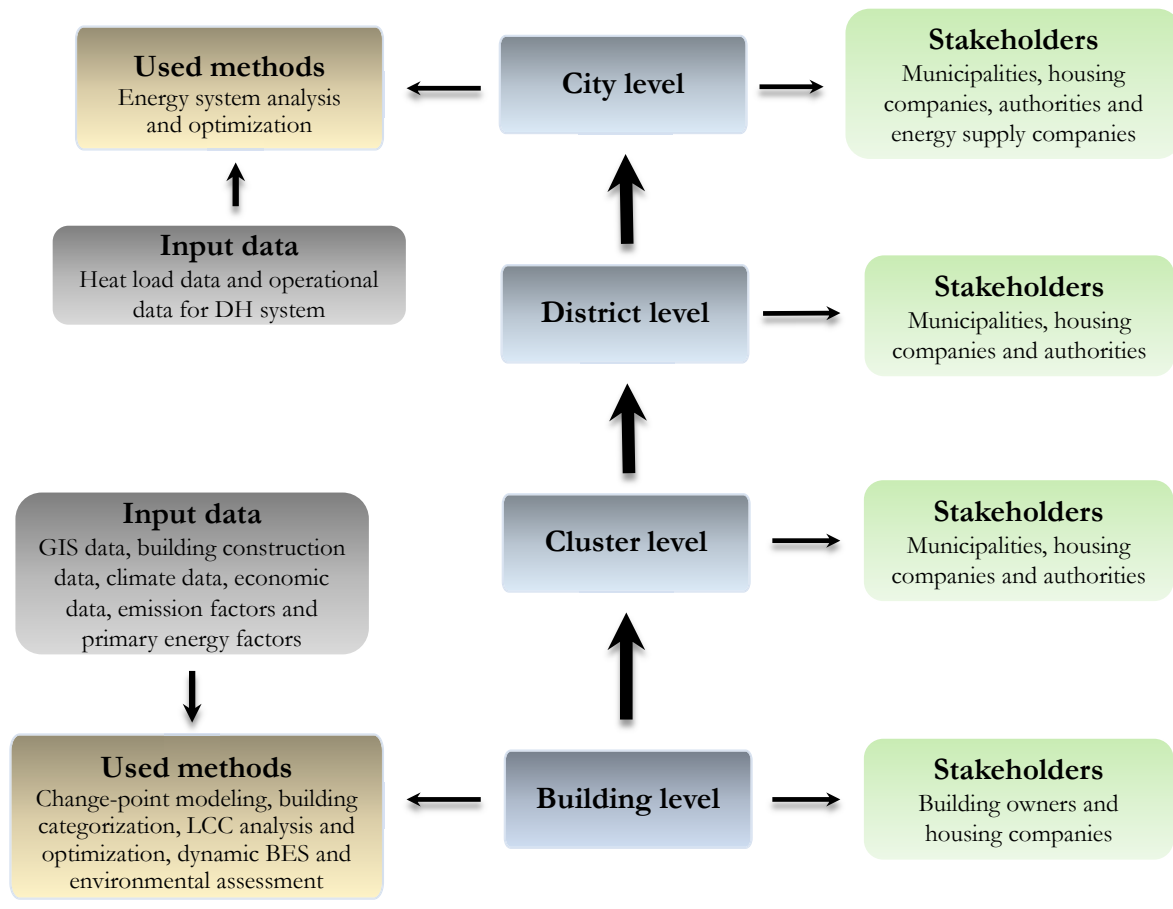

Figure 10: Schematic of the connection between the studied levels, methods used and stakeholders.

\subsubsection{Building level}

In all appended papers in the thesis, some type of case study has been used. In Papers I-IV, the case studies are based on the 12 buildings representative of the residential district built before 1945 in Visby, as presented in section 6.1, and in Paper V on the residential district in Linköping described in section 6.2. By the use of case studies, it is possible to generate detailed data about the studied system or object with a real-world context [51], which consequently allows for a deep understanding about the studied object. The method is suitable during investigations when the key research questions can be formulated as "bow" and "why" questions. Case studies are applicable for studying topics such as life cycles of various products and services, processes, etc. and can be found in a wide range of disciplines including engineering, anthropology and education.

A variety of different methods have been used on building level which include changepoint modeling, building categorization, LCC analysis and optimization, dynamic BES and environmental assessment. The obtained results with the use of the developed change-point model include a description of the thermal power characteristics of a 
building. The temperature-independent load of a building consisting of the energy use for HTW and HWC is predicted, and the heat losses depending on varying outdoor temperature, i.e., the specific heat losses $\left(\mathrm{W} /{ }^{\circ} \mathrm{C}\right)$. In addition, the change-point model allows for calculation of the balance temperature. The developed model is implemented in the MATLAB software. Input data to the model consists of hourly heating supply data and local climate data in the form of outdoor temperature.

The use of LCC optimization generates the optimal package of cost-effective EEMs with or without targets related to LCC, energy use and preservation of building heritage values. For this purpose, the techno-economic software OPERA-MILP has been used as can be seen in Papers I-IV. Other factors that have been studied on building level with OPERA-MILP include the influence from varying discount rates and geographic location. In addition, considering the incorporated BES in OPERA-MILP, the energy use before and after energy renovation is calculated. A consequence of this is the possibility for predictions of the building environmental performance in terms of primary energy use and $\mathrm{CO}_{2}$ emissions. Furthermore, dynamic BES generates the building heat demand with high time resolution before and after suggested EEMs, as well as heat load duration curves. In this research, BES software IDA ICE has been used, see Paper I and Paper IV.

The generated results with the developed change-point model are of interest to building owners to investigate the thermal performance of buildings, which can be used as guidance for selection of the object for energy renovation. The results from the building categorization can be used to facilitate simulation of the energy efficiency potential in entire districts, and differentiate building types in regard to cost-effective energy efficiency potential. The findings from LCC optimization procedures with the associated BES are useful for building owners and housing companies when analyzing their properties considering thermal performance and for assessing what building elements are most profitable to target during future energy renovation in a life-cycle perspective. The approach also allows building owners to understand a building's limitations in terms of cost-effective energy efficiency potential due to building heritage values.

\subsubsection{Cluster level}

By the use of a bottom-up approach which is allowed through the mapping and data collection for an entire district, followed by case studies of buildings representative of the studied district, it is possible to generate results on a cluster and district level. Four building clusters are considered in this research, which are formed using the 12 building types studied in Papers II-IV. Each cluster includes building types with similarities in 
building size and type of building structure. By considering the sample size of each building type, the results from building level consisting of LCC, energy use, primary energy use, $\mathrm{CO}_{2}$ emissions and cost-effective EEMs can be generated on a cluster level. This has been performed in Papers III-IV.

The results generated on cluster level show that cost-effective energy renovation measures are often rather similar for buildings within the same cluster. Hence, through categorization followed by dividing buildings into clusters, it can be seen that despite varying number of adjoining walls and some differences in heated area and volume between buildings within the same cluster, packages of cost-effective EEMs are comparable. In addition, by assessing the LCC before and after techno-economic optimization, the profitability of energy renovating the respective cluster can be predicted. The selection of packages of cost-effective EEMs, including heating system, varies between the various clusters even though all buildings are located in the same district and within the same DH network. A consequence of these differences is varying environmental performance in terms of $\mathrm{CO}_{2}$ emissions and primary energy use between the clusters. Considering the abovementioned findings, housing companies which own a larger number of buildings may identify techno-economic energy renovation packages for buildings with similar properties within a district. Other stakeholders that can use these types of results include municipalities which often own entire districts within the municipal borders in Sweden, as well as authorities with the objective of increasing national energy efficiency and spreading knowledge to the public audience. This can be performed by the Swedish Energy Agency, the Swedish National Board of Housing, Building and Planning and the Swedish National Heritage Board.

\subsubsection{District level}

As stated by Dall'O' et al. [52], in order to increase the rate of energy renovation in buildings with poor thermal performance it is important to understand the thermal performance of entire districts. By doing so, sustainable energy planning strategies can be generated. In this research, using results first generated on building level and thereafter on cluster level, relevant key indicators, such as LCC and energy use, can be predicted on district level.

As in the case for the results obtained on cluster level, results generated on district level are of interest to multiple stakeholders. For housing companies and municipalities owning an entire district, hotspots in terms of buildings with high cost-effective energy efficiency potential can be identified within a residential district. Hence, these findings are also valuable for authorities by enabling ranking between different building clusters for increasing energy efficiency in the building stock in a profitable manner. 


\subsubsection{City level}

When increasing energy efficiency in buildings, it is important to be aware of the environmental and economic impacts on the surrounding DH system. By doing so, energy planning strategies are made feasible that achieve the overall most beneficial solutions in perspectives of long-term profitability and decrease of greenhouse gas emissions. This is especially when considering the energy renovation of a larger number of buildings, such as districts, which correspond to a significant share of the total $\mathrm{DH}$ load. Using the previously generated results based on a combination of building categorization, LCC optimization, BES, together with energy system analysis and optimization, enables an assessment of the effects from techno-economic optimization of a residential district built before 1945 on the surrounding DH system. In this step it is important to consider all buildings connected to the DH network and not only the buildings represented by the building categorization. In addition, since each DH system is unique in terms of operation and fuel input, it is important to model the actual conditions for the studied DH system.

The results calculated on city level are key for policy makers in their path for transformation to a sustainable energy system. Using relevant findings in the form of economic and environmental aspects connected to both DH suppliers and users, city planning, and decision-making can be facilitated by maximizing overall environmental benefits in a cost-effective manner. Consequently, this may also help to erase shortterm energy renovation decisions towards long-term sustainable decisions both in terms of economic and environmental performance. Authorities can use the results for development of policies in the quest for reaching national and EU energy and climate goals. Furthermore, sustainable energy management strategies can be developed for municipalities to secure future energy supply.

\subsection{METHODS AND TOOLS}

\subsubsection{Bottom-up approach}

Investigations on energy renovation of entire residential districts are enabled by the use of a bottom-up approach. Using a bottom-up approach based on representative buildings for assessing the impact from energy renovation has been successfully investigated in numerous research studies. Mattinen et al. [53] divided 700 residential buildings located in Kaukajärvi, Finland, into 60 building archetypes. The buildings were divided into three residential groups: single-family houses, terraced houses and apartment buildings, and 20 age groups. By using data from the Finnish Environment 
Institute's urban structure monitoring system, such as floor area, volume and year of construction, the effects from behavioral and technical changes on energy use and greenhouse gas emissions were presented. On a national level in Finland, Tuominen et al. [54] investigated the impact of EEMs in the entire building stock by the use of four representative building types (detached houses, multi-family buildings, office buildings and holiday homes). The building types were also divided into four age groups, pre1960, 1960-1979, 1980-2000 and 2001-2010, with differences in thermal performance corresponding to a total of 16 building types. The results showed possible reductions of $13 \%$ and $30 \%$ in energy use and $\mathrm{CO}_{2}$ emissions, respectively, by 2050 in the building stock. However, the predicted figures are significantly dependent on national policy measures and introduction of new technologies.

Streicher et al. [55] developed a bottom-up methodology resulting in 54 archetype buildings in the Swiss building stock, with differences in terms of construction period, building type and urban typology. The differentiation was based on data from more than 25,000 energy certificates. Rural typology, single-family houses and building construction year were parameters that resulted in generally higher energy use. Moreover, it was shown that additional insulation of external walls most likely holds a high energy efficiency potential since most heat is lost through the external walls, which is especially true for buildings constructed between 1920 and 1945 .

Mata et al. [56] modeled the Spanish building stock with 120 representative buildings based on six building types (single-family houses, multi-family buildings, commercial buildings, culture and leisure buildings, offices and others), four construction periods (pre-1975, 1975-1979, 1980-2005 and post-2005) and five locations, to assess the economic and environmental effects from implementing EEMs. The results show that there is techno-economical potential for reductions of 33\% and 37\% in final energy demand and $\mathrm{CO}_{2}$ emissions, respectively.

Mata et al. [57] applied a bottom-up building physics-model for assessing the effects in terms of energy use, $\mathrm{CO}_{2}$ emissions and costs from EEMs in the Swedish building stock. Fourteen hundred buildings, representative of the Swedish residential building stock, were used as the study object. The results showed that the EEMs are in most cases costeffective with possible reductions in energy use by $55 \%$ and $\mathrm{CO}_{2}$ emissions by $63 \%$. Wang and Holmberg [58] also investigated the cost-effectiveness of energy renovating the existing Swedish residential building stock based on four typical building archetypes: detached single family houses pre-1945, multi-family buildings built between 19461960, multi-family buildings built between 1961-1975 and high slab apartment buildings built between 1965-1975. Energy savings of 36-54\% are possible in the archetype buildings with variations in optimal energy renovation packages between the 
archetypes. In addition, the EEMs corresponding to the highest reduction in energy use are not always the most cost-effective. Liu et al. [59] studied the residential district built before 1945 in Visby, using a bottom-up approach with 12 building types representative of 920 buildings. The research focused on cost-optimal energy renovation strategies based on building categorization and LCC optimization. The results showed potential decreases of $31 \%$ in energy use decreasing $\mathrm{CO}_{2}$ emissions by $57 \%$. In addition, it was concluded that cost-effective EEMs vary depending on building type.

The categorization of the district built before 1945 in Visby has previously been presented in $[60,61]$. The method includes three major steps: (1) inventory of the district (gathering and compilation of building data); (2) categorization (allocating buildings in groups depending on building characteristics); and (3) selection of building types that are representative of the building district (each building type selected based on average values of various building properties). The inventory included 1048 buildings. Data for each building was obtained using a database with qualitative information on every building in the district built before 1945 in Visby [62], supplemented with Geographic Information System (GIS) data. After eliminating diverging buildings from each category, in terms of building volumes outside the standard deviation, the number of buildings was reduced to 920. Results from the building categorization consist of a description of building properties in the form of construction properties, areas of various building elements with associated $U$-values, etc., which consequently allows for modeling, simulation and techno-economic optimization of a building.

By generating representative buildings of a larger number of buildings, it is possible to analyze packages of cost-effective EEMs of an entire district. This has been performed by detailed modeling of 12 residential building types which represent 920 buildings of the district built before 1945 in Visby. Consequently, results in the form of costeffective packages of EEMs, LCC, heat demand before and after energy renovation, primary energy use and $\mathrm{CO}_{2}$ emissions, are possible to calculate by the use of OPERAMILP as a techno-economic optimization tool. By dividing the buildings into four clusters, based on similarities in terms of building size and type of building structure, the corresponding results can be generated on a cluster level. Moreover, including all clusters allows for investigation of the entire district. In order to study the impact on the DH system from cost-effective packages of EEMs on a residential district, it is necessary to include all buildings connected to the DH network in Visby, titled as city level. By doing so, $\mathrm{CO}_{2}$ emissions and primary energy use, optimal $\mathrm{DH}$ production and system cost from the DH system can be calculated using the energy systems optimization model MODEST. Prior to this, the heat load for the DH system is 
converted into a flexible time division suitable for larger DH systems by using the software Converter [63].

\subsubsection{Building energy simulation}

Building energy simulation (BES) is a type of forward modeling approach, meaning that building physical parameters are used as input data which commonly consist of user behavior, geographic location and building envelope construction properties, for prediction of building energy use. Traditionally, this type of modeling approach is the one most often used [64], and applied during the design phase of a construction project.

BES processes are either based on single-zone modeling with coarse dynamic calculation procedures in the form of static and quasi-steady state models, or dynamic BES models. In static and quasi-steady state calculations there is no need for highresolution data describing user behavior and climate conditions, while this is the case for dynamic BES models. However, fast calculation procedures are enabled by using low-resolution data due to the use of low computational effort. Hence, a time-effective overview of the building energy use is made possible. A quasi-steady state calculation approach has been applied in Papers I-IV based on a time resolution of 12 time steps, each time step corresponding to a month during a year. A utilization factor, $\eta$, for the heat gains is included in the calculation approach, which means that the energy calculations are performed in accordance with the calculation procedure in EN ISO 13790 [65].

Compared to a coarse dynamic calculation procedure and single-zone modeling, the necessity of a refined dynamic energy calculation procedure is needed for highresolution analysis of energy use, buildings with a high time constant, complex energy systems including both comfort cooling and heating, and fluctuating IHG such as industrial facilities. IDA Indoor Climate and Energy (IDA ICE) is a dynamic multizone BES software in which the building energy balance and its thermal comfort are studied. The software has been used in Paper I and Paper IV. IDA ICE is one of the well-known BES software programs within the field for validation of energy models in research [66]. The software allows for consideration of building geometry, solar radiation (both direct and diffuse), IHG, HVAC (heating, ventilation and air conditioning) requirements and building construction data in the building energy balance. Moreover, IDA ICE considers various climate properties, such as air temperature, humidity and wind properties. The heat balance calculation includes contributions from e.g. occupants, heating units, insolation, thermal inertia and surface transmission. The software can handle simulation design days based on daily extreme temperatures. The mathematical models in IDA ICE are described as Neutral Model 
Format source code, allowing users to interconnect and develop their own models in the software. The performance of IDA ICE has previously been validated according to Envelope BESTEST in the scope of IEA Task 12. In addition, in [67] it was stated that IDA ICE performs well compared to other BES software with respect to the ASHRAE Standard 140-2004.

BES has commonly been used among researchers to investigate EEMs in various residential buildings and locations, including residential buildings built before 1945 in a Northern European climate ${ }^{7}$. For example, Wang and Holmberg [58] applied a quasisteady state calculation procedure in accordance with EN ISO 13790 to investigate 13 energy renovation strategies on a single-family house built before 1945 typical of the Swedish residential building stock. The study allowed for predictions of decreases in energy use for the various strategies. Other investigations using quasi-steady state calculation approaches for assessing EEMs in residential buildings include Broström et al. [68] and Liu et al. [37]. In both studies, techno-economic optimizations were used to generate cost-effective EEMs. Broström et al. [68] used a typical Swedish singlefamily wooden house from the 1920s as the study object and Liu et al. [37] a typical multi-family building from the 1890s in Stockholm, Sweden. Examples of dynamic BES methods for investigating EEMs in residential buildings built before 1945 can be seen in $[40,69]$. Alev et al. [40] investigated three historic rural single-family houses in the Baltic Sea region using IDA ICE. The study included different scenarios in terms of energy savings levels, as well as the impact from varying climates. Arumägi and Kalamees [69] also used IDA ICE for investigating EEMs, however with wooden multifamily buildings in Estonia built before the Second World War as study objects. The study focused on the effects on primary energy use from different insulation measures, HVAC solutions and energy sources.

\subsubsection{Change-point modeling}

By using data on energy use and outdoor temperature, a building's change-point model (also commonly called energy signature) can be determined by quantification of a number of building thermal power characteristics, such as specific heat losses $\left(\mathrm{W} /{ }^{\circ} \mathrm{C}\right)$ and balance temperature $\left({ }^{\circ} \mathrm{C}\right)$. This is a type of inverse modeling compared to the forward modeling with BES described above, which has gained interest due to higher availability of data.

\footnotetext{
7 The research overview listed below is limited to residential buildings built before 1945, and Northern European climate due to large differences in climate conditions and building energy systems compared to warmer climates.
} 
Hammarsten [70] highlighted already in 1987 that change-point models are suitable for calculating building thermal performance. In 1992, Claridge et al. [71] assessed the potential with using data from building energy use. The results showed additional possibilities in the form of investigating a building's energy systems for proper function, evaluation of EEMs and eventual changes in the system's regulation to reduce energy use. To date, change-point models have been used in numerous research studies to predict building thermal performance in various contexts. For example, Park et al. [72] quantified the thermal performance for 128 apartment complexes representative of the building stock in Seoul, Korea, using change-point modeling. Input data included building properties and monthly utility bills in the form of natural gas, electricity and DH for three years, 2009-2011. The results showed that it is possible to determine the optimal energy renovation measures by using parameters in change-point models. Sjögren et al. [73] studied the specific heat losses of 100 multi-family buildings in Sweden through the use of change-point modeling. For accurate prediction of specific heat losses, the authors point out the need for data describing the use of household electricity and indoor temperature. Moreover, the figure $\mathrm{kWh} /\left(\mathrm{m}^{2} \cdot\right.$ year $)$ is questioned since it is highly dependent on user behavior, which is also addressed by $[72,74,75]$. Hitchin [76] reviewed the energy performance standard for buildings ISO 13790:2008 (commonly used for implementation of the Energy Performance of Buildings Directive in Europe), and an alternative method based on a change-point model. It was concluded that the change-point model is in general more robust than the standard ISO calculation and provides more information about the building, such as balance temperature, and is therefore preferred.

In Paper V, the thesis author has presented a novel development of the change-point model, titled DTPC (Differentiating Thermal Power Characteristics), for predicting thermal power characteristics in terms of specific heat losses, $Q_{\text {total }}\left(\mathrm{W} /{ }^{\circ} \mathrm{C}\right), \mathrm{HWC}(\mathrm{W})$, HTW demand $(\mathrm{W})$ and balance temperature, $T_{\text {balance }}\left({ }^{\circ} \mathrm{C}\right)$, using selected time periods based on time-dependent variations in climate and user behavior. Input to the model consists of heating supply data with hourly resolution and local climate data in the form of outdoor temperature. Hence, no data for user behavior is required, such as IHG. The model is implemented in the MATLAB software. The overall methodology in DTPC consists of five steps. In Step I, hourly heating supply data for the studied buildings is collected, and corresponding outdoor temperature for a continuous time period of minimum one year. Data in the form of heated area and construction year is also collected. Step II consists of the selection of time periods based on seasonal and daily patterns in terms of climate and user behavior. Hence, a differentiation between building thermal power characteristics is made possible. In Step III, assumptions are made connected to building operation and user behavior followed by the numerical 
procedure in Step $I V$. In Step $V$, the generated results are interpreted and analyzed. In addition, to investigate and potentially enhance the robustness of the model, a sensitivity analysis is performed with regard to the model assumptions and selection of time periods. A schematic of DTPC can be seen in Figure 11.

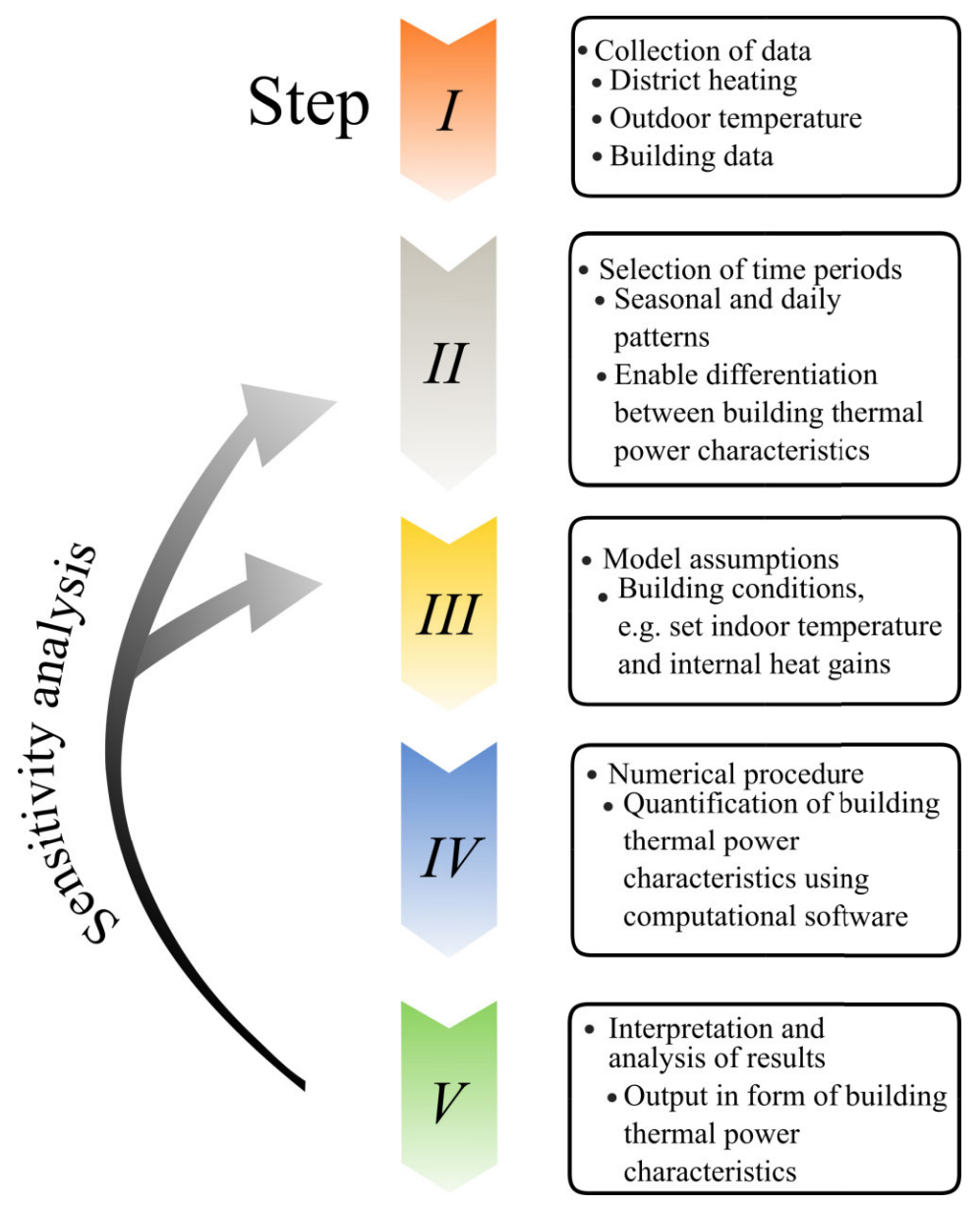

Figure 11: Methodology in DTPC [77].

The collection of data in the form of heating supply, outdoor temperature and heated area is the first step of the methodology. By the use of heated area, it is possible to compare the thermal performance of the various buildings. Following is the selection of time periods used in the numerical procedure, Step II. By doing so, prediction of various thermal power characteristics is enabled based on seasonal and daily patterns in 
terms of climate and user behavior, such as predictions of the energy use for HWC during time periods when space heating is uncommon. The selection of time periods can be seen in Figure 12. January and February, between 00:00-05:00 are used for predictions of $Q_{\text {total. }}$. Time periods when heating supply occur above the balance temperature in June are used for predictions of the energy use for HTW, the four lowest hourly averages of heating supply in July are used for predictions of the energy use for HWC and the whole year is used for predictions of $T_{\text {balance. }}$. The red bars in the top left corner visualize hourly HTW profiles for multi-family buildings based on the standard EN 12831-3 [78]. Accordingly, energy use for HTW is uncommon during the time steps used for predictions of $Q_{\text {total. }}$.

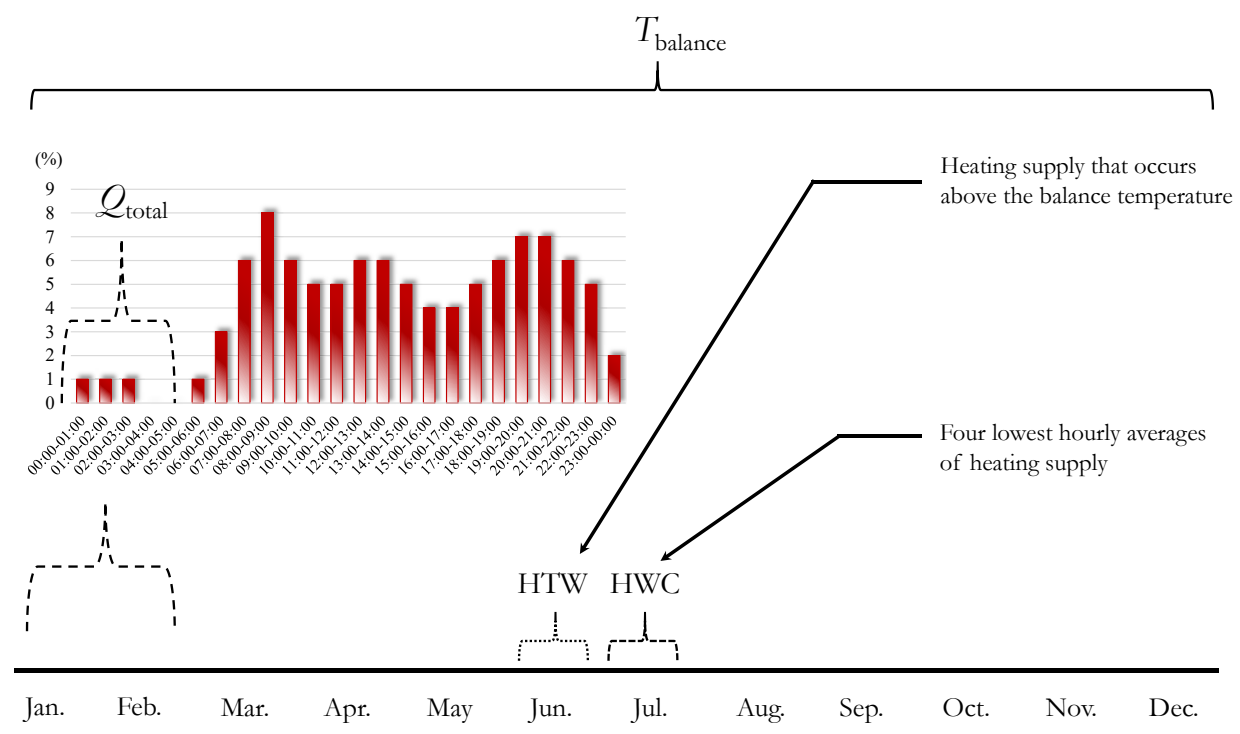

Figure 12: Selection of time periods for prediction of thermal power characteristics [77].

In Step III, model assumptions connected to e.g. IHG and set indoor temperature are set to enable the numerical procedure in Step $I V$, which are presented in detail in Paper $\mathrm{V}$. This is necessary since the change-point model does not require any data on user behavior. Following is the numerical procedure which is implemented in the MATLAB software to enable time-effective analysis of an entire district. The procedure starts with predictions of the energy use for HWC, which is calculated according to Eq. 10-Eq. 11. 


$$
\begin{gathered}
\overline{P(\mathrm{HWC})_{0}}=\frac{P(\mathrm{HWC})_{0,1}+\ldots+P(\mathrm{HWC})_{0,31}}{31} \\
P(\mathrm{HWC})=\frac{\overline{P(\mathrm{HWC})_{0, \min }+\ldots+\bar{P}(\mathrm{HWC})_{o, \min +3}}}{4}
\end{gathered}
$$

Eq. 11

In which $\overline{P(\mathrm{HWC})}$, represents the individual average power for each hour of the day (i.e., $o=00: 00,01: 00, \ldots, 22: 00,23: 00)$. The numerical procedure is performed considering all the days in July, and the average for each hour is hence calculated by dividing the sum by 31. In Eq. 11, $P(\mathrm{HWC})$ is the energy use for HWC and

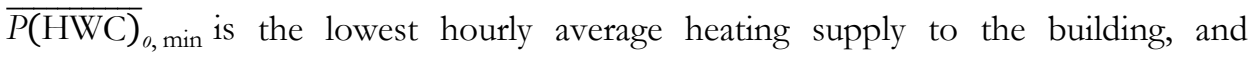
$\overline{P(H W C}_{o, \min +3}$ the fourth lowest hourly average. Hence, the energy use for HWC is set to the average of the four hours with the lowest averages in terms of heating power supply. The total specific heat losses, $Q_{\text {total, }}$ are calculated according to Eq. 12-Eq. 13.

$$
\begin{gathered}
Q_{\text {total }, \text { sum }}=\sum_{p=1}^{q} \frac{\left(P_{\cdot p}-P(\mathrm{HWC})\right)}{\left(T_{\text {in }}-T_{\text {out }, p}\right)} \\
Q_{\text {total }}=\frac{Q_{\text {total sum }}}{q}
\end{gathered}
$$

In which $P_{. p}$ is the hourly heating supply to the building at hour $p . P(\mathrm{HWC})$ refers to

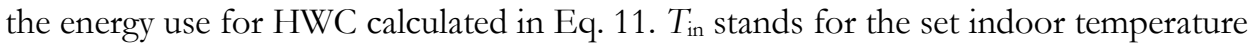
and $T_{\text {out }, k}$ refers to the outdoor temperature at hour $p$. The mathematical operation is performed for each hour during January-February between $00.00-05.00$ as mentioned above. $Q_{\text {total }}$ is set to the average based on the calculations during the selected time period as can be seen in Eq. 13 , with $Q_{\text {total sum }}$ as the sum of all hourly $Q_{\text {total }}$ divided by the number of time steps, $q$, in the selected time period.

Through an iterative calculation process, predictions of the balance temperature, $T_{\text {balance, }}$ and energy use for HTW are made possible using the calculated HWC and $Q_{\text {total. }}$. The calculation process is performed until a preset tolerance level is achieved between the 
calculated $T_{\text {balance }}$ and the previously guessed $T_{\text {balance. }}$ The HTW is set to the average energy use that occurs during outdoor temperatures above $T_{\text {balance }}$ in June. The calculations of $T_{\text {balance }}$ and the energy use for the HTW are presented in Eq. 14-Eq. 15,

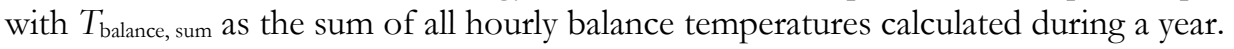

$$
\begin{array}{cc}
T_{\text {balance, sum }}=\sum_{r=1}^{8,760} \frac{(\mathrm{P} \cdot r-P(\mathrm{HWC})-P(\mathrm{HTW}))}{\left(Q_{\text {total }}\right)}+T_{\text {out }, r} & \text { Eq. } 14 \\
T_{\text {balance }}=\frac{T_{\text {balance,sum }}}{8,760} & \text { Eq. } 15
\end{array}
$$

In the final step of DTPC, Step $V$, the results are interpreted and analyzed. In order to assess and potentially enhance the robustness of the developed model, it is possible to perform a sensitivity analysis with regard to the assumptions in the model and the selection of time periods for prediction of various thermal power characteristics.

\subsubsection{Life cycle cost analysis and optimization}

The life cycle cost (LCC) approach allows for consideration of expenditures connected to both investments and the operation phase during a product's expected life cycle [79]. Hence, LCC is a calculation technique that can be used to rank different investment options. The Buildings and Constructed Assets Standard ISO 15686 defines LCC as "a valuable technique that is used for predicting and assessing the cost performance of constructed assets" [80]. One of the earliest papers on LCC analysis in buildings is the work from 1988 by Gustafsson and Karlsson [81] highlighting the possibilities for finding a building's optimal energy renovation package. A Swedish cross-disciplinary research project based on different perspectives on LCC, which included amongst others decision makers and practitioners, suggests LCC analysis as a relevant tool for decision support during building energy renovation [82].

When performing building energy renovation, it is important to calculate the costoptimal package of EEMs corresponding to the building's lowest possible LCC. The selection of cost-effective EEMs depends on numerous parameters, such as building thermal performance, energy cost, renovation costs, discount rate and life length of the various building elements $[37,83,84]$. In order to minimize LCC one needs to use some type of optimization procedure. Minimizing building LCC is an approach that has been 
used in several scientific investigations. Examples of scientific investigations for minimizing building LCC include the work by Marszal and Heiselberg [85] in which LCC analysis was used to find the correlation between cost-optimal EEMs and renewable energy technologies for a multi-family net zero energy building in Denmark. By considering expenditures related to investment, operation, replacement and demolition, it was found that cost-effective net zero energy buildings are dependent on decreasing energy use to a minimum and covering the remaining energy use with renewable energy technologies. Moreover, Hasan et al. [86] used optimization software to minimize the LCC of a typical Finnish detached single-family house. Profitable EEMs include in most cases insulation of the external walls and roof, as well as replacement to better windows. A decrease of $23-49 \%$ in space heating demand was achieved for the optimized house. LCC optimization procedures based on quasi-steady state energy calculations were used by La Fleur et al. [35] when investigating costoptimal energy renovation of a multi-family building from the 1960s in Sweden. The results showed that it is not cost-optimal to implement EEMs to decrease space heating demand due to relatively good thermal performance and low energy prices. There are a limited number of scientific investigations on minimizing LCC for residential buildings built before 1945 in a Northern European climate. In fact, Loli and Bertolin [87] point out the low number of papers published in peer-reviewed journals written by authors with Scandinavian affiliations within the research field despite the large quantity of historic buildings in Scandinavia. In any way, examples on minimizing LCC in residential buildings built before 1945 in a Northern European climate can be seen in $[37,59,68]$. Broström et al. [68] investigated the energy efficiency potential in a Swedish single-family wooden house from the 1920s with cultural significance, mainly connected to the building's visual appearance. The results showed that the energy savings potential and potential decrease in LCC is limited by building preservation requirements due to the need for character-changing measures to achieve ambitious energy targets $(50 \%$ decrease in energy use), such as external wall insulation. However, a $20 \%$ decrease in energy use is feasible and reduces LCC by $15 \%$ by replacement of heating system, weather-stripping, attic insulation and secondary glazing. Also using LCC optimization, however with a Swedish multi-family brick building from the 1890s as study object, Liu et al. [37] found that the cost-optimal energy renovation package varies whether regarding the building as listed or non-listed. The cost-optimum point corresponds to a decrease of $28 \%$ and $21 \%$ in energy use when regarding the building as non-listed compared to listed, respectively, while lowering LCC by $24 \%$ and $22 \%$. Insulation measures targeting the external walls are required for achieving a 50\% decrease in energy use limiting the energy savings potential for the listed buildings. Moreover, applying LCC optimization procedures, Liu et al. [59] found that the cost-optimal energy efficiency potential for the residential district built before 1945 in Visby, Sweden, 
corresponds to decreases of $31 \%$ in energy use, decreasing $\mathrm{CO}_{2}$ emissions by $57 \%$. In addition, it was concluded that cost-effective EEMs in the district vary depending on building type.

In order to generate the cost-optimal package of EEMs for the buildings studied in Papers I-IV, LCC optimization software OPtimal Energy Retrofit Advisory-Mixed Integer Linear Program (OPERA-MILP) has been used. OPERA-MILP is the result of a further development of OPtimal Energy Retrofit Advisory (OPERA) developed first at the Division of Energy Systems at Linköping University in the late 1980s [88]. In the current version of the software, a Mixed Integer Linear Problem (MILP) problem is designed which is solved using the optimizer CPLEX [89]. OPERA-MILP has been used for studying various types of residential buildings, including historic single-family buildings, historic multi-family buildings and multi-family buildings from the 1960s [35, 37, 84].

The mathematical formulation in OPERA-MILP consists of an objective function which considers parameters as various costs and thermal properties connected to EEMs, among other constraints, to calculate the lowest possible LCC while maintaining a preset indoor temperature. Input data to the software are rather basic, consisting of e.g. $U$-values of building elements, air changes per hour $(\mathrm{ACH})$, monthly average outdoor temperature, preset indoor temperature and renovation costs for the various building elements. In addition, OPERA-MILP allows for time-effective LCC analysis due to a fast optimization procedure. Costs that are included in the LCC include investment costs for the heating system and EEMs on the building envelope. Energy costs and maintenance costs for building elements are also considered. The residual value at the end of the life cycle is subtracted from the total LCC. The total LCC of a building, $L C C_{\text {total }}$, can therefore be calculated according to Eq. 16.

$$
L C C_{\text {total }}=L C C_{\text {investment cost }}+L C C_{\text {energy cost }}+L C C_{\text {maintenance cost }} \quad \text { Eq. } 16
$$

In which $L C C_{\text {investment cost }}$ represents the investment cost for the EEMs, $L C C_{\text {energy cost }}$ is the energy cost which consists of expenditures connected to heating supply and $L C C_{\text {maintenance cost }}$ is the maintenance cost, which includes cost connected to expenditures such as demolition and construction of a new façade. Expenditures that occur in the future are transferred to a base year by the use of a discount rate, $d$. The selection of discount rate directly influences the profitability of investment. A low rate makes more value for future investments and vice versa. The method for using a discount rate for managing future expenditure in the calculations of LCC is performed through the Net 
Present Value (NPV) method. The NPV method considers non-annual recurring costs and annually recurring costs. Non-annual recurring future costs are calculated as stated in Eq. 17, and annually recurring costs according to Eq. 18.

$$
\begin{gathered}
N P V=\frac{C}{(1+d)^{s}} \\
N P V=C \cdot \frac{1-(1+d)^{-s}}{d}
\end{gathered}
$$

In Eq. 17 and Eq. 18, $s$ corresponds to the number of years between today and when the expenditure occurs, and the number of years in the studied time period, respectively, and $C$ is the cost.

In order to calculate the lowest possible LCC by the selection of a cost-optimal package of energy renovation measures, a number of EEMs targeting the building envelope and heating systems have been incorporated into the OPERA-MILP software. The EEMs on the building envelope include replacement of windows to three different types, improving airtightness by weather-stripping, floor insulation, roof insulation and insulation on the inside and outside of the external walls. In Papers I-IV, a step resolution of $2 \mathrm{~cm}$ between each insulation step has been used, with the minimum insulation thickness set at $2 \mathrm{~cm}$, and the maximum at $42 \mathrm{~cm}$. Incorporated heating supply systems include DH, electric radiator (ER), groundwater heat pump (GHP) and wood boiler (WB).

The expenditures are calculated using cost functions for both the EEMs targeting the building envelope and the heating systems including costs connected to labor and material. The cost for the insulation measures and heating systems are predicted by the use of linear functions depending on insulation thickness for the insulation measures and maximum power of the heating system. Moreover, a base cost is also considered for the heating system. The cost for weather-stripping is calculated based on the number of windows that are air-tightened and the cost for window replacement is calculated depending on the total window area. An overview of the cost functions used and other expenditures related to the LCC can be seen in Papers I-IV, which have been calculated using the database Wikells with up-to-date market costs [26]. 
With use of OPERA-MILP and post-processing of the generated optimization data, there are three different optimization procedures related to LCC and energy use. If an EEM is suggested that is not appropriate with regard to e.g. heritage values, the LCC optimization is performed again in which the inappropriate EEM is excluded as a possible measure in the solution space. In the first procedure, an optimization of the LCC is performed in which the lowest LCC is calculated together with corresponding energy use. This is achieved by the selection of a cost-optimal heating system along with suggested cost-effective EEMs on the building envelope. The objective in the optimization problem is minimized by a simultaneous optimization of all measures and factors connected to them, which includes parameters such as discount rate, energy prices and set life length of the various measures. Secondly, LCC optimization can also be performed by introducing a condition in the formulation of the optimization problem consisting of setting the allowed energy use to an arbitrary lower value than the energy use obtained at LCC optimum. In the third optimization option, the energy use is set at a higher value than the energy use at LCC optimum. To enable this, postprocessing of the optimization results is performed through a comparison between the EEMs on the building envelope in terms of cost-effectiveness (based on cost per $\mathrm{kWh}$ saved) with the most expensive EEM removed first, etc., until the set energy target is generated.

\subsubsection{Environmental assessment $-\mathrm{CO}_{2}$ emissions and primary energy use}

A result of buildings undergoing energy renovation is a change in environmental performance. Due to major global environmental challenges related to factors such as growing economies in many parts of the world, with larger greenhouse gas emissions and higher energy use as a result, the environmental performance of buildings is a strong incentive for performing energy renovations. However, considering the large proportion of buildings connected to DH systems in Sweden, it is important to assess the effects from building energy renovation on the environmental performance from a $\mathrm{DH}$ supplier perspective. The environmental performance, in terms of $\mathrm{CO}_{2}$ emissions and primary energy use, from a building perspective has been calculated in Paper II, and the corresponding effects from a DH supplier perspective have been investigated in Paper IV. It is important to note that this research does not aim to calculate specific emission factors and primary energy factors from various energy sources, but rather to show the overall environmental effects from the selection of cost-effective packages of EEMs in a residential district built before 1945. In Paper II, considered heating systems included GHP, ER, DH and WB. A primary energy factor of 2.5 is set for electricity since in European electricity production approximately 2.5 units of energy are needed 
in order to deliver 1 unit of electricity to the end user [90]. For wood pellets, a factor of 0.11 is used considering extraction, processing and transportation [91]. A primary energy factor of 0.31 is set for $\mathrm{DH}$ since it is the local factor for the $\mathrm{DH}$ production in Visby [92]. The low primary energy factors for WB and DH are explained by the fact that only the energy for production of the fuels is taken into account, and not the energy content of the fuels. Concerning $\mathrm{CO}_{2}$ emissions, due to the use of different emission factors related to the marginal production of electricity in Paper II and Paper IV, updated figures are used in this thesis ${ }^{8}$. Two different $\mathrm{CO}_{2}$ emission factors for electricity production and biomass have been considered, in order to assess the effects from different system boundaries. For emissions related to electricity production, average Swedish electricity production and marginal electricity production have been considered with emissions of $13 \mathrm{~kg} \mathrm{CO}$ eq. / MWh [93] and $969 \mathrm{~kg} \mathrm{CO}_{2}$ eq. $/ \mathrm{MWh}$ [94], respectively. The marginal production of electricity is assumed to occur during peak hours, produced by a condensing coal power plant in a fully deregulated European market. Hence, the local electricity used will increase the electricity production in coalfired condensed power plants and result in an increase of $\mathrm{CO}_{2}$ emissions. Biomass is considered as both a limited and unlimited resource. Condensing coal plants are assumed to be the marginal user of biomass giving emission factors of $405 \mathrm{~kg} \mathrm{CO}_{2}$ eq. $/ \mathrm{MWh}$ [95] and $11 \mathrm{~kg} \mathrm{CO}$ eq. $/ \mathrm{MWh}$ [96], respectively. For DH, $57 \mathrm{~kg} \mathrm{CO} 2$ eq. $/ \mathrm{MWh}$ is used which also is the local value for the DH system in Visby [92]. The relatively low factors for $\mathrm{DH}$ are explained by the low proportion of fossil fuels used for the fuel input.

In Paper IV, to investigate the environmental effects from performed energy renovation of the residential district built before 1945 in Visby on the local DH system, the actual fuel input to the heat production is considered. As mentioned above, 0.31 is used as the primary energy factor for the $\mathrm{DH}$ production since it is local value for Visby [92]. A summary of $\mathrm{CO}_{2}$ emission factors for the various fuels used in the local heat production is presented in Table 2. Both production and transportation are included in the emission factors. Concerning the local electricity use, the marginal electricity production accounting model has been used in order to calculate global $\mathrm{CO}_{2}$ emissions.

\footnotetext{
${ }^{8}$ Nonetheless, it should be noted that the same system boundaries are used in Paper II and Paper IV for marginal production of electricity.
} 
Table 2: DH utilities with corresponding heat production and $\mathrm{CO}_{2}$ emission factors [96, 97$]$.

\begin{tabular}{lc}
\hline Fuel & $\begin{array}{c}\mathbf{C O}_{2} \text { emission factor } \\
(\mathbf{k g ~ C O}\end{array}$ \\
\hline Bio oil & $/ \mathbf{M W h})$ \\
Biomass & 5 \\
Oil & 11 \\
Electricity & 290 \\
\hline
\end{tabular}

Decreased building energy use will directly improve building environmental performance provided that the heating supply system is not changed after energy renovation. Nonetheless, the environmental performance is strongly influenced by the type of heating supply system and system boundary as shown in a study by Liu et al. [37] when investigating the effects on primary energy use and $\mathrm{CO}_{2}$ emissions from costeffective energy renovation. However, increased energy efficiency in the building stock will also affect the environmental performance from a $\mathrm{DH}$ supplier perspective. While there are a few scientific investigations on the connection between energy renovation of buildings and the associated environmental effects on the local DH system, research on energy renovation based on techno-economic energy renovation of a residential district built before 1945 are scarce. Below is an overview of the related research on the topic.

Åberg and Widén [98] studied the effects of implementing EEMs in residential buildings in six different DH systems in Sweden based on a cost-optimization model structure. The decrease in heat demand resulted in a reduced use of fossil fuels and biomass in the $\mathrm{DH}$ system, and mainly affected the heat-only production boiler. Similar results were found by Åberg [99] with a decrease in global $\mathrm{CO}_{2}$ emissions, and the use of biomass and fossil fuel due to building energy efficiency improvement based on four pre-defined DH systems describing a DH sector in aggregated form. To maximize the decrease in $\mathrm{CO}_{2}$ emissions, the heat production technologies in different $\mathrm{DH}$ systems should be considered. Lundström and Wallin [100] also showed that decreased greenhouse gas emissions are enabled through energy efficiency improvement in the form of insulation of the building envelope. The study object consisted of two multifamily buildings in Eskilstuna, Sweden, from the 1960s and 1970s. Similar results with a decrease in greenhouse gas emissions from performed energy renovation are found in Lidberg et al. [101] using energy systems optimization model MODEST (Model for Optimization of Dynamic Energy Systems with Time-dependent components and boundary conditions), which was also used in Paper IV. Forty multi-family buildings in the municipality of Borlänge, Sweden, were selected as the case study. The authors, however, highlight that the findings are strongly linked with the fact that biomass is a 
possible replacement for fossil fuels elsewhere. Moreover, it was stated that energy renovation on the building envelope without increasing electricity use decreases global greenhouse gas emissions more. Other examples of positive environmental effects from building energy efficiency include the work by Åberg and Henning [102] assessing energy saving measures in residential buildings built during 1961-1980 on the $\mathrm{DH}$ system in Linköping, Sweden. A reduction in heat demand decreased global $\mathrm{CO}_{2}$ emissions and use of fossil fuels. Le Truong et al. [103] showed that measures that decrease more peak load production also decrease the primary energy use more based on a DH multi-family building in Växjö, Sweden. Efficient electric appliances, ventilation heat recovery and external wall insulation corresponded to the measures with highest primary energy savings.

\subsubsection{Local energy system analysis and optimization}

By modeling energy systems a systematic and simplified view can be achieved of a complex energy system [104]. Hence, it is possible to analyze various issues related to the energy system, and consequently better understand the behavior of the system [105]. Modeling of energy systems is carried out by first setting the framework of the system by including and specifying parameters of interest, e.g. definition and properties of energy utilities and energy demands, together with assumptions connected to the model [104]. This follows predefined analysis in the energy system tool used which can be optimization or simulation procedures of various types. The analysis outputs constitutes the last step of the energy system procedure. The tool-specific purpose of an energy system framework specifically depends on the abovementioned parameters: system modeling, objective of analysis and possible outputs, and is crucial to consider during selection of a specific framework.

In Paper IV, the studied system consists of the energy utilities in the local DH system, the distribution network and the heat load of the entire DH system, including the heat load from the residential district built before 1945 studied in Papers II-IV. An optimization framework known as MODEST $[99,106,107]$ has been selected to model and analyze the effects from cost-effective packages of EEMs in the residential district built before 1945 in Visby on the DH system. To reflect the dynamics in a system in the form of demand peaks and diurnal, weekly and seasonal variations in energy demand and other parameters, e.g. fuel and electricity prices, MODEST has a flexible time division.

When modeling an energy system in MODEST, input data in the form of analysis period, time division, discount rate, energy utilities and energy demands are required. Other components that need to be specified include distribution network and different 
types of nodes which include possible fuels to run the various energy utilities, as well as production of excess heat and by-products to sell to consumers. The utilities in MODEST are described by parameters such as efficiency, investment costs, capacity, and technical and economic life length.

The optimization framework allows for a numerical optimization with the objective of minimizing the total present value costs of the entire system, i.e., the system cost, over a specified period of time. The entire system in MODEST, from supply to demand side, is represented as a network of energy flows including the primary energy supply, energy conversion utilities and DH demand. Present and potential installations and energy flows are considered, and their optimal combination is obtained through optimization for each time period. The system is optimized by linear programming based on the system cost over the whole study period (in Paper IV set to 50 years) as the objective function. Other outputs besides the system cost are data about the fuels and electricity used in the energy utilities during the various time steps and production data from the utilities. To date, MODEST has been used to study approximately 50 utilities of electricity and DH systems [108-110].

The economic performance of a local $\mathrm{DH}$ system is directly dependent on the energy use of the buildings connected to the DH network and is therefore influenced by potential energy renovation in the building stock. As shown in section 5.2.5, there are generally positive effects on the environmental performance of a $\mathrm{DH}$ system due to decreased building energy use. Nonetheless, the economic performance is also a key parameter to assess since $\mathrm{DH}$ systems are dependent on the revenues from selling heat in order to be profitable. In fact, investigating the DH system in Linköping, Sweden, with an approximate annual production of $\mathrm{DH}$ and steam of 1,700 GWh and peak load of 500 MW, Difs et al. [111] showed that additional insulation of the attic on multifamily buildings within the $\mathrm{DH}$ network is profitable for the residences but not for the DH system. This is despite reduced use of oil and coal boilers during peak hours. However, reduced electricity use and heat load control are profitable for both the $\mathrm{DH}$ supplier and users, while simultaneously decreasing $\mathrm{CO}_{2}$ emissions as when insulating the attic. The counter-productive economic effects for DH systems in terms of losses in profitability from improved building energy efficiency are also highlighted by Pädam et al. [112]. The consequences of this leads to a scarcity of incentives for utilities to promote energy renovation in DH users. Increased degree of cooperation is suggested in the study to achieve higher energy efficiency which is beneficial for multiple actors. 


\section{STUDY OBJECT DESCRIPTION}

The following chapter presents the 12 building types that have been used as the study object in Papers I-IV and the residential district investigated in Paper $V$. In addition, the district heating system in $V$ isby which was investigated in Paper III is described in connection with the building types.

\subsection{BUILDING TYPES AND DISTRICT HEATING SYSTEM IN VISBY}

The buildings used for the studies in Papers I-IV are 12 residential building types, typical of the building stock built before 1945 in the city of Visby, Sweden. The city of Visby was included to the World Heritage List by the United Nations Educational Scientific and Cultural Organization (UNESCO) in 1995 due to its well-preserved fortified medieval sites. Visby is located on the island of Gotland, approximately 200 $\mathrm{km}$ south of Stockholm. There are approximately 24,000 inhabitants in Visby and the area of the city is $12 \mathrm{~km}^{2}$.

The 12 building types used in this research are obtained based on a categorization study of the district built before 1945 in Visby [60, 61]. The building types can be divided into six building categories. Categories 1-3 represent single-family houses standing on a crawl space with one story and a heated attic floor, Categories 4-6 represent multifamily buildings standing on an unheated basement with two stories and a heated attic floor. Categories 1 and 4 have no adjoining walls to the building. Categories 2 and 5 have one adjoining wall and categories 3 and 6 have two adjoining walls. Each category consists of both wood and stone buildings. This results in a total of 12 building types: $1 W-6 W$ and $1 S-6 S$ (" $W$ " indicating a building structure of wood and " $S$ " indicating a building structure of stone). The differences between the building types can hence be summarized by the following parameters: building structure, building envelope thermal performance, basement type, number of stories and adjoining walls. Furthermore, the 12 building types can be divided into four clusters based on similarities in building size and type of building structure, which was first performed by Liu et al. [59]. Single-family houses $1 W-3 W$ form Cluster $I$, multi-family buildings $4 W-6 W$ Cluster $I I$, single-family houses $1 S-3 S$ Cluster $I I I$ and multi-family buildings $4 S-6 S$ Cluster $I V$. Cluster $I$ consists of 500 single-family wood buildings, Cluster II of 81 multi-family wood buildings, Cluster III of 117 single-family stone buildings and Cluster IV of 222 multi-family stone buildings. The 12 building types are visualized in Figure 13 together with photos of the respective building type. Associated construction data and the number of buildings each building type represents are presented in Table 3 . 
$1 W, 1 S$

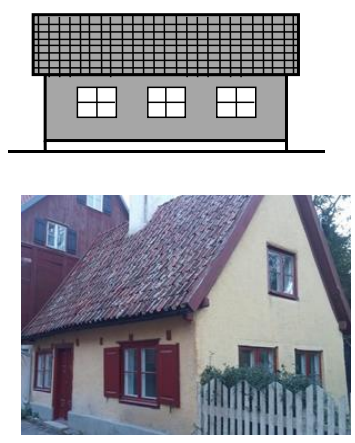

$4 W, 4 S$
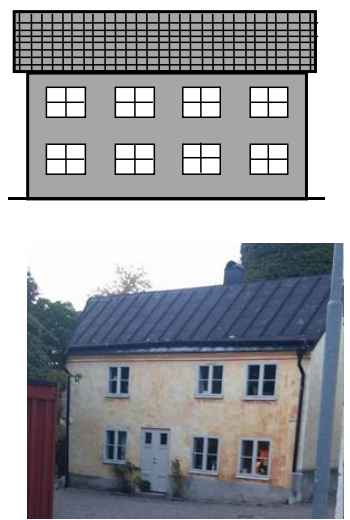

$2 W, 2 S$
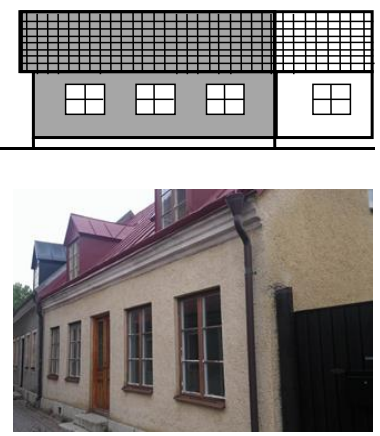

$5 W, 5 S$
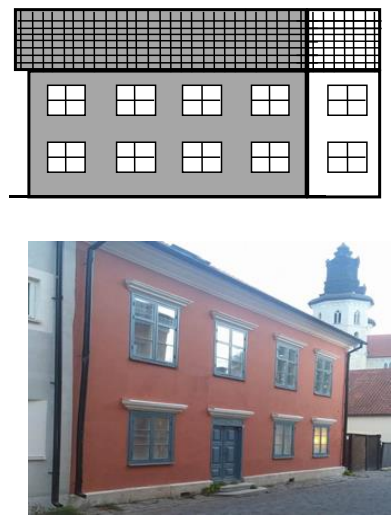

$3 W, 3 S$
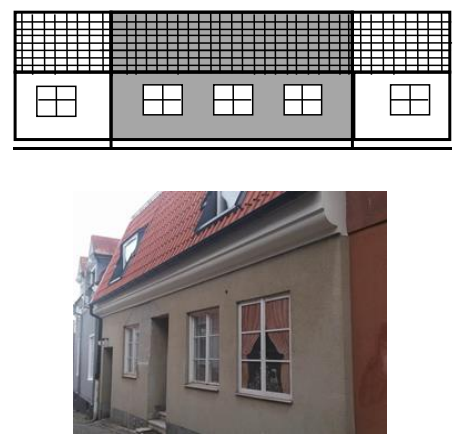

$6 W, 6 S$
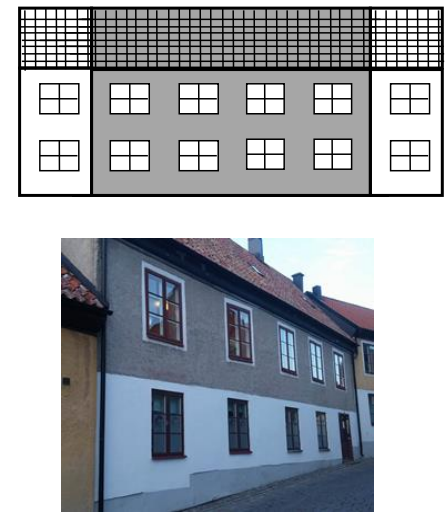

Figure 13: The building types with photos of the corresponding building categories [113]. 
Table 3: Construction data for the building types and the number of buildings each building type represents.

\begin{tabular}{|c|c|c|c|c|c|c|c|c|c|c|c|c|c|}
\hline \multirow{2}{*}{\multicolumn{2}{|c|}{$\begin{array}{c}\text { Cluster } \\
\text { Building type }\end{array}$}} & \multicolumn{3}{|c|}{$I$} & \multicolumn{3}{|c|}{$I I$} & \multicolumn{3}{|c|}{$I I I$} & \multicolumn{3}{|c|}{$I V$} \\
\hline & & $1 W$ & $2 W$ & $3 W$ & $4 W$ & $5 W$ & $6 W$ & $1 S$ & $2 S$ & $3 S$ & $4 S$ & $5 S$ & $6 S$ \\
\hline \multicolumn{2}{|c|}{ No. of buildings } & 309 & 166 & 25 & 33 & 30 & 18 & 55 & 46 & 16 & 75 & 83 & 64 \\
\hline \multirow{2}{*}{$\begin{array}{l}\text { Building } \\
\text { structure }\end{array}$} & Wood & $x$ & $x$ & $x$ & $x$ & $x$ & $x$ & & & & & & \\
\hline & Stone & & & & & & & $x$ & $x$ & $x$ & $x$ & $x$ & $x$ \\
\hline \multirow{2}{*}{$\begin{array}{c}\text { Basement } \\
\text { type }\end{array}$} & Crawl space & $\times$ & $x$ & $x$ & & & & $x$ & $\times$ & $x$ & & & \\
\hline & Unheated basement & & & & $\times$ & $x$ & $x$ & & & & $x$ & $x$ & $x$ \\
\hline \multicolumn{2}{|c|}{ No. of adjoining walls } & 0 & 1 & 2 & 0 & 1 & 2 & 0 & 1 & 2 & 0 & 1 & 2 \\
\hline \multirow{2}{*}{$\begin{array}{c}\text { External } \\
\text { walls }\end{array}$} & Area $\left(\mathrm{m}^{2}\right)$ & 86 & 61 & 45 & 245 & 180 & 116 & 80 & 57 & 43 & 235 & 173 & 112 \\
\hline & $U$-value $\left(\mathrm{W} /\left(\mathrm{m}^{\left.2 \cdot{ }^{\circ} \mathrm{C}\right)}\right)\right.$ & 0.65 & 0.65 & 0.65 & 0.67 & 0.67 & 0.67 & 1.8 & 1.8 & 1.8 & 1.97 & 1.97 & 1.97 \\
\hline \multirow[t]{2}{*}{ Windows } & Area $\left(\mathrm{m}^{2}\right)$ & 12 & 12 & 12 & 44 & 37 & 30 & 12 & 12 & 12 & 44 & 37 & 30 \\
\hline & $U$-value $\left(\mathrm{W} /\left(\mathrm{m}^{\left.2 \cdot{ }^{\circ} \mathrm{C}\right)}\right)\right.$ & 2.9 & 2.9 & 2.9 & 2.9 & 2.9 & 2.9 & 2.9 & 2.9 & 2.9 & 2.9 & 2.9 & 2.9 \\
\hline \multirow[t]{2}{*}{ Roof } & Area $\left(\mathrm{m}^{2}\right)$ & 71 & 79 & 92 & 170 & 159 & 159 & 65 & 73 & 86 & 161 & 150 & 150 \\
\hline & $U$-value $\left(\mathrm{W} /\left(\mathrm{m}^{\left.2 \cdot{ }^{\circ} \mathrm{C}\right)}\right)\right.$ & 0.18 & 0.18 & 0.18 & 0.25 & 0.25 & 0.25 & 0.18 & 0.18 & 0.18 & 0.25 & 0.25 & 0.25 \\
\hline \multirow[t]{2}{*}{ Floor } & Area $\left(\mathrm{m}^{2}\right)$ & 49 & 50 & 58 & 133 & 124 & 129 & 44 & 44 & 52 & 123 & 115 & 120 \\
\hline & $U$-value $\left(\mathrm{W} /\left(\mathrm{m}^{\left.2 \cdot{ }^{\circ} \mathrm{C}\right)}\right)\right.$ & 1.10 & 1.10 & 1.10 & 0.23 & 0.23 & 0.23 & 1.10 & 1.10 & 1.10 & 0.23 & 0.23 & 0.23 \\
\hline \multicolumn{2}{|c|}{ Heated area $\left(\mathrm{m}^{2}\right)$} & 98 & 100 & 116 & 398 & 372 & 387 & 87 & 88 & 104 & 369 & 345 & 360 \\
\hline \multicolumn{2}{|c|}{ Heated volume $\left(\mathrm{m}^{3}\right)$} & 216 & 219 & 256 & 942 & 881 & 917 & 192 & 194 & 228 & 874 & 817 & 852 \\
\hline \multicolumn{2}{|r|}{$\mathrm{ACH}$} & 0.76 & 0.74 & 0.72 & 0.65 & 0.64 & 0.62 & 0.77 & 0.75 & 0.73 & 0.65 & 0.64 & 0.62 \\
\hline
\end{tabular}

In Papers I-IV, different conditions in the techno-economic optimizations have been included in the analysis related to remaining lifetime of building elements, targets concerning LCC and energy use. Consequences of varying remaining lifetime of building elements can be inevitable replacement or maintenance of windows, or not. The heritage values have been included in Papers I-II and Paper IV by considering the heritage values being affected when outside insulation of the external walls or replacement to windows with aluminum cladding is selected in the optimization procedures. In Paper III, the heritage values were considered through the development of a balanced and a restricted energy renovation scenario based on an interpretation of the local building scheme performed by co-author Petra Eriksson. A summary of the main differences between the investigated cases in Papers I-IV is presented in Table 4. Detailed descriptions of the investigated cases can be seen in each paper. The buildings have been investigated during a time period of 50 years in all papers.

The heat production generated by the DH system in Visby is delivered by energy utilities which belong to the local energy company Gotlands Energi AB (GEAB). The total heat provided to end users through the $\mathrm{DH}$ distribution network is approximately 185 GWh/year based on normal-year corrected data using Energy-Index from SMHI. The power demand over the year for the DH system with a corresponding duration curve can be seen in Figure 14. 
Table 4: Summary of main differences between the cases in Papers I-IV in terms of buildings starting conditions and targets concerning LCC and energy use.

\begin{tabular}{|c|c|c|c|c|c|}
\hline \multicolumn{2}{|c|}{$\begin{array}{l}\text { Main differences between the cases in } \\
\text { Papers I-IV }\end{array}$} & \multirow[t]{2}{*}{ Paper I } & \multirow{2}{*}{$\frac{\text { Paper II }}{\times}$} & \multirow{2}{*}{$\frac{\text { Paper III }}{\times}$} & \multirow{2}{*}{$\frac{\text { Paper IV }}{\times}$} \\
\hline Remaining life time & 0 & & & & \\
\hline (years) & 50 & $x$ & $x$ & & \\
\hline \multirow{3}{*}{$\begin{array}{l}\text { LCC and energy } \\
\text { targets }\end{array}$} & LCC optimum & $x$ & $x$ & $x$ & $x$ \\
\hline & $\begin{array}{l}50 \% \text { decrease in } \\
\text { energy use }\end{array}$ & & $\times$ & & \\
\hline & BBR & & & & $x$ \\
\hline
\end{tabular}
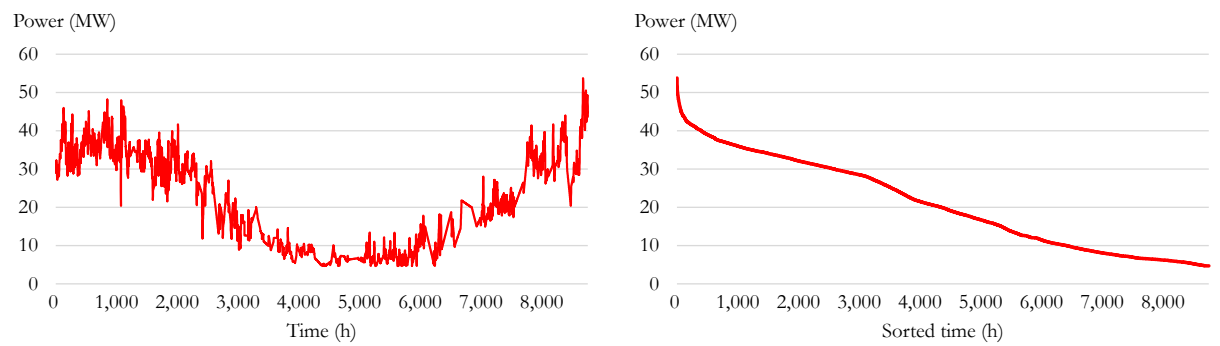

Figure 14: Power demand over the year for the DH system (to the left) with a corresponding duration curve (to the right).

A schematic description of the DH system in Visby connected to end users, including the district built before 1945 studied in Paper IV with heat production facilities is given in Figure 15. The DH production is dominated by biomass and most of the production occurs in heat-only boilers (HOBs), i.e., HOB 5 and HOB 6 with flue gas condensation, corresponding to an average of about $90 \%$ of the $\mathrm{DH}$ production. The compressor heat pump generates slightly less than $10 \%$ of the $\mathrm{DH}$ production. Moreover, the heat-only peak load boilers, i.e., HOB 1, HOB 2, HOB 3, HOB 4, HOB 7 and HOB 8, are only in operation during the winter season. In addition, landfill gas supplies around $1.4 \mathrm{GWh}$ heat to the DH system. 


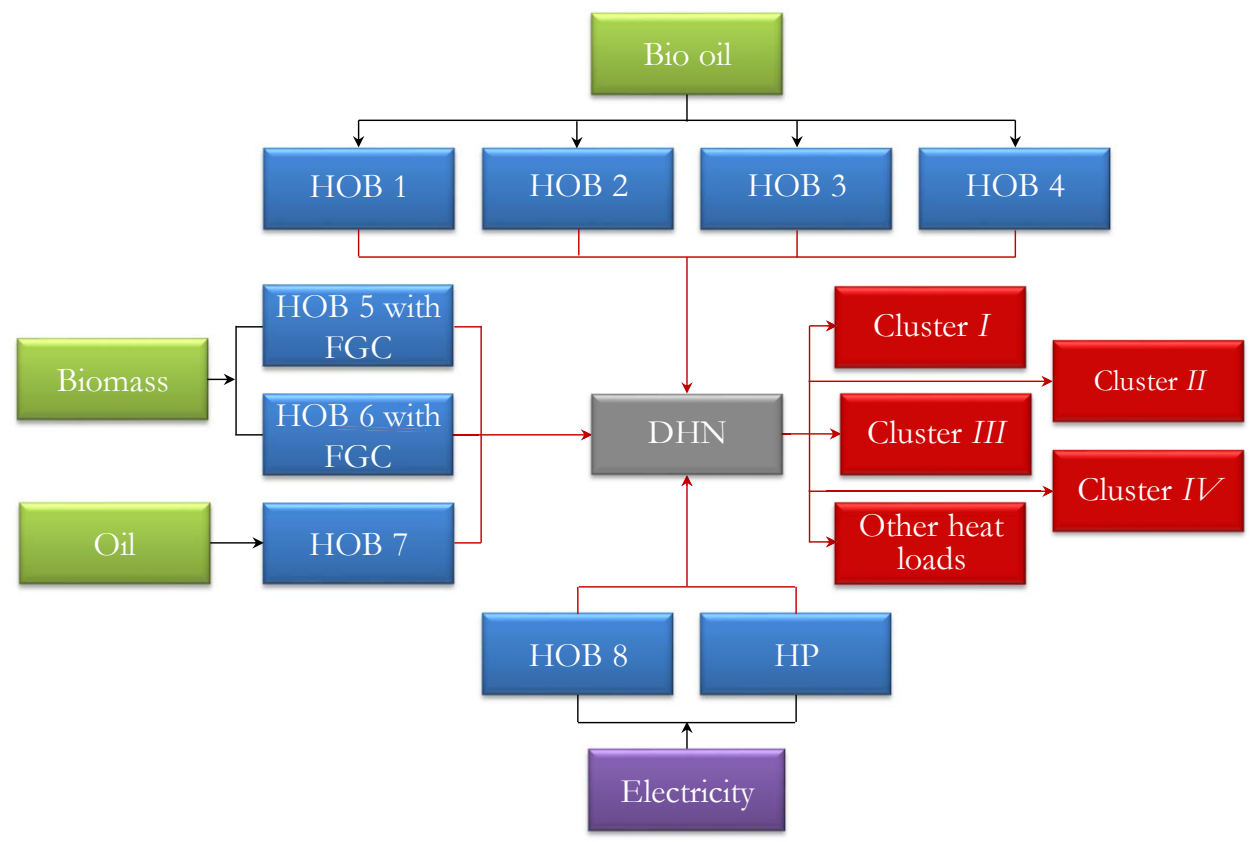

Figure 15: A schematic of the DH network in Visby [113]. FGC = flue gas condensation, HOB = heat-only boiler, $H P=$ heat pump and DHN = district heating network.

\subsection{RESIDENTIAL DISTRICT IN LINKÖPING}

Linköping is a city in Sweden with 150,000 inhabitants located $200 \mathrm{~km}$ southwest of Stockholm. Vasastaden is a residential district located in central Linköping and characterized by rental properties with buildings built before 1960, of which a significant part of the built environment is built in 1945 or before. Seventy-three buildings in Vasastaden are used for the study in Paper V. All buildings are connected to the DH network. The studied buildings are constructed between 1908 and 1945 . Hourly energy use for each building has been collected between 2014 and 2016 at the local energy company Tekniska Verken AB. Local climate data in the form of outdoor temperate data for the same time period has been obtained from SMHI from a weather station located at Malmslätt, which is approximately $8 \mathrm{~km}$ west of Vasastaden. The outdoor temperature during the three studied years is overall higher from November to April compared to a normal year when considering historical data between 1961 and 1990. The mean annual outdoor temperature is $8.4^{\circ} \mathrm{C}, 8.3{ }^{\circ} \mathrm{C}, 7.8^{\circ} \mathrm{C}$ and $6.8^{\circ} \mathrm{C}$ for 2014, 2015, 2016 and a normal year, respectively. A duration diagram of the outdoor temperature for 2014, 2015 and 2016 is shown in Figure 16. 


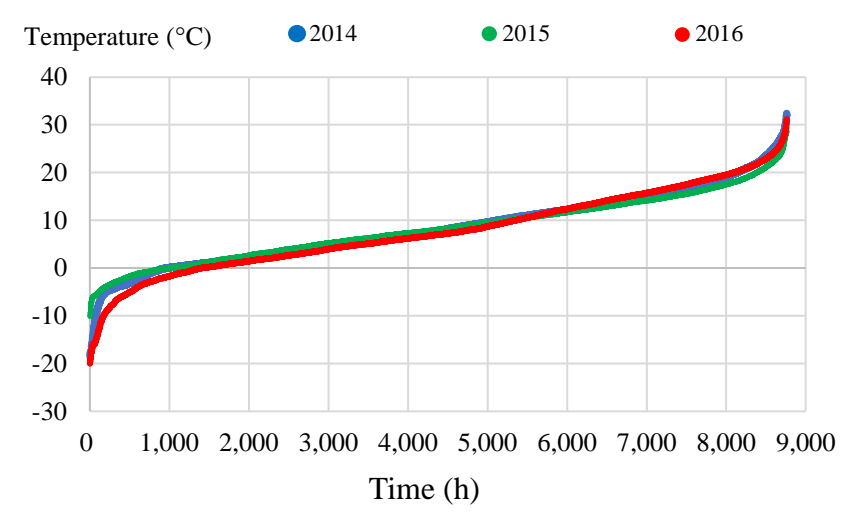

Figure 16: Duration diagram of the outdoor temperature in Linköping, Sweden, for 2014 (blue), 2015 (green) and 2016 (red) [77].

Data on the total heated area distributed by construction year for the 73 buildings is given in Figure 17. The total heated area of the district is $127,000 \mathrm{~m}^{2}$. There is a large variation in heated area between various construction years. A large share of the total area in the district can be derived to buildings constructed 1929, 1942 and 1944 corresponding to $58,500 \mathrm{~m}^{2}, 46 \%$ of the total area. It is important to note that many buildings constructed prior to 1929 were given 1929 as construction year, hence the large heated area. Photos of representative buildings for the time period can be seen in Figure 18. The building to the left is constructed between 1908 and 1925, the building in the middle between 1926 and 1935 and the building to the right between 1936 and 1945. The purpose of the age differentiation is to allow for a comparison of buildings constructed in different time periods, and for pedagogical reasons during later interpretation of the results. 


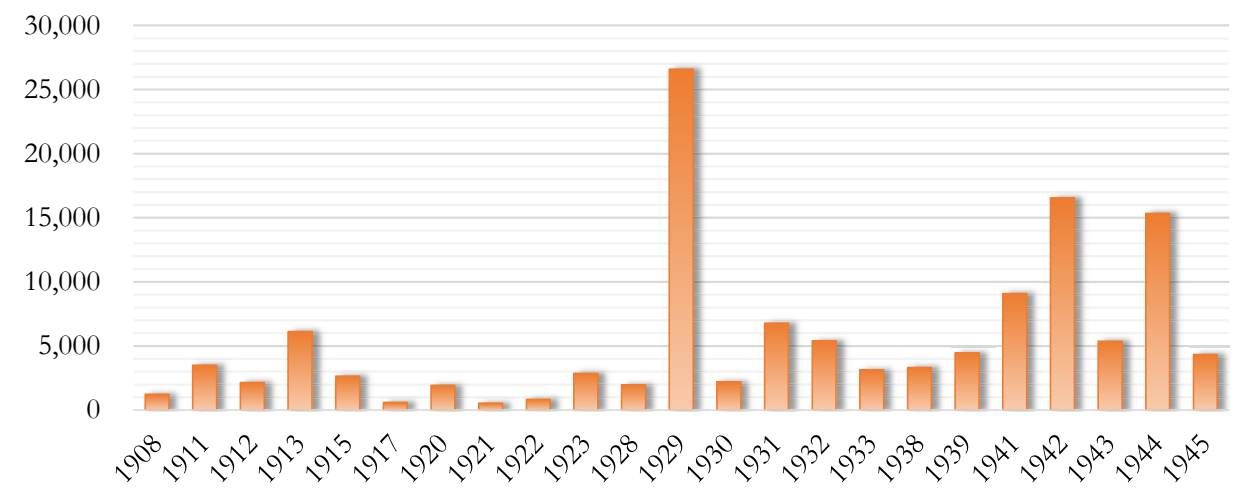

Figure 17: Total heated area $\left(\mathrm{m}^{2}\right)$ for the 73 buildings distributed by construction year from 1908 to 1945 [77].
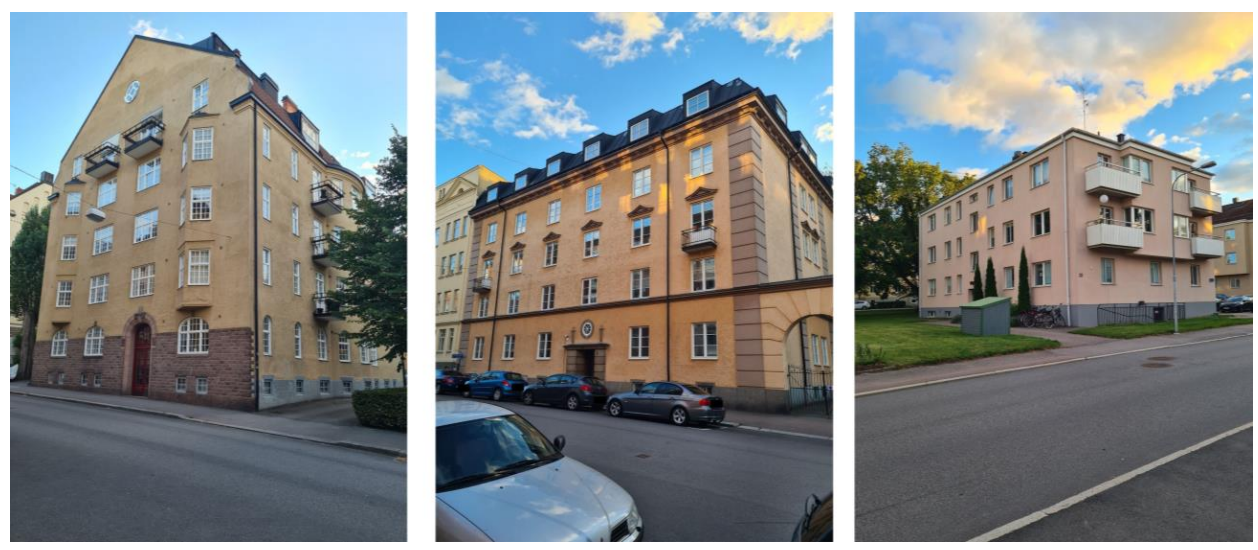

Figure 18: Photos of representative buildings for the time periods [77]. 


\section{RESULTS AND DISCUSSION}

This chapter presents the results for each research question together with an associated discussion. Section 7.1 and section 7.2 are based on the results from Papers $I-I V$, section 7.3 is based on the results from Paper II and Paper IV and section 7.4 is based on the results from Paper V.

\subsection{RESEARCH QUESTION 1}

"How can a bottom-up approach be used to analyze packages of cost-effective EEMs on a residential district built before 1945?"

In the proposed bottom-up approach, techno-economic LCC optimization software OPERA-MILP has been used in Papers I-IV to minimize the LCC of building types representative of a residential district through the selection of cost-effective packages of EEMs. The optimizations have been performed with regard to different targets in terms of LCC (LCC optimum) and energy use (50\% decrease in energy use compared to status quo and energy targets according to BBR). Furthermore, the effects on the selection of cost-effective EEMs from different building starting conditions with regard to maintenance have been investigated. In total, 12 building types representative of the residential district built before 1945 in Visby, Sweden, have been selected for the optimization procedures. The analysis of cost-effective packages of EEMs on the entire district is allowed through the use of a bottom-up approach. A categorization study of the district in Visby, which is based on mapping together with data collection for every building in the district, lays the foundation for the bottom-up approach used. The generated building types differ in terms of physical properties and can be divided into four clusters based on similarities in building size and type of building structure.

Since the numerical procedure of the building's energy balance for space heating is performed using a quasi-steady state approach, it is important to investigate the performance of the OPERA-MILP software. By doing so, the reliability in the predictions of the associated LCC is also strengthened. Thus, the author of the thesis has investigated the performance of the calculations approach in OPERA-MILP in regard to energy use and power demand together with the consequential impact on LCC in Paper I. Established BES software IDA ICE was used as a comparative tool in the research. IDA ICE has previously been validated according to Envelope BESTEST in the scope of IEA Task 12 in which it was stated that IDA ICE is a good example of software for performing detailed building physics and HVAC simulations [114]. Hence, the selection of IDA ICE for comparative testing against OPERA-MILP is wellfounded. The results presented in Paper I state a satisfactory accuracy in the calculations 
performed with OPERA-MILP, both before and after techno-economic optimization. The total percentage difference in calculations of annual energy use between the two types of software was a maximum of $8 \%$.

\subsubsection{Cost-effective packages of EEMs on a residential district}

Packages of cost-effective EEMs for the studied buildings in the residential district are presented in Table 5. Categories 1-3 represent single-family houses, categories 4-6 multi-family buildings, " $W$ " indicating a building structure of wood and " $S$ " of stone. The effects on specific energy use and specific LCC from the techno-economic optimization are shown in Table 6, together with the total percentage decrease compared to the reference case, i.e., before any EEMs. The optimization procedures that have generated the results in this section are performed with the assumption of a remaining lifetime of 0 years for the building elements. In addition, $\mathrm{DH}$ is set as the default heating system before and after energy renovation. Additional optimizations (performed in connection with Paper II) show that WB is cost-optimal in the multifamily buildings, i.e., buildings $4 W-6 W$ and $4 S-6 S$, when $\mathrm{DH}$ is not set as the heating system by default. However, tougher restrictions in terms of allowed EEMs on the building envelope, which is fairly common in buildings built before 1945, can alter the selection of a cost-optimal heating system. Based on the cost functions developed for the results presented in the thesis, the tougher restrictions can result in GHP, with a low running cost and high installation cost, being cost-optimal for buildings with a high energy use and power demand, such as for buildings $4 S-6 S$. ER is never selected as a heating system due to its high running cost.

As shown in Table 5, the cost-effective packages of EEMs are unique for each building and case. This is the result of varying building properties in the form of layout and thermal performance. Nonetheless, the generated packages of EEMs are in many cases similar for buildings within the same cluster due to similar building properties. Doubleglazed windows are selected in almost all cases, except for building $6 \mathrm{~W}$ in which tripleglazed windows with low emission glass are required in order to achieve a $50 \%$ decrease in energy use. Moreover, a sensitivity analysis shows that when the remaining lifetime of the building elements is set to 50 years, window replacement is not a common costeffective EEM, which is one of the conclusions in Paper II. However, secondary glazing is cost-effective in some cases for the wood buildings. It is noteworthy that weatherstripping is regarded as a side effect when replacing windows. Nonetheless, weatherstripping is also a cost-effective EEM with a remaining lifetime of 50 years on the building elements. 
Table 5: Cost-effective packages of EEMs at LCC optimum, BBR and a 50\% decrease in energy use compared to the reference case. Categories 1-3 represent single-family houses, categories 4-6 multi-family buildings, " $W$ " indicating a building structure of wood and " $S$ " of stone.

\begin{tabular}{|c|c|c|c|c|c|c|c|c|c|c|c|c|c|}
\hline Cluster & & $I$ & & & $I I$ & & & $I I I$ & & & $I V$ & & \\
\hline Building Type & & $1 W$ & $2 W$ & $3 W$ & $4 W$ & $5 W$ & $6 W$ & $1 S$ & $2 S$ & $3 S$ & $4 S$ & $5 S$ & $6 S$ \\
\hline \multirow{3}{*}{ Window type } & Optimum & $\mathrm{DG}^{*}$ & ${ }^{k} \mathrm{DG}$ & DG & DG & DG & DG & DG & DG & DG & DG & DG & DG \\
\hline & BBR & DG & DG & DG & DG & DG & DG & DG & DG & DG & DG & DG & DG \\
\hline & $50 \%$ & DG & DG & DG & DG & DG & $\begin{array}{l}\text { TG+ } \\
\text { L.E.** }\end{array}$ & DG & DG & DG & DG & DG & DG \\
\hline \multirow{3}{*}{$\begin{array}{l}\text { Floor insulation } \\
(\mathrm{cm})\end{array}$} & Optimum & 26 & 26 & 26 & 0 & 0 & 0 & 24 & 24 & 24 & 0 & 0 & 0 \\
\hline & BBR & 24 & 32 & 26 & 0 & 0 & 0 & 24 & 24 & 24 & 0 & 0 & 0 \\
\hline & $50 \%$ & 24 & 32 & 26 & 0 & 20 & 36 & 24 & 24 & 24 & 0 & 0 & 0 \\
\hline \multirow{3}{*}{$\begin{array}{l}\text { Roof insulation } \\
(\mathrm{cm})\end{array}$} & Optimum & 12 & 12 & 12 & 18 & 16 & 16 & 10 & 10 & 10 & 16 & 16 & 16 \\
\hline & BBR & 10 & 18 & 4 & 24 & 24 & 6 & 0 & 0 & 0 & 16 & 16 & 10 \\
\hline & $50 \%$ & 10 & 18 & 12 & 24 & 24 & 40 & 0 & 0 & 0 & 10 & 10 & 10 \\
\hline \multirow{3}{*}{$\begin{array}{l}\text { Inside insulation } \\
\text { of the external } \\
\text { walls }(\mathrm{cm})\end{array}$} & Optimum & 0 & 0 & 0 & 0 & 0 & 0 & 20 & 20 & 20 & 20 & 20 & 20 \\
\hline & BBR & 8 & 2 & 0 & 6 & 4 & 0 & 20 & 14 & 6 & 12 & 8 & 4 \\
\hline & $50 \%$ & 2 & 0 & 0 & 24 & 22 & 38 & 2 & 2 & 2 & 4 & 4 & 6 \\
\hline
\end{tabular}

$* \mathrm{DG}=$ double-glazed windows, ${ }^{* *} \mathrm{TG}+\mathrm{L} . \mathrm{E} .=$ triple-glazed windows with low emission glass

Concerning the selection of insulation measures in the buildings included in the district, there is a clear connection between the selection of cost-effective EEMs, poor thermal performance of the building elements and a low investment cost. The overall tendencies for the selection of insulation measures for the floor, roof and external walls are:

- Floor insulation with $24-36 \mathrm{~cm}$ is cost-effective for all single-family houses $(1 \mathrm{~W}$ $3 W$ and $1 S-3 S)$ due to a high $U$-value of $1.10 \mathrm{~W} /\left(\mathrm{m}^{2 .}{ }^{\circ} \mathrm{C}\right)$ and fairly low investment costs. Due to overall good thermal performance originally in buildings $5 \mathrm{~W}-6 \mathrm{~W}$, floor insulation is also shown to be cost-effective in order to achieve a $50 \%$ decrease in energy use

- The thermal performance of the roof is good prior to energy renovation varying between $0.18-0.25 \mathrm{~W} /\left(\mathrm{m}^{2} \cdot{ }^{\circ} \mathrm{C}\right)$. However, due to a fairly low investment cost, it is selected in all buildings and cases, except for $1 S-3 S$ at BBR and the $50 \%$ energy target due to a lower cost-effectiveness $\left(\mathrm{SEK}^{9} / \mathrm{kWh}_{\text {saved }}\right)$ compared to the other selected EEMs

\footnotetext{
${ }^{9}$ SEK, Swedish kronor, is the currency in Sweden.
} 
- Insulation of the inside of the external walls is cost-effective for all stone buildings in all cases due to a high initial $U$-value, $1.80-1.97 \mathrm{~W} /\left(\mathrm{m}^{2} \cdot{ }^{\circ} \mathrm{C}\right)$, despite rather high investment costs. In addition, inside insulation of the external walls is selected in some cases in the wood buildings in order to achieve the energy targets in BBR and a 50\% decrease in energy use. The reason why insulation on the inside of the external walls is suggested and not on the outside is because of lower investment costs

Table 6: Specific energy use and LCC before and after techno-economic optimization according to the predetermined LCC and energy targets. The total percentage decrease in energy use and LCC can be seen below the specific figures.

\begin{tabular}{|c|c|c|c|c|c|c|c|c|c|c|c|c|c|}
\hline Cluster & & $I$ & & & $I I$ & & & III & & & $I V$ & & \\
\hline Building $t$ & type & $1 W$ & $2 W$ & $3 W$ & $4 W$ & $5 W$ & $6 W$ & $1 S$ & $2 S$ & $3 S$ & $4 S$ & $5 S$ & $6 S$ \\
\hline \multirow{2}{*}{ Referenc } & $\mathrm{kWh} /\left(\mathrm{m}^{2} \cdot\right.$ year $)$ & 200 & 179 & 161 & 128 & 115 & 99 & 324 & 266 & 218 & 220 & 187 & 143 \\
\hline & $\mathrm{kSEK} / \mathrm{m}^{2}$ & 5.6 & 5.0 & 4.4 & 3.7 & 3.3 & 2.7 & 8.1 & 6.8 & 5.6 & 5.5 & 4.8 & 3.6 \\
\hline \multirow{2}{*}{ Optimum } & $\mathrm{kWh} /($ & $\begin{array}{l}112 \\
(44 \%)\end{array}$ & $\begin{array}{l}94 \\
(48 \%)\end{array}$ & $\begin{array}{l}80 \\
(50 \%)\end{array}$ & $\begin{array}{l}98 \\
(24 \%)\end{array}$ & $\begin{array}{l}88 \\
(24 \%)\end{array}$ & $\begin{array}{l}76 \\
(23 \%)\end{array}$ & $\begin{array}{l}79 \\
(78 \%)\end{array}$ & $\begin{array}{l}72 \\
(74 \%)\end{array}$ & $\begin{array}{l}68 \\
(70 \%)\end{array}$ & $\begin{array}{l}74 \\
(68 \%)\end{array}$ & $\begin{array}{l}69 \\
(65 \%)\end{array}$ & $\begin{array}{l}65 \\
(56 \%) \\
\end{array}$ \\
\hline & $\mathrm{kSEI}$ & $\begin{array}{l}4.3 \\
(24 \%)\end{array}$ & $\begin{array}{l}3.7 \\
(26 \%)\end{array}$ & $\begin{array}{l}3.1 \\
(28 \%)\end{array}$ & $\begin{array}{l}3.2 \\
(14 \%)\end{array}$ & $\begin{array}{l}2.9 \\
(14 \%)\end{array}$ & $\begin{array}{l}2.4 \\
(14 \%)\end{array}$ & $\begin{array}{l}5.6 \\
(37 \%) \\
\end{array}$ & $\begin{array}{l}4.7 \\
(35 \%)\end{array}$ & $\begin{array}{l}3.8 \\
(34 \%)\end{array}$ & $\begin{array}{l}4.0 \\
(32 \%)\end{array}$ & $\begin{array}{l}3.5 \\
(30 \%)\end{array}$ & $\begin{array}{l}2.7 \\
(27 \%) \\
\end{array}$ \\
\hline \multirow{2}{*}{$50 \%$} & $\mathrm{kWh} /$ & $\begin{array}{l}98 \\
(52 \%)\end{array}$ & $\begin{array}{l}91 \\
(49 \%)\end{array}$ & $\begin{array}{l}80 \\
(50 \%)\end{array}$ & $\begin{array}{l}70 \\
(49 \%)\end{array}$ & $\begin{array}{l}62 \\
(49 \%)\end{array}$ & $\begin{array}{l}51 \\
(50 \%)\end{array}$ & $\begin{array}{l}147 \\
(55 \%)\end{array}$ & $\begin{array}{l}117 \\
(56 \%)\end{array}$ & $\begin{array}{l}100 \\
(54 \%)\end{array}$ & $\begin{array}{l}99 \\
(55 \%)\end{array}$ & $\begin{array}{l}89 \\
(53 \%)\end{array}$ & $\begin{array}{l}73 \\
(49 \%) \\
\end{array}$ \\
\hline & kSEK/ & $\begin{array}{l}4.8 \\
(15 \%)\end{array}$ & $\begin{array}{l}3.7 \\
(26 \%)\end{array}$ & $\begin{array}{l}3.1 \\
(28 \%)\end{array}$ & $\begin{array}{l}3.6 \\
(10 \%)\end{array}$ & $\begin{array}{l}3.2 \\
(8 \%) \\
\end{array}$ & $\begin{array}{l}3.1 \\
(10 \%)\end{array}$ & $\begin{array}{l}6.3 \\
(23 \%) \\
\end{array}$ & $\begin{array}{l}5.2 \\
(25 \%)\end{array}$ & $\begin{array}{l}4.2 \\
(26 \%)\end{array}$ & $\begin{array}{l}4.2 \\
(25 \%)\end{array}$ & $\begin{array}{l}3.7 \\
(23 \%)\end{array}$ & $\begin{array}{l}2.8 \\
(24 \%) \\
\end{array}$ \\
\hline \multirow{2}{*}{ BBR } & $\mathrm{kWh} /\left(\mathrm{m}^{2} \cdot\right.$ year $)$ & $\begin{array}{l}82 \\
(61 \%)\end{array}$ & $\begin{array}{l}81 \\
(55 \%)\end{array}$ & $\begin{array}{l}83 \\
(48 \%)\end{array}$ & $\begin{array}{l}78 \\
(41 \%)\end{array}$ & $\begin{array}{l}76 \\
(36 \%)\end{array}$ & $\begin{array}{l}79 \\
(21 \%) \\
\end{array}$ & $\begin{array}{l}83 \\
(77 \%) \\
\end{array}$ & $\begin{array}{l}82 \\
(71 \%)\end{array}$ & $\begin{array}{l}82 \\
(63 \%)\end{array}$ & $\begin{array}{l}78 \\
(66 \%)\end{array}$ & $\begin{array}{l}77 \\
(60 \%)\end{array}$ & $\begin{array}{l}78 \\
(46 \%) \\
\end{array}$ \\
\hline & $\mathrm{kSEK} / \mathrm{m}^{2}$ & $\begin{array}{l}4.7 \\
(20 \%)\end{array}$ & $\begin{array}{l}4.1 \\
(18 \%)\end{array}$ & $\begin{array}{l}3.2 \\
(28 \%)\end{array}$ & $\begin{array}{l}3.5 \\
(8 \%) \\
\end{array}$ & $\begin{array}{l}3.2 \\
(7 \%) \\
\end{array}$ & $\begin{array}{l}2.4 \\
(13 \%)\end{array}$ & $\begin{array}{l}5.7 \\
(36 \%) \\
\end{array}$ & $\begin{array}{l}4.8 \\
(34 \%)\end{array}$ & $\begin{array}{l}3.9 \\
(32 \%)\end{array}$ & $\begin{array}{l}4.0 \\
(31 \%) \\
\end{array}$ & $\begin{array}{l}3.5 \\
(28 \%) \\
\end{array}$ & $\begin{array}{l}2.9 \\
(21 \%) \\
\end{array}$ \\
\hline
\end{tabular}

It is clear that the effects from techno-economic optimization are unique in terms of both energy use and LCC for the various building types. The energy use varies between 99-200 kWh/( $\mathrm{m}^{2}$.year) and $143-324 \mathrm{kWh} /\left(\mathrm{m}^{2} \cdot\right.$ year $)$ in the reference case for the wood buildings and stone buildings, respectively. The corresponding figures in terms of specific LCC are 2.7-5.6 $\mathrm{kSEK} / \mathrm{m}^{2}$ and 3.6-8.1 $\mathrm{kSEK} / \mathrm{m}^{2}$. The reason for the higher specific energy use and LCC in the stone buildings compared to the wood buildings is due to the poorer thermal performance of the external walls. Moreover, it should be noted that the higher $U$-value of the floor in the single-family houses $\left(1.10 \mathrm{~W} /\left(\mathrm{m}^{2} \cdot{ }^{\circ} \mathrm{C}\right)\right)$ compared to the multi-family buildings $\left(0.23 \mathrm{~W} /\left(\mathrm{m}^{2} \cdot{ }^{\circ} \mathrm{C}\right)\right)$ has a strong correlation with 
higher energy use and $\mathrm{LCC}^{10}$. Energy renovation at the cost-optimum point, LCC optimum, decreases the specific energy use and LCC the most in the stone buildings standing on a crawl space, i.e., the buildings in Cluster III, due to the abovementioned reasons concerning building properties. The decreases in total energy use vary between $70 \%$ and $78 \%$, and between $34 \%$ and $37 \%$ in LCC. The wood buildings in Cluster II correspond to the buildings with the best thermal performance originally. These buildings have moderate energy savings at LCC optimum ranging between $23 \%$ and $24 \%$, and a $14 \%$ profitability during the optimization period. The specific energy use varies between $65 \mathrm{kWh} /\left(\mathrm{m}^{2}\right.$.year) and $112 \mathrm{kWh} /\left(\mathrm{m}^{2} \cdot\right.$ year $)$ at LCC optimum for the twelve building types. It should be noted that eight of the twelve buildings achieve the energy targets in BBR at the cost-optimum point, which can be seen in Figure 19, with buildings ranging from oldest construction year to newest. Of the buildings that achieve the energy target in BBR at the cost-optimum point, six buildings have a construction of stone and two of wood. Interestingly, the energy use at the cost-optimum point varies significantly between the various building types, despite the fact that the current Swedish building energy regulations do not consider differences in building properties in terms of parameters such as construction material, construction year and what type of floor the building is standing on. The current energy regulations in BBR only consider in what climate zone the building is located, type of heating system and whether the building is a single-family house or a multi-family building. The results presented in this thesis suggest that the Swedish building energy regulations need to be reviewed considering the variations in energy use at the cost-optimum point for different building types. Consequently, the energy targets should be differentiated on more parameters than the regulations include today.

The 50\% energy target is achieved in seven of twelve optimizations at LCC optimum, which means that a cost-effective comparison between the EEMs on the building envelope is performed according to section 5.2.4 (not in $3 W$ since LCC optimum corresponds to a $50 \%$ decrease in energy use). This is also the case for $1 \mathrm{~W}, 2 \mathrm{~W}, 4 \mathrm{~W}$, $5 W$ and $6 W$ in order to achieve the predetermined energy target in BBR. Total LCC is decreased between $8 \%$ and $28 \%$ at the $50 \%$ energy target and $7-36 \%$ for BBR. Hence, even though LCC optimum corresponds to lower expenditures during the building's life span, it is possible to generate cost-effective packages of EEMs for other targets connected to the thermal performance of the building. The reason for not targeting the lowest possible LCC may be connected to the need to fulfill tougher energy targets, or lack of investment capital from the building owner's perspective. Therefore, in order to

${ }^{10}$ The single-family houses are standing on a crawl space and the multi-family buildings on an unheated basement 
enable decreases in investment costs it is of interest to differentiate the various expenditures during a building's life span. Hence, cost-effective energy savings can be achieved with lower investment costs and this may promote a higher renovation pace in the building stock, which is important in order to achieve a decarbonized building stock in the EU by 2050. A differentiation of expenditures in the form of inevitable costs (also titled maintenance cost as described in section 5.2.4), investment cost for the EEMs (including expenditures for $\mathrm{DH}$ ), and running cost, i.e., fuel cost, can be seen in Figure 20 in the reference case, LCC optimum, the 50\% energy target and when energy renovating according to BBR. Overall, three main tendencies can be found by differentiating the expenditures during the buildings' life cycle. First, the cost-optimum level for the wood buildings in Clusters $I-I I$ is achieved with relatively low investment cost for EEMs corresponding to $12 \%$ of total LCC. However, in some cases there is a need for higher investment costs in order to achieve the two predetermined energy targets. For example, in building $6 \mathrm{~W}$, investment of $512 \mathrm{SEK}$ in thousands $(44 \%$ of total LCC) is needed to achieve a 50\% decrease in energy use. The second tendency constitutes of the connection between rather high investment cost for EEMs to achieve LCC optimum, as well as a 50\% decrease in energy use and the energy target according to BBR, in Clusters $I I I-I V$, which are calculated at an average of $30 \%$. Lastly, in order to decrease expenditures at year 0 in the analysis period from techno-economic optimization, the 50\% energy target and BBR corresponds to somewhat lower investment costs for all buildings in Cluster III-IV compared to LCC optimum. Total average investment costs at LCC optimum are $246 \mathrm{kSEK}, 218 \mathrm{kSEK}$ at the $50 \%$ energy target and $229 \mathrm{kSEK}$ for BBR.

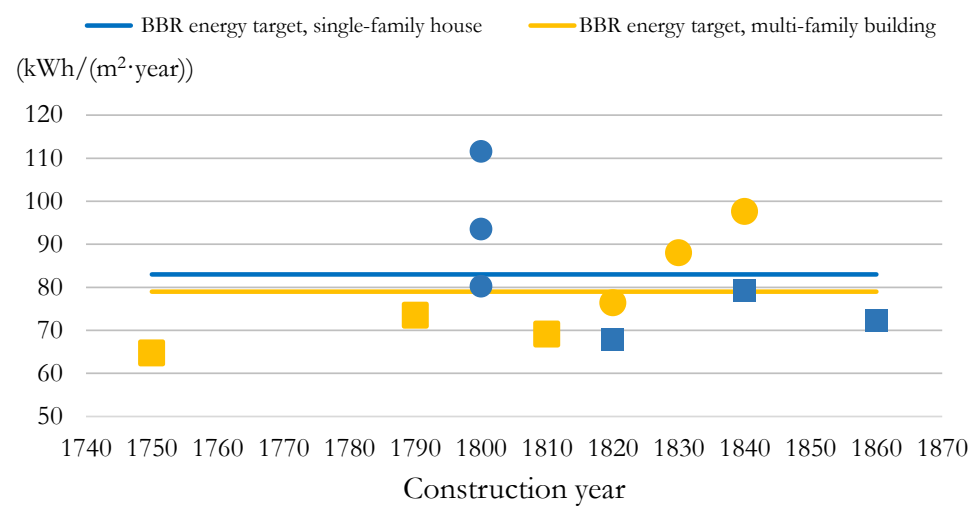

Figure 19: Energy use at LCC optimum for the buildings with construction year given on the y-axis. The wood buildings are indicated with circles and stone buildings with squares. The single-family houses are indicated with blue and multi-family buildings with yellow. 


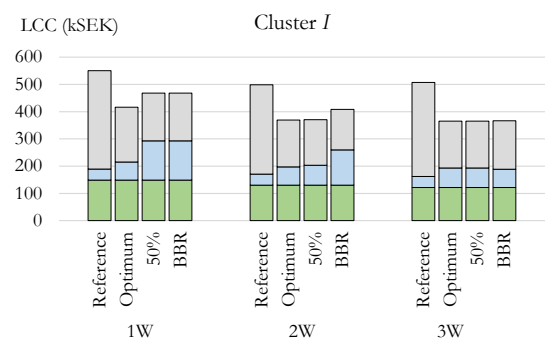

$\square$ Inevitable costs $\quad \square$ Investment cost EEMs $\quad \square$ Running cost

Cluster II

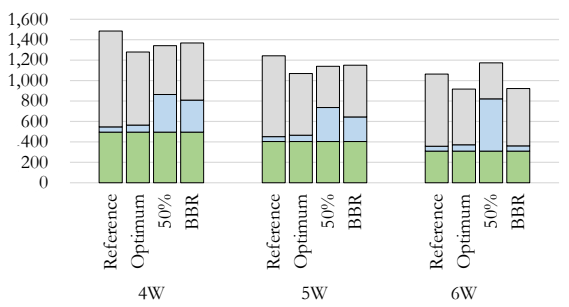

$\square$ Inevitable costs $\square$ Investment cost EEMs $\square$ Running cost

Cluster III

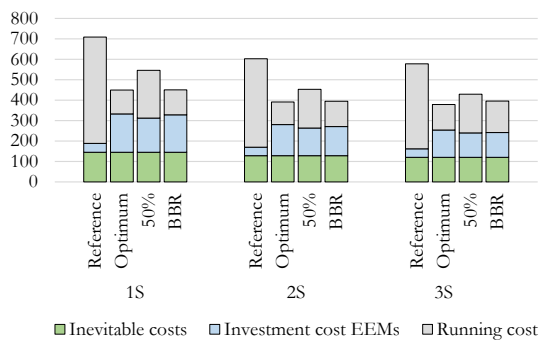

Cluster IV

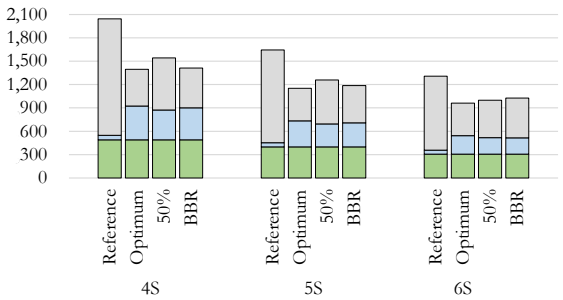

$\square$ Inevitable costs $\square$ Investment cost EEMs $\square$ Running cost

Figure 20: Inevitable costs (green), investment cost for EEMs (blue) and running cost (grey) for the studied building types in the reference case, LCC optimum, 50\% target and energy renovation according to BBR. 
The selection of cost-effective packages of EEMs is dependent on the discount rate used in the techno-economic optimization procedures. This will in turn affect the profitability and energy use after energy renovation. LCC and specific energy use with discount rates of $1 \%, 3 \%, 5 \%, 7 \%$ and $9 \%$ can be seen in Figure 21. The results are presented for buildings $1 \mathrm{~W}, 4 \mathrm{~W}, 1 \mathrm{~S}$ and $4 S$. The lower discount rate used in the optimizations results in a higher LCC, and a lower optimum energy use. This is the result of more EEMs being selected when using a lower discount rate because it is more profitable to save future running costs. Moreover, the impact from a low discount rate on optimum energy use is larger on the wood buildings compared to the stone buildings. This is due to the selection of inside insulation of the external walls when using a discount rate of $1 \%$ and $3 \%$, which is not cost-effective with a discount rate of $5 \%, 7 \%$ and $9 \%$. The optimum energy use varies on average $40 \mathrm{kWh} /\left(\mathrm{m}^{2} \cdot\right.$ year $)$ for the wood buildings, and $12 \mathrm{kWh} /\left(\mathrm{m}^{2}\right.$.year) for the stone buildings, when considering a discount rate of either $1 \%$ or $9 \%$. The corresponding figure in terms of LCC is $700 \mathrm{kSEK}$ and $576 \mathrm{kSEK}$ for the wood and stone buildings, respectively.
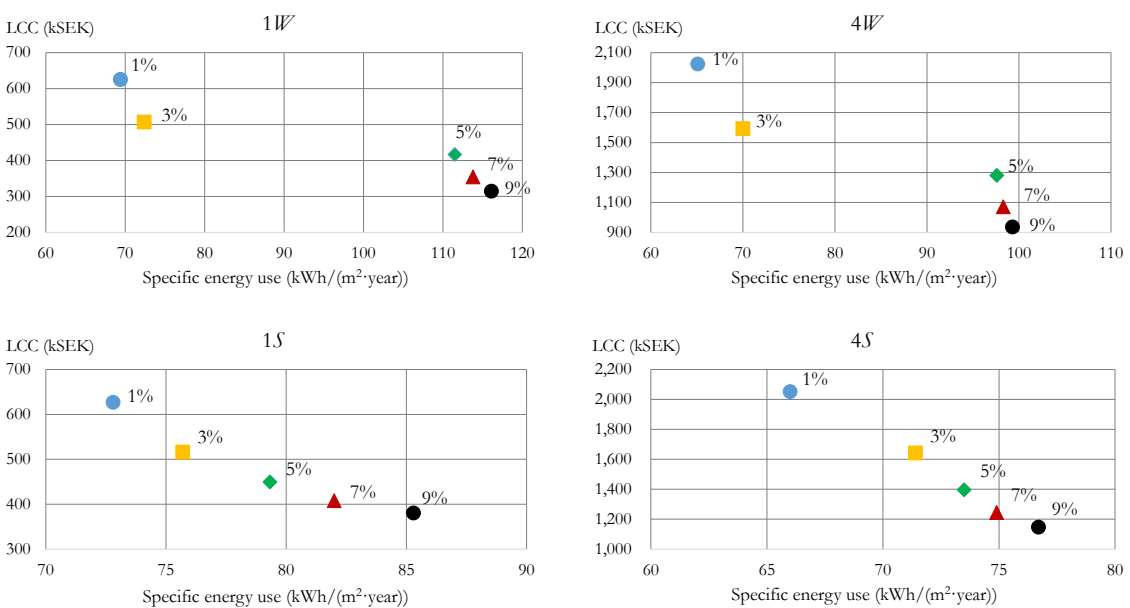

Figure 21: LCC and specific energy use for $1 \mathrm{~W}, 4 \mathrm{~W}, 1 \mathrm{~S}$ and $4 \mathrm{~S}$ with a discount rate of $1 \%, 3 \%$, $5 \%, 7 \%$ and $9 \%$. 


\subsection{RESEARCH QUESTION 2}

"How can preservation of building heritage values be integrated in the proposed bottom-up approach when analyzing packages of cost-effective EEMs on a residential district built before 1945?"

Improving the thermal performance in buildings built before 1945 is a complex task considering the need for long-term profitability and preservation of heritage values. Two different ways for integrating building heritage values in the proposed bottom-up approach have been demonstrated in Papers I-IV. The building types representative of the residential district built before 1945 in Visby have been used as the study object in all four papers.

In Papers I-II and Paper IV, the integration of heritage values is based on an assessment of the suitability of the suggested EEMs after optimization. Consequently, an analysis of the potential energy efficiency gap is made possible when considering and when not considering the heritage character of a building. The non-suitable EEMs consisted of outside insulation of the external walls and replacement of existing windows with windows containing exterior aluminum cladding, which are commonly regarded as measures distorting the heritage values of an historic building. In addition to a reference case with $\mathrm{DH}$ as the default heating system and no EEMs on the building envelope allowed, three different cases with regard to targets of LCC and energy targets were investigated to assess the effects on cost-effective packages of EEMs from preserving heritage values. First, LCC optimum was found by allowing the selection of costeffective EEMs on the building envelope, and a cost-optimal heating system. Second, a $50 \%$ decrease in energy use, compared to the reference case, was achieved through the selection of cost-effective EEMs on the building envelope and a cost-optimal heating system. Thirdly, the energy targets in BBR were achieved by allowing the selection of cost-effective EEMs on the building envelope.

In Paper III, a cross-disciplinary approach has been developed for integrating the balancing of heritage values when analyzing cost-effective EEMs on a residential district. The approach consists of building categorization, definition of restriction levels based on preservation objectives for energy renovation scenarios and techno-economic optimizations, which consequently allows for quantifying the impact on the costeffective energy efficiency potential from restriction levels. In addition, the approach allows for well-grounded planning and policy development for residential districts built before 1945 considering the combination of quantitative and qualitative analysis. The restricted levels were formed by co-author Petra Eriksson based on interpretations of the local building scheme for the city of Visby and consisted of a balanced and a restricted energy renovation scenario. In the balanced scenario, a maximum of $16 \mathrm{~cm}$ 
of floor, roof and external wall insulation was allowed in the optimizations which corresponds to medium change to the building, and in the restricted scenario no external wall insulation and window replacement were allowed (same restriction for floor and roof were valid as in the balanced scenario). Hence, measures with a negative impact on visible character-defining elements were not allowed. A reference case was also calculated with $\mathrm{DH}$ as the heating system.

Of the cases investigated in Papers I-II and Paper IV, building $6 \mathrm{~W}$ was affected by the preservation requirements in order to achieve a decrease of $50 \%$ in energy use. The package of cost-effective EEMs included triple-glazed + low emission glass windows with aluminum cladding, i.e., the windows with the best thermal performance, which is regarded as a measure distorting the building heritage values as mentioned above. The reason for the selection of the windows with the best thermal performance is because of the fairly good thermal performance in building $6 W$ before energy renovation. In the iterated optimization procedure when considering the heritage values of $6 \mathrm{~W}$, the maximum insulation steps are selected together with triple-glazed windows without aluminum cladding. The LCC and specific energy use in the reference case, at LCC optimum and when targeting a 50\% decrease in energy use (with consideration and without consideration of heritage values) are presented in Figure 22. It should be noted that the optimization results are generated based on a remaining lifetime of 50 years on the various building elements. The specific energy use is $99 \mathrm{kWh} /\left(\mathrm{m}^{2}\right.$.year $)$ in the reference case, $87 \mathrm{kWh} /\left(\mathrm{m}^{2} \cdot\right.$ year $)$ at LCC optimum, $54 \mathrm{kWh} /\left(\mathrm{m}^{2} \cdot\right.$ year $)$ when targeting a $50 \%$ decrease in energy use with consideration of heritage values and 51 $\mathrm{kWh} /\left(\mathrm{m}^{2} \cdot\right.$ year $)$ when targeting a $50 \%$ decrease in energy use without consideration of heritage values. The corresponding figures in terms of LCC are $754 \mathrm{kSEK}, 581 \mathrm{kSEK}$, $983 \mathrm{kSEK}$ and 1,096 kSEK. Consequently, this suggests that the techno-economic energy efficiency potential may be affected by preservation requirements on heritage values, which previous research also has highlighted [37, 40, 69]. However, it is important to be aware that energy efficiency potential is affected in only one of twelve buildings based on the preservation requirements considered in Papers I-II and Paper IV. That only one of twelve buildings is affected may be explained by the rather light requirements in terms of what EEMs are allowed. Moreover, in order to achieve the highest possible decrease in energy use in building $6 \mathrm{~W}$ when considering heritage values, the maximum insulation thickness, i.e., $42 \mathrm{~cm}$, is suggested for all building elements ${ }^{11}$. In addition, window replacement to triple-glazed windows is selected, which is allowed

\footnotetext{
${ }^{11}$ It should be noted that practical issues exist with a high insulation thickness. In many situations it may not be practically feasible to insulate with the proposed thickness.
} 
from a heritage perspective, and weather-stripping which is also selected when not considering heritage values. The other selected EEMs on the building envelope when not considering heritage values consist of inside insulation of the external walls, roof insulation and floor insulation with $38 \mathrm{~cm}, 40 \mathrm{~cm}$ and $36 \mathrm{~cm}$, respectively.

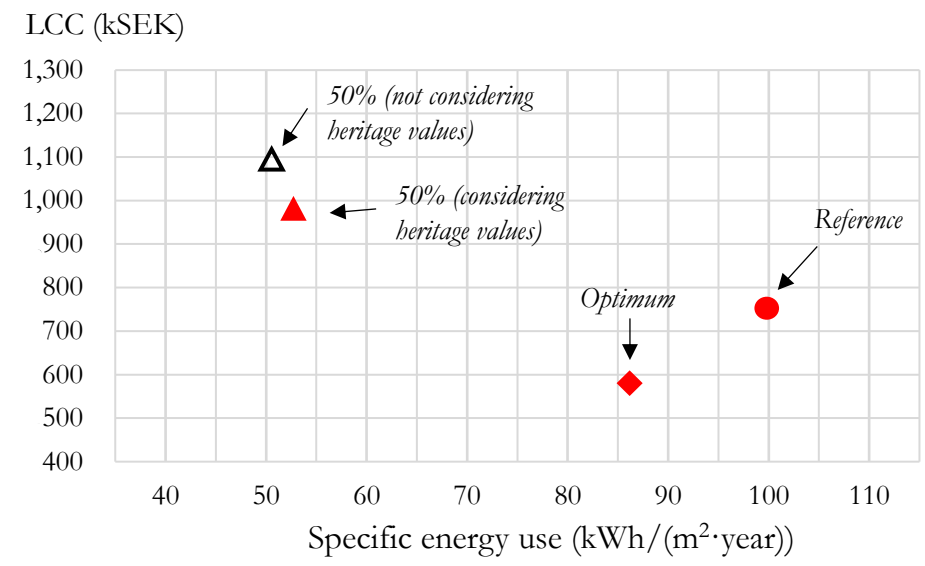

Figure 22: LCC and specific energy before in the reference case, at LCC optimum and when targeting a $50 \%$ decrease in energy use when considering and when not considering heritage values, in building $6 W$.

The impact on the cost-effective energy efficiency potential from requirements on preservation of heritage values is significantly higher in Paper III compared to Papers I-II and Paper IV, due to the tougher preservation requirements. This can be seen in Figure 23 for the balanced and restricted energy renovation scenario, together with a reference case, with the LCC presented to the left in the figure and the specific energy use to the right. For the building types in Clusters $I-I I$, i.e., $1 W-6 W$, there is no difference in either LCC or energy use between the balanced and restricted energy renovation scenario. The reason for this is that the cost-effective packages of EEMs are the same for the two scenarios. In any event, as can be seen in Figure 23, decreases in both LCC and energy use are made possible for these two clusters compared to the reference case through techno-economic LCC optimization. The decrease in LCC varies between 90-256 kSEK (16-20\%) during a time period of 50 years, and the decrease in specific energy use is $12-69 \mathrm{kWh} /\left(\mathrm{m}^{2} \cdot\right.$ year $)(12-40 \%)$. For the building types in Clusters $I I I-I V$, i.e., $1 S-6 S$, energy renovation according to the balanced scenario results in fairly high decreases in energy use of $66-222 \mathrm{kWh} /\left(\mathrm{m}^{2} \cdot\right.$ year) $(46-$ $69 \%)$, corresponding to an energy use of $77-102 \mathrm{kWh} /\left(\mathrm{m}^{2} \cdot\right.$ year $)$ after energy 
renovation. This is explained by the selection of external wall insulation and the poor performance of the external walls varying between $1.80 \mathrm{~W} /\left(\mathrm{m}^{2 .}{ }^{\circ} \mathrm{C}\right)$ and 1.97

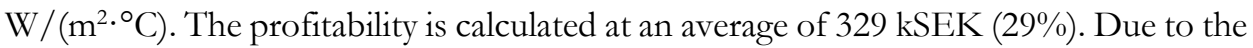
tougher restrictions in the restricted scenario with insulation of the external walls not allowed, the decrease in energy use is significantly lower compared to the balanced scenario, calculated at $12-72 \mathrm{kWh} /\left(\mathrm{m}^{2}\right.$.year) $(8-30 \%)$. The restriction on allowed EEMs is also reflected in the profitability from energy renovation. The average decrease in LCC is $243 \mathrm{kSEK}(20 \%)$. In any event, despite the rather tough preservation requirements in the restricted scenario, financial savings are enabled compared to no energy efficiency improvements during the optimization period. Moreover, it is important to be aware that the selection of cost-effective packages of EEMs is linked with the conditions in the various scenarios set in the optimization procedures and is unique for each building. In contrast to Papers I-II and Paper IV, in which the preservation restrictions were lighter, which resulted in overall lower energy use for the buildings after techno-economic optimization, GHP is selected as the cost-optimal heating system in Paper III for stone buildings $4 S-6 S$ in the restricted scenario. The reason for this is the fairly large heated area in these buildings, together with a high energy use and power demand, as well as the low running cost for the GHP.

There is a clear tendency that the selection of cost-effective packages of EEMs is dependent on building cluster, building type, and also what kind of preservation requirements are considered. This means that there is a need for assessing each building type prior to energy renovation in terms of what EEMs can be implemented. In addition, when investigating an entire district, hotspots can be found in the district in terms of what type of buildings hold the highest energy savings potential while maintaining profitability and not distorting the heritage values. For example, the disadvantages are high for Clusters III-IV concerning potential decreases in LCC and energy use when energy renovating according to the balanced and restricted scenario compared to LCC optimum. Consequently, it is possible to quantify what the long-terms costs are for preserving heritage values through comparison of the results from optimization for different energy renovation scenarios. 

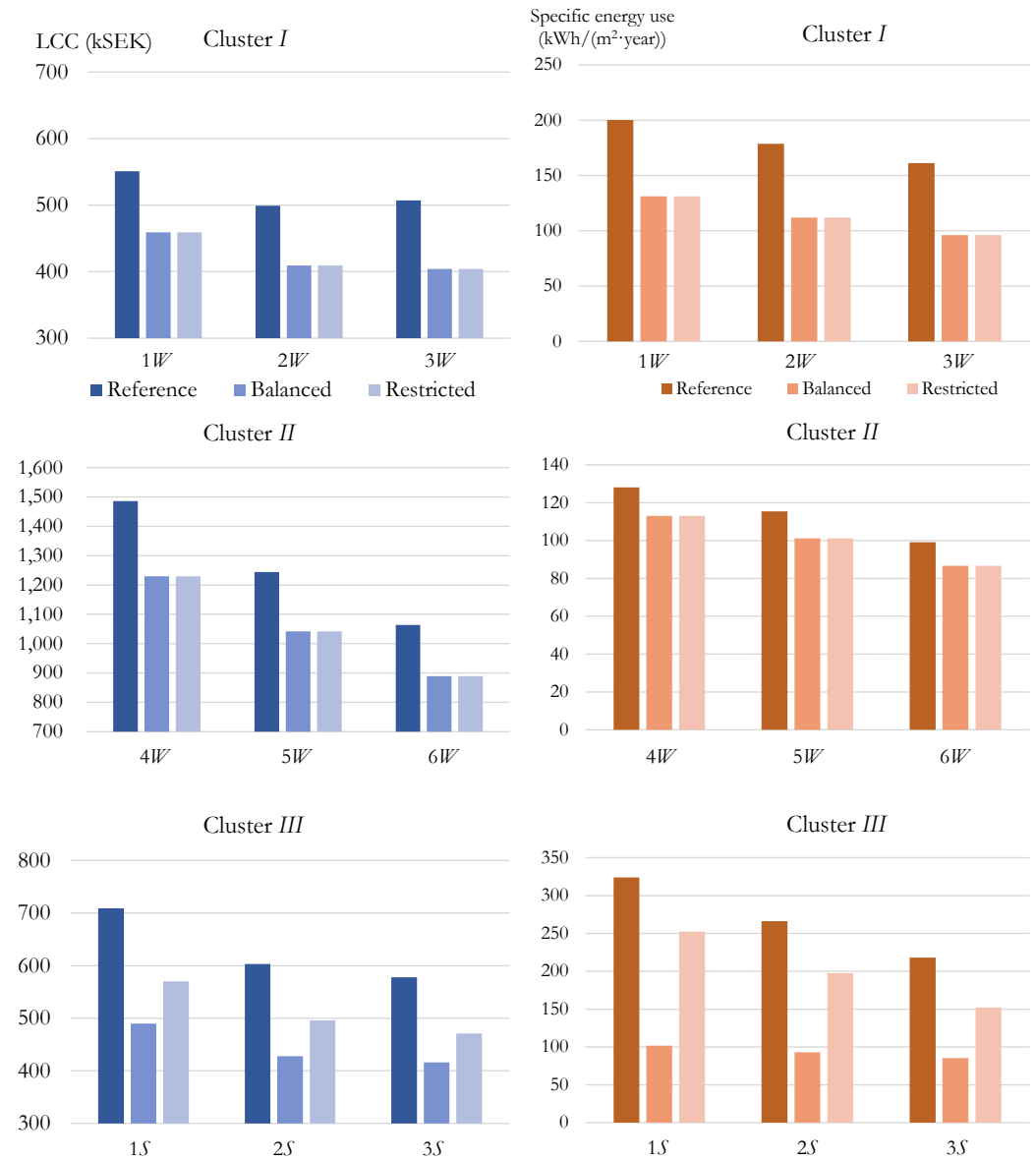

Cluster IV
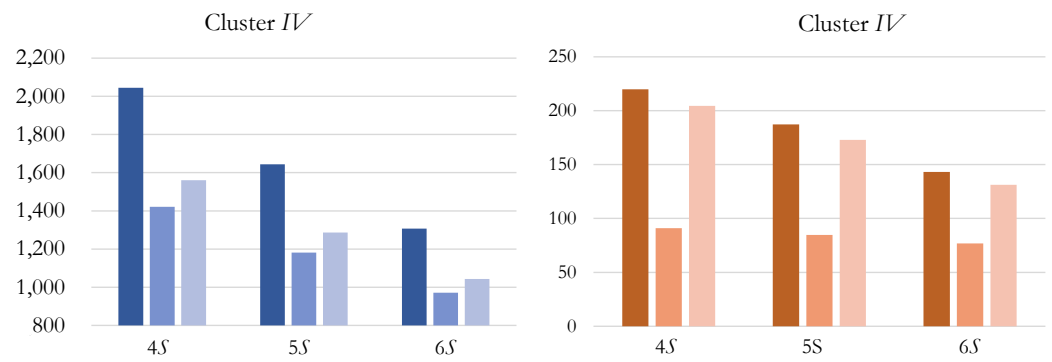

Figure 23: LCC and specific energy use in the reference case (left), the balanced energy renovation scenario (center) and the restricted energy renovation scenario (right). 


\subsection{RESEARCH QUESTION 3}

"How can local energy system analysis and optimization be combined with the bottom-up approach on a district level to analyze $\mathrm{CO}_{2}$ emissions, primary energy use and system costs on a city level?"

By using actual factors for $\mathrm{CO}_{2}$ emissions and primary energy use, analysis of the environmental performance from a building owner perspective is made possible before and after energy renovation. Moreover, by combining local energy system analysis and optimization with the proposed bottom-up approach, predictions of $\mathrm{CO}_{2}$ emissions and primary energy use can be made from the $\mathrm{DH}$ supplier perspective, and the associated system cost. Hence, a holistic viewpoint can be achieved for analyzing costeffective EEMs on a residential district and the consequential effects on the local DH system. A schematic of the approach is presented in Figure 24 in which four different levels are included: building level, cluster level, district level and city level. By using case studies on building level, which are representative of a larger number of buildings and the proposed bottom-up approach, it is possible to calculate the corresponding results on a cluster level and district level. BES software is used to model and simulate the heat demand over time for the various building types, followed by converting the heat demand into a flexible time division suitable for larger DH systems using the Converter software [63]. Furthermore, by considering the heat load from other buildings connected to the DH network in the city, it is possible to generate results on city level, which consist of optimal DH production, system cost, primary energy use and $\mathrm{CO}_{2}$ emissions, by the use of local energy system analysis and optimization.

\subsection{1 $\mathrm{CO}_{2}$ emissions and primary energy use}

Calculated specific $\mathrm{CO}_{2}$ emissions for the studied building types can be seen in Table 7 before and after techno-economic optimization. The targets considered in the optimizations include LCC optimum and energy renovation according to BBR. The $\mathrm{CO}_{2}$ emissions are directly dependent on the type of fuel supply and heating system used in the building, as well as the energy use of the building. Of the available heating systems in OPERA-MILP, either WB or DH is selected as the cost-optimal heating system. As mentioned in section 5.2.5, different assumptions with regard to the use of biomass are considered, i.e., biomass is regarded as both an unlimited resource $(11 \mathrm{~kg}$ $\mathrm{CO}_{2}$ eq. $/ \mathrm{MWh}$ ) and a limited resource $(405 \mathrm{~kg} \mathrm{CO} 2$ eq. $/ \mathrm{MWh}$ ) with condensing coal power plants assumed to be the marginal user of biomass. The annual specific $\mathrm{CO}_{2}$ emissions vary between $5.6 \mathrm{~kg} \mathrm{CO} 2$ eq. $/\left(\mathrm{m}^{2} \cdot\right.$ year $)$ and $18.5 \mathrm{~kg} \mathrm{CO}_{2}$ eq. $/\left(\mathrm{m}^{2}\right.$. year $)$ in the reference case, and are calculated at $0.7-6.4 \mathrm{~kg} \mathrm{CO} 2 \mathrm{eq} /\left(\mathrm{m}^{2} \cdot\right.$ year $)$ and $3.9-40.0 \mathrm{~kg} \mathrm{CO}_{2}$ eq. $/\left(\mathrm{m}^{2}\right.$.year $)$ after energy renovation when considering biomass as an unlimited and 
limited resource, respectively. For multi-family buildings $4 S-6 S$ and $4 W-6 W$, there is an increase in $\mathrm{CO}_{2}$ emissions when considering biomass as a limited resource. This is because WB is selected as the heating system instead of DH. Hence, the results in terms of $\mathrm{CO}_{2}$ emissions from implementing cost-effective packages of EEMs are highly dependent on the assumptions connected to the availability and use of biomass. Furthermore, it should be noted that tougher restrictions on the EEMs result in GHP being cost-optimal for buildings $4 S-6 S$ according to the restricted scenario in Paper III, as mentioned previously in section 7.1.1. When using figures for average Swedish electricity production, the $\mathrm{CO}_{2}$ emissions vary between $0.6 \mathrm{~kg} \mathrm{CO}_{2}$ eq. $/\left(\mathrm{m}^{2}\right.$.year $)$ and 0.9 $\mathrm{kg} \mathrm{CO} 2$ eq. $/\left(\mathrm{m}^{2} \cdot\right.$ year) for $4 S-6 S$, which is in the same range when considering biomass as an unlimited resource at LCC optimum and BBR. However, the corresponding figures when considering marginal electricity production with condensing coal power plants are $42.4-66.1 \mathrm{~kg} \mathrm{CO} 2$ eq. $/\left(\mathrm{m}^{2} \cdot\right.$ year $)$.

Table 7: Annual $\mathrm{CO}_{2}$ emissions per heated area for the building types in the reference case, LCC optimum and BBR.

\begin{tabular}{|c|c|c|c|c|c|c|c|c|c|c|c|c|c|}
\hline \multirow{2}{*}{\multicolumn{2}{|c|}{$\begin{array}{l}\text { Cluster } \\
\text { Building type }\end{array}$}} & \multicolumn{3}{|l|}{$I$} & \multicolumn{3}{|l|}{$I I$} & \multicolumn{3}{|l|}{ III } & \multicolumn{3}{|l|}{$I V$} \\
\hline & & $1 W$ & $2 W$ & $3 W$ & $4 W$ & $5 W$ & $6 W$ & $1 S$ & $2 S$ & $3 S$ & $4 S$ & $5 S$ & $6 S$ \\
\hline Reference & $\mathrm{kg} \mathrm{CO}_{2}$ eq. $/\left(\mathrm{m}^{2} \cdot\right.$ year $)$ & 11.4 & 10.2 & 9.2 & 7.3 & 6.6 & 5.6 & 18.5 & 15.2 & 12.4 & 12.5 & 10.7 & 8.2 \\
\hline Optimum & $\mathrm{kg} \mathrm{CO}_{2}$ eq. $/\left(\mathrm{m}^{2} \cdot\right.$ year $)$ & 6.4 & 5.3 & 4.6 & $\begin{array}{l}1.1^{\mathrm{a}} / \\
40.0^{\mathrm{b}}\end{array}$ & $\begin{array}{l}1.0^{\mathrm{a}} / \\
36.1^{\mathrm{b}}\end{array}$ & $\begin{array}{l}0.9^{\mathrm{a}} / \\
31.4^{\mathrm{b}}\end{array}$ & 4.5 & 4.1 & 3.9 & $\begin{array}{l}0.8^{\mathrm{a}} / \\
30.8^{\mathrm{b}}\end{array}$ & $\begin{array}{l}0.8^{\mathrm{a}} / \\
28.9^{\mathrm{b}}\end{array}$ & $\begin{array}{l}0.7^{\mathrm{a}} / \\
31.0^{\mathrm{b}}\end{array}$ \\
\hline BBR & $\mathrm{kg} \mathrm{CO}_{2}$ eq. $/\left(\mathrm{m}^{2} \cdot\right.$ year $)$ & 4.7 & 4.6 & 4.7 & $\begin{array}{l}0.9^{\mathrm{a}} / \\
31.4^{\mathrm{b}}\end{array}$ & $\begin{array}{l}0.8^{\mathrm{a}} / \\
30.7^{\mathrm{b}}\end{array}$ & $\begin{array}{l}0.9^{\mathrm{a}} / \\
31.9^{\mathrm{b}}\end{array}$ & 4.7 & 4.7 & 4.7 & $\begin{array}{l}0.9^{\mathrm{a}} / \\
31.4^{\mathrm{b}}\end{array}$ & $\begin{array}{l}0.8^{\mathrm{a}} / \\
31.1^{\mathrm{b}}\end{array}$ & $\begin{array}{l}0.7^{\mathrm{a}} / \\
31.4^{\mathrm{b}}\end{array}$ \\
\hline
\end{tabular}

a Biomass unlimited resource

b Biomass limited resource

The specific primary energy use for the abovementioned cases in this section are presented in Table 8. A primary energy factor of 0.31 and 0.11 has been used for the $\mathrm{DH}$ and wood pellets, respectively. The low figures mean that only the energy to produce the fuel is considered, and not the energy content of the respective fuel, as stated in section 5.2.5. The primary energy use varies between $31 \mathrm{kWh} /\left(\mathrm{m}^{2} \cdot\right.$ year $)$ and $100 \mathrm{kWh} /\left(\mathrm{m}^{2} \cdot\right.$ year $)$ before techno-economic optimization. The corresponding figures after techno-economic optimization are $7-35 \mathrm{kWh} /\left(\mathrm{m}^{2} \cdot\right.$ year $)$. The highest decreases in primary energy use (81-88\%) occur in the multi-family buildings in stone, $4 S-6 S$, due to the overall highest decrease in specific energy use and a change in heating system from $\mathrm{DH}$ to $\mathrm{WB}$ with a lower primary energy factor. Single-family houses $1 \mathrm{~W}-3 \mathrm{~W}$ correspond to the buildings with the lowest decrease (44-59\%) in primary energy use because of the lowest decrease in energy use after techno-economic optimization. Nevertheless, the average decrease in primary energy use is $51 \%$ for buildings $1 \mathrm{~W}-3 \mathrm{~W}$ 
and $70 \%$ when considering all buildings, indicating a rather high potential considering decreased primary energy use for the investigated district.

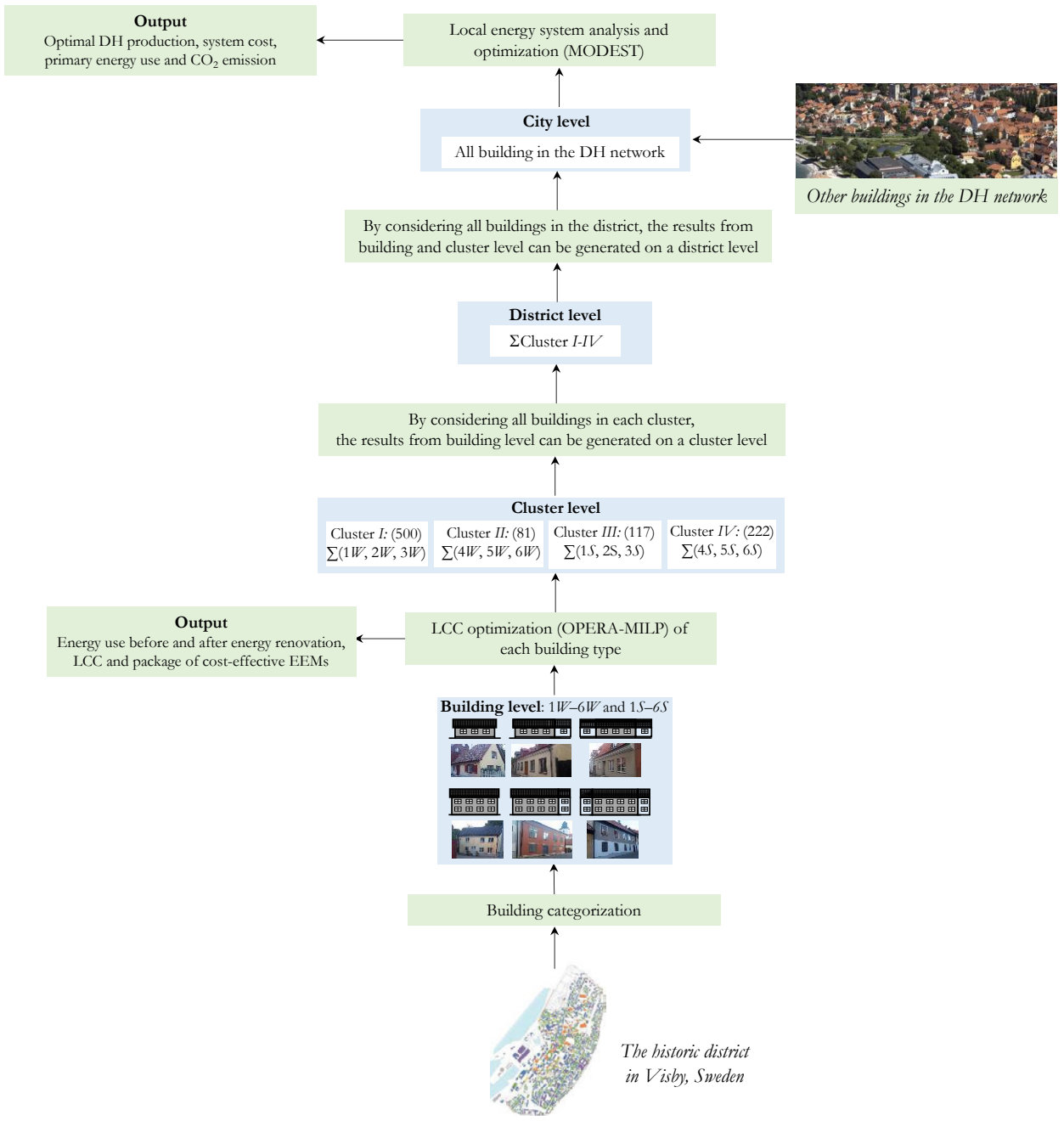

Figure 24: Schematic of the approach for analyzing $\mathrm{CO}_{2}$ emissions, primary energy use and system cost at a city level. 
Table 8: Specific primary energy use for the building types in the reference case, LCC optimum and $B B R$.

\begin{tabular}{|c|c|c|c|c|c|c|c|c|c|c|c|c|}
\hline Cluster & $I$ & & & II & & & $I I I$ & & & $I V$ & & \\
\hline Building type & $1 W$ & $2 W$ & $3 W$ & $4 W$ & $5 W$ & $6 W$ & $1 S$ & $2 S$ & $3 S$ & $4 S$ & $5 S$ & $6 S$ \\
\hline Reference $\mathrm{kWh} /\left(\mathrm{m}^{2} \cdot\right.$ year $)$ & 62 & 55 & 50 & 40 & 36 & 31 & 100 & 83 & 68 & 68 & 58 & 44 \\
\hline Optimum $\mathrm{kWh} /\left(\mathrm{m}^{2} \cdot\right.$ year $)$ & 35 & 29 & 25 & 11 & 10 & 9 & 25 & 22 & 21 & 8 & 8 & 7 \\
\hline $\mathrm{kWh} /\left(\mathrm{m}^{2} \cdot\right.$ year $)$ & 25 & 25 & 26 & 9 & 8 & 9 & 26 & 25 & 25 & 9 & 8 & 9 \\
\hline
\end{tabular}

By improving the thermal performance of the residential district through cost-effective packages of EEMs, the performance of the DH system will be affected. The DH production and energy supply to the DH system in the reference case, LCC optimum and BBR are presented in Table 9. The total $\mathrm{DH}$ production before energy renovation is 184.6 GWh. The DH production after techno-economic optimization of the district at LCC optimum and when energy renovating according to BBR is $168.4 \mathrm{GWh}$ and 167.6 GWh, respectively. The decreases in energy supply after energy renovation originate almost exclusively from reduced use of biomass (6.3-6.7 GWh) and electricity (3.6-3.8 GWh).

Table 9: DH production and energy supply to the DH system in the studied cases.

DH production and
energy supply Reference LCC optimum $\quad$ BBR

\begin{tabular}{cccc}
\hline $\mathrm{DH}(\mathrm{GWh} /$ year $)$ & 184.6 & 168.4 & 167.6 \\
\hline Energy supply (GWh/year) & & & \\
\hline Biomass & 149.7 & 143.4 & 143.0 \\
\hline Electricity & 7.2 & 3.6 & 3.4 \\
\hline Bio oil & 0.6 & 0.3 & 0.3 \\
\hline
\end{tabular}

Calculated $\mathrm{CO}_{2}$ emissions and primary energy use from the DH system in Visby can be seen in Table 10. The local $\mathrm{CO}_{2}$ emissions are decreased from 1,667 tonnes/year in the 
reference case to 1,596 tonnes/year (4\%) and 1,592 tonnes/year (4\%) at LCC optimum and the energy targets in BBR, respectively. The corresponding decreases in global $\mathrm{CO}_{2}$ emissions are 3,545 tonnes/year (41\%) and 3,727 tonnes/year (43\%) compared to before energy renovation. In terms of primary energy use, reductions of $5.0 \mathrm{GWh} /$ year $(9 \%)$ are achieved at LCC optimum and $5.2 \mathrm{GWh} /$ year $(9 \%)$ at the energy targets in BBR. Hence, from an environmental perspective, there are solely benefits from implementing techno-economic EEMs in the district built before 1945 in Visby. Furthermore, it is of interest to highlight the rather large decrease in global $\mathrm{CO}_{2}$ emissions. This is explained by two factors: the significant decrease of electricity in the energy supply to the DH production which is the range of $50 \%, 3.6-3.8 \mathrm{GWh}$, compared to before energy renovation, and that a coal-fired condensing power plant has been assumed to be the short-term marginal power plant in the European electricity system as described in section 5.2.5. The correlation between a decreased heat load and enhanced environmental performance in the form of decreased $\mathrm{CO}_{2}$ emissions can be found during studies of other DH systems in cold climate, such as [99, 100].

$\mathrm{CO}_{2}$ emissions and primary energy use when energy renovating the various clusters at LCC optimum ranging from the cluster with the highest energy savings to the cluster with the lowest energy savings can be seen in Table 11. The largest impact on $\mathrm{CO}_{2}$ emissions and primary energy use is achieved from energy renovating Cluster $I V$ and Cluster I, mainly because these two clusters constitute more than $75 \%$ of the total heated area. For example, of the total decreases in global $\mathrm{CO}_{2}$ emissions $\left(3,545 \mathrm{CO}_{2}\right.$ eq. tonnes/year corresponding to 41\%), energy renovation of Cluster $I V$ and Cluster $I$ equal decreases emissions by $2,930 \mathrm{CO}_{2}$ eq. tonnes/year $(34 \%)$. This shows significant differences from cost-effective packages of EEMs in various building clusters on the $\mathrm{CO}_{2}$ emissions and primary energy use of a DH system.

\begin{tabular}{|c|c|c|c|}
\hline Case & $\begin{array}{c}\text { Local } \mathrm{CO}_{2} \text { eq. } \\
\text { emissions } \\
\text { (tonnes/year) }\end{array}$ & $\begin{array}{l}\text { Global } \mathrm{CO}_{2 \text { eq. }} \\
\text { emissions } \\
\text { (tonnes/year) }\end{array}$ & $\begin{array}{c}\text { Primary } \\
\text { energy use } \\
\text { (GWh/year) }\end{array}$ \\
\hline Reference case & 1,667 & 8,648 & 57.2 \\
\hline LCC optimum & 1,596 & 5,103 & 52.2 \\
\hline BBR & 1,592 & 4,921 & 52.0 \\
\hline
\end{tabular}


Table 11: Local and global $\mathrm{CO}_{2}$ emissions after techno-economic optimization of the various building clusters at LCC optimum.

\begin{tabular}{|c|c|c|c|c|c|}
\hline $\begin{array}{l}\text { Local and global } \mathrm{CO}_{2} \\
\text { emissions, and } \\
\text { primary energy use }\end{array}$ & Case 1 & $\begin{array}{l}\text { Cluster } \\
I V\end{array}$ & $\begin{array}{l}\text { Clusters } \\
I V+I\end{array}$ & $\begin{array}{l}\text { Clusters } \\
I V+I+I I I\end{array}$ & $\begin{array}{l}\text { Clusters } \\
I V+I+I I I+I I\end{array}$ \\
\hline $\begin{array}{l}\text { Local } \mathrm{CO}_{2 \text { eq. }} \text { emissions } \\
\text { (ton/year) }\end{array}$ & 1,667 & 1,630 & 1,610 & 1,600 & 1,596 \\
\hline $\begin{array}{l}\text { Global } \mathrm{CO}_{2 \text { eq. }} \text { emissions } \\
\text { (tonnes/year) }\end{array}$ & 8,648 & 6,606 & 5,718 & 5,285 & 5,103 \\
\hline $\begin{array}{l}\text { Primary energy use } \\
\text { (GWh/year) }\end{array}$ & 57.2 & 54.5 & 53.1 & 52.5 & 52.2 \\
\hline
\end{tabular}

An objective of local municipalities is to support national and international sustainability goals for achieving sustainable development. Based on the results generated in Paper IV, increased thermal performance in the building stock can be used as a meaningful measure to decrease $\mathrm{CO}_{2}$ emissions and primary energy use from a local DH system. Moreover, as presented earlier in this section, a consequence of energy renovation of the studied district is that biomass and electricity are made available on the energy market. With a future time perspective, it is of particular interest to decrease the use of electricity in the DH production considering the ongoing electrification of various sectors and thereby enable a more efficient use of energy. Consequently, this can avoid construction of new electricity generation capacity, which may in turn lead to reduced use of primary energy and decrease of $\mathrm{CO}_{2}$ emissions. In addition, by reducing the peak load and need of imported fuels in the DH production, a higher energy security can be achieved for the $\mathrm{DH}$ system.

\subsubsection{System cost}

The cost for the production of $\mathrm{DH}$, i.e., the system cost, will directly be affected as a result of a decreased heating load due to improved thermal performance in the district. In addition, since less $\mathrm{DH}$ is sold to end users, the revenues from $\mathrm{DH}$ will be decreased. Therefore, by considering the system cost of the DH system together with the revenue for the sold $\mathrm{DH}$, it is possible to predict the net income of the $\mathrm{DH}$ system, which can be seen in Figure 25. It should be noted that only expenditures connected to the DH production are considered, and no other costs for running the DH system are included, such as employee salaries. In order to show the economic effects from energy 
renovating the various clusters separately, Table 12 presents the same parameters as given in Figure 25, as well as the variation in $\mathrm{DH}$ production, ranging from the cluster with the highest energy savings to the cluster with the lowest energy savings at LCC optimum, which corresponds to the following order: Cluster $I V$, Clusters $I V+I$, Clusters $I V+I+I I I$ and Clusters $I V+I+I I I+I I$.

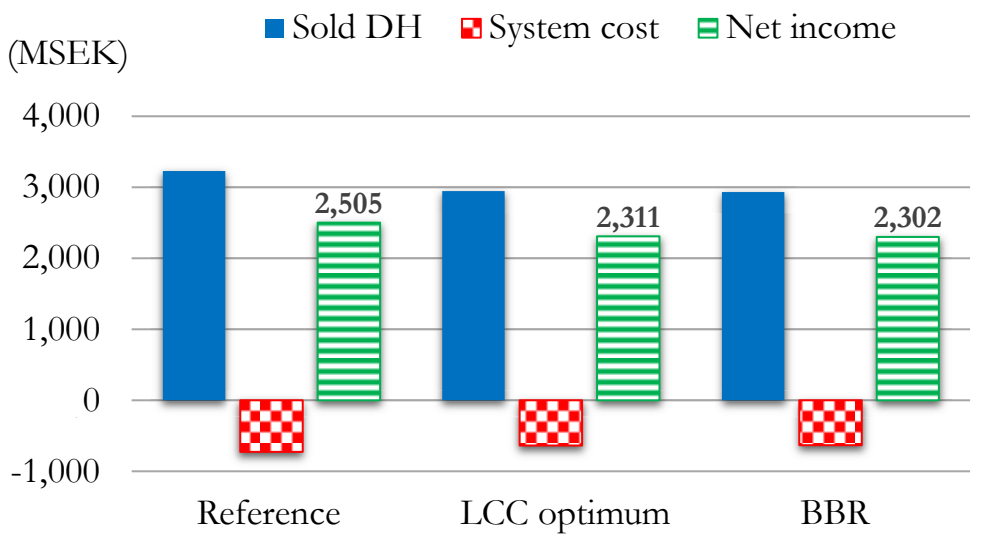

Figure 25: Revenue from DH sold, system cost and net income for the DH system in Visby in the reference case, $L C C$ optimum and $B B R$.

Table 12: DH production, revenue from DH sold, system cost and net income for the DH system after techno-economic optimization of the various building clusters at LCC optimum.

\begin{tabular}{|c|c|c|c|c|c|}
\hline $\begin{array}{l}\text { DH production, sold } \\
\text { DH, system cost } \\
\text { and net income }\end{array}$ & Case 1 & $\begin{array}{c}\text { Cluster } \\
\text { IV }\end{array}$ & $\begin{array}{c}\text { Clusters } \\
I V+I\end{array}$ & $\begin{array}{l}\text { Clusters } \\
I V+I+I I I\end{array}$ & $\begin{array}{c}\text { Clusters } \\
I V+I+I I I+I I\end{array}$ \\
\hline $\begin{array}{l}\text { DH production } \\
\text { (GWh/year) }\end{array}$ & 184.6 & 175.7 & 171.4 & 169.3 & 168.4 \\
\hline $\begin{array}{l}\text { Income from sold DH } \\
(\mathrm{MSEK})\end{array}$ & 3,232 & 3,076 & 3,001 & 2,964 & 2,948 \\
\hline System cost (MSEK) & 727 & 676 & 654 & 641 & 637 \\
\hline Net income (MSEK) & 2,505 & 2,400 & 2,347 & 2,323 & 2,311 \\
\hline
\end{tabular}


As can be seen in Figure 25, the net income for the DH system is decreased from 2,505 MSEK in the reference case to 2,311 MSEK (8\%) at LCC optimum and 2,302 MSEK $(8 \%)$ during energy renovation according to BBR. The system cost is decreased by 89 94 MSEK (12-13\%) after techno-economic optimization compared to the reference case. The reason for the lower system cost after energy renovation of the district is a decreased energy supply in the DH production. Moreover, when investigating the effects of techno-economic optimization at LCC optimum of the various clusters it can be seen that the net income of the DH system is decreased from 2,505 MSEK in the reference case to 2,400 MSEK (4\%), 2,347 MSEK (6\%), 2,323 MSEK (7\%) and 2,311 $(8 \%)$ MSEK when energy renovating Cluster $I V$, Clusters $I V+I$, Clusters $I V+I+I I I$ and Clusters $I V+I+I I I+I I$, respectively. The relatively high losses in revenue from energy renovation of Cluster $I V$ and Cluster $I$ is explained by the large decreases in $\mathrm{DH}$ production corresponding to $8.9 \mathrm{GWh}$ and $4.3 \mathrm{GWh}$, respectively. This is to a large extent explained by the large heated area of these two clusters (Cluster $I \sim 49,800 \mathrm{~m}^{2}$ and Cluster $I V \sim 79,400 \mathrm{~m}^{2}$ ) compared to Cluster $I I$ and Cluster III, which have heated areas of $\sim 31,300 \mathrm{~m}^{2}$ and $\sim 10,500 \mathrm{~m}^{2}$, respectively.

The results show that by increasing the thermal performance of buildings connected to a DH network and consequently reducing the heat load, the profitability of the $\mathrm{DH}$ system is reduced. Hence, for the owners of energy supply companies, decreased heat load in the DH system is disadvantageous from an economic perspective, which has previously been highlighted as a potential consequence from building energy renovation by the research performed by Pädam et al. [112]. However, it is important to be aware of dynamic factors influencing the operation and performance of a DH system. This includes, among other factors, urbanization, future change in costs of competing heating systems and global warming. In addition, considering the unique character of DH systems in terms of operation and heating load, it is not possible to predict the economic outcome of energy renovation of different districts located within other $\mathrm{DH}$ systems with a high reliability.

Since DH systems and networks are often owned by municipal companies in Sweden, it is important to be aware that by increasing energy efficiency in districts, revenues can be reduced for the municipality. However, other incentives exist for the municipality besides profitability, such as increased energy security as a direct consequence of energy renovation of buildings connected to the $\mathrm{DH}$ network. Moreover, due to the multifaceted effects of increased energy efficiency in the building stock, it is important that governments promote technical solutions that are sustainable both in terms of profitability and environmental effects. This is especially necessary considering other purposes DH systems fulfill for a municipality, e.g. using waste that would otherwise 
be sent to landfill and high supply security of energy for the local residents. As suggested by Pädam et al. [112], an increase of cooperation can be applied in order to develop solutions that are beneficial for multiple actors. Furthermore, in order to manage and compensate for less revenue due to reduced heating load in the DH system, owners of energy supply companies can modify their energy utilities through integration of cooling production using excess heat from the $\mathrm{DH}$ production. This is a relevant measure considering the probable increase in cooling demand in the future as a result of global warming. By doing so, revenue can be generated despite decreases in heat load.

\subsection{RESEARCH QUESTION 4}

\section{"How can the bottom-up approach be combined with a change-point model for analysis of a residential district built before 1945?”}

A unique change-point model, DPTC, has been developed in Paper V for assessment of building thermal power characteristics in a residential district. The main input consists of easily accessible heating power supplies with hourly resolution, and no measured detailed data about user behavior in the building is used. Seventy-three buildings in the district of Vasastaden located in Linköping, Sweden, were selected as the study object. The model is based on the use of selected time periods depending on time-dependent variations in climate and user behavior. The predicted thermal power characteristics include total specific heat losses, $Q_{\text {total }}$, energy use for hot water circulation $P(\mathrm{HWC})$ and hot tap water $P(\mathrm{HTW})$, as well as balance temperature, $T_{\text {balance. }}$ The generated output shows significantly varying performance characteristics when comparing 2014, 2015 and 2016 in terms of balance temperature for three buildings: Building number B33, B39 and B63. The reason the balance temperature is assessed is because it is the final step of the numerical procedure in DTPC. Detailed investigation of the hourly heating supply over the course of the three years shows that the heating supply is significantly lower during the night in B33, indicating e.g. a lowered indoor temperature or a building with high thermal inertia which emits heat during this time period when temperature changes occur. Ambiguous heating supply patterns are revealed for both $B 39$ and $B 63$. There are strong fluctuations in measured heating supply, which may be explained by the use of an accumulator tank and some type of commercial activity in the building. However, the reasons behind these patterns are difficult to elucidate without detailed knowledge about factors such as user behavior and performance of the building's technical system. Due to the atypical heating supply data in these three buildings, they are not included in the further analysis. 
The energy use, calculated as the average figure for 2014, 2015 and 2016, for HWC is presented in Figure 26 and for HTW in Figure 27. Buildings constructed between 1908 and 1925 are presented at the top, buildings constructed between 1926 and 1935 in the center, and buildings constructed between 1936 and 1945 at the bottom. As visualized by the dotted line, the average annual energy use for $\mathrm{HWC}$ is $11 \mathrm{kWh} /\left(\mathrm{m}^{2} \cdot\right.$ year $), 17$ $\mathrm{kWh} /\left(\mathrm{m}^{2}\right.$.year $)$ and $14 \mathrm{kWh} /\left(\mathrm{m}^{2}\right.$.year $)$ for buildings constructed between 1908 and 1925, between 1926 and 1935, and between 1936 and 1945, respectively. The corresponding figures for the energy use for HTW are $8 \mathrm{kWh} /\left(\mathrm{m}^{2} \cdot\right.$ year $), 14$ $\mathrm{kWh} /\left(\mathrm{m}^{2} \cdot\right.$ year $)$ and $12 \mathrm{kWh} /\left(\mathrm{m}^{2} \cdot\right.$ year $)$, respectively. In comparison with Belok [115] and a study by the Swedish Energy Agency and residential owners [116], which calculated the HWC at between $2.3 \mathrm{kWh} /\left(\mathrm{m}^{2}\right.$ year $)$ and $28 \mathrm{kWh} /\left(\mathrm{m}^{2}\right.$.year $)$, it can be noted that the energy use for HWC is in the same range as earlier Swedish studies. Moreover, the average variation width, i.e., the largest difference in energy use when comparing the three years, is $2 \mathrm{kWh} /\left(\mathrm{m}^{2}\right.$.year), which corresponds to $12 \%$ after excluding diverging heating supply trends in the data during July. Hence, the calculated energy use for HWC is relatively constant overall for each building, regardless of which year the DH data is based on. The variation in energy use for HTW is higher between the years compared to the energy use for HWC. This can be directly attributed to the energy use for HTW reflecting the user behavior.

The specific heat losses, given in $\mathrm{W} /\left(\mathrm{m}^{2} \cdot{ }^{\circ} \mathrm{C}\right)$, are presented in Figure 28 and the balance temperature in Figure 29. The results are presented as the average figures for 2014, 2015 and 2016, and the error bars for each building show the maximum and minimum figure. The specific heat losses in the district vary between $0.59 \mathrm{~W} /\left(\mathrm{m}^{2 .}{ }^{\circ} \mathrm{C}\right)$ and 2.25

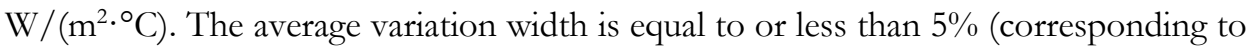
$\sim 0.05 \mathrm{~W} /\left(\mathrm{m}^{2 .}{ }^{\circ} \mathrm{C}\right)$ ) when comparing calculations from 2014, 2015 and 2016. Moreover, there are low differences in predicted specific heat losses post-processing measured heating supply data and outdoor temperature based on a low volatility of an average standard deviation less than $0.11 \mathrm{~W} /\left(\mathrm{m}^{2 .}{ }^{\circ} \mathrm{C}\right)$. In addition, the selected time period for calculations of the specific heat losses, i.e., January and February between 00:00-05:00, gives a sufficient number of time steps that are used for the numerical procedure and correspond to the highest average $\mathrm{R}^{2}$ value $(0.70)$ for the building district. When including time steps before 00:00 or after 05:00, the dependency from outdoor temperature on heat power supply is decreased based on sensitivity analysis. This is shown by a significantly lower $\mathrm{R}^{2}$ and higher specific heat losses. These tendencies can be attributed to occupants waking up in the morning and using energy for HTW. The average balance temperature is $16.6{ }^{\circ} \mathrm{C}$ for the district when using the set model assumptions in the change-point model. As shown by the dotted line in Figure 29, the 
balance temperature is slightly lower in newer buildings compared to older ones indicating somewhat better thermal performance. This tendency is to a great extent linked to lower heat losses since the assumed IHG are directly proportional to the heated area. However, the balance temperature is also dependent on the building's thermal mass, which means that buildings with a higher thermal mass have a lower balance temperature. Furthermore, the predictions of the balance temperature are directly linked to previous calculations since this is the last step of the numerical procedure. Sixty-one of 73 buildings, or $84 \%$ of the buildings in the district, have a variation width equal to or less than $2.0^{\circ} \mathrm{C}$. This means that by using several years of heating power supply data, it is shown that the robustness of the DTPC model is fairly satisfactory.

In light of the need for analyzing entire districts and identifying hotspots for energy efficiency improvements in a time-effective manner, automatic data processing is required. This is a key feature of the developed change-point model with the numerical procedure implemented in the MATLAB software. Moreover, the main input consists of easily accessible heating power supplies with hourly resolution and local outdoor temperature, and no measured detailed data about user behavior is needed. Through the collection of hourly heating supply data for a district and outdoor temperature, a screening of the studied district is allowed by the use of the DPTC model. Consequently, the predicted thermal power characteristics which are generated from the screening enable a categorization of the district which can provide more information compared to the original categorization study included in the bottom-up approach in which qualitative data and GIS data were used. This includes energy use for HWC and HTW, specific heat losses and balance temperature. Hence, combining the developed changepoint model together with the proposed bottom-up approach allows for consideration of the technical performance of buildings in a time-effective manner when analyzing potentialities in energy renovation of a residential district. Consequently, buildings in a district may be ranked depending on energy savings potential based on actual technical performance. This means that DTPC may assist the proposed bottom-up approach in decision-making in large-scale energy renovation. 
Energy use for

HWC

$\left(\mathrm{kWh} /\left(\mathrm{m}^{2} \cdot\right.\right.$ year $\left.)\right)$

- - Average

40

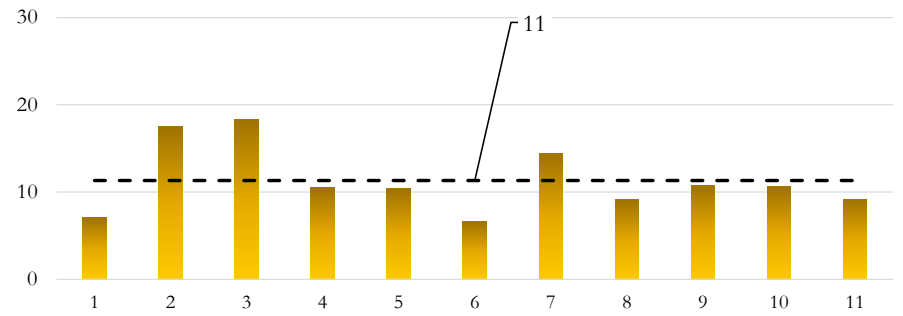

40

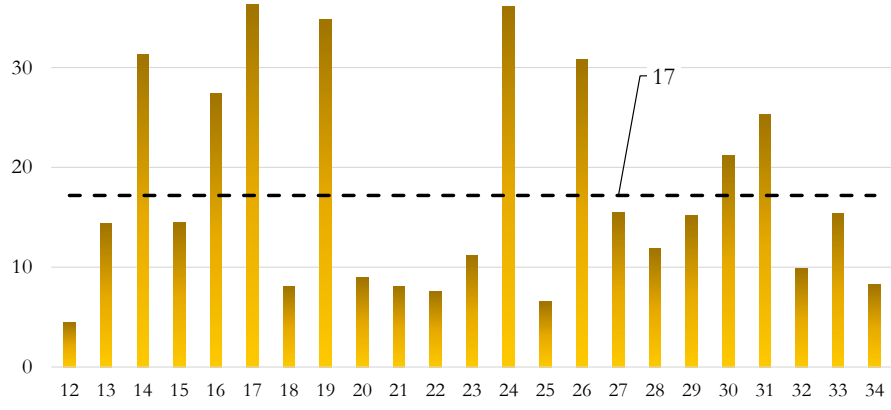

40

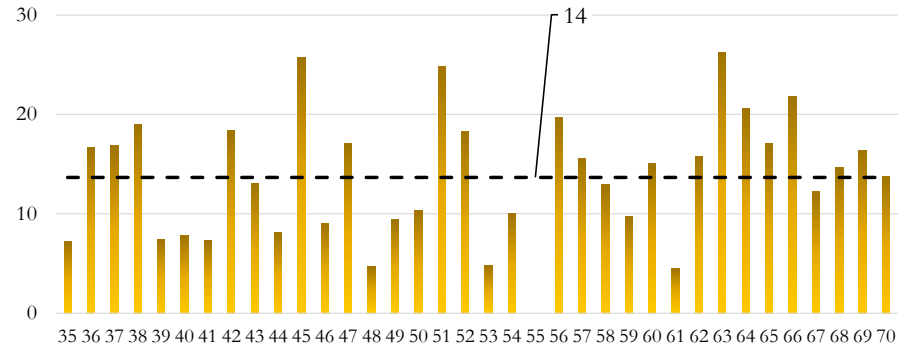

Figure 26: Energy use for HWC [77]. Buildings constructed between 1908 and 1925 are presented at the top, buildings constructed between 1926 and 1935 in the center and buildings constructed between 1936 and 1945 at the bottom. The average when including all buildings in each time period is visualized with a dotted line. 

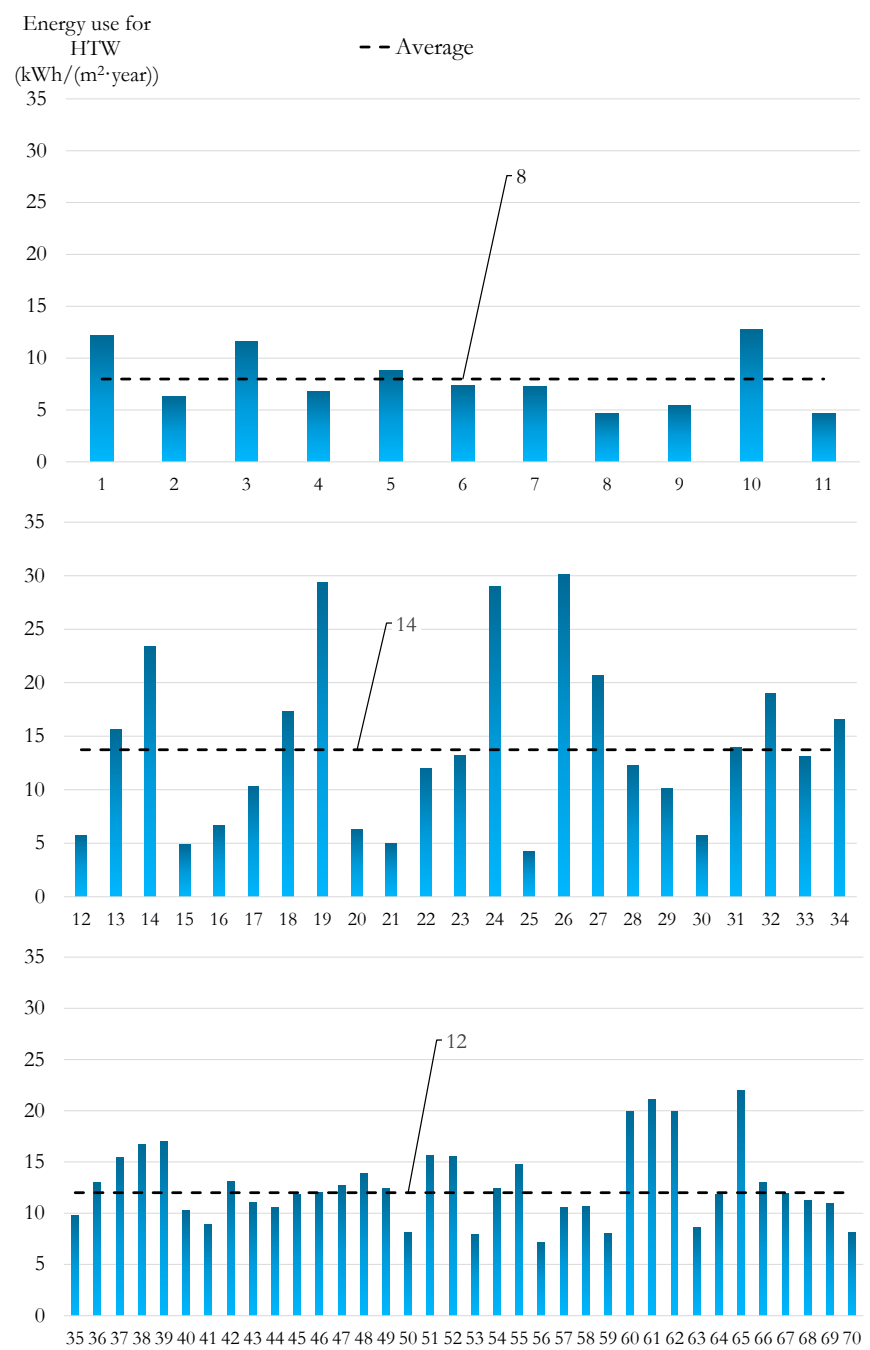

Figure 27: Energy use for HTW [77]. Buildings constructed between 1908 and 1925 are presented at the top, buildings constructed between 1926 and 1935 in the center and buildings constructed between 1936 and 1945 at the bottom. The average when including all buildings in each time period is visualized with a dotted line. 


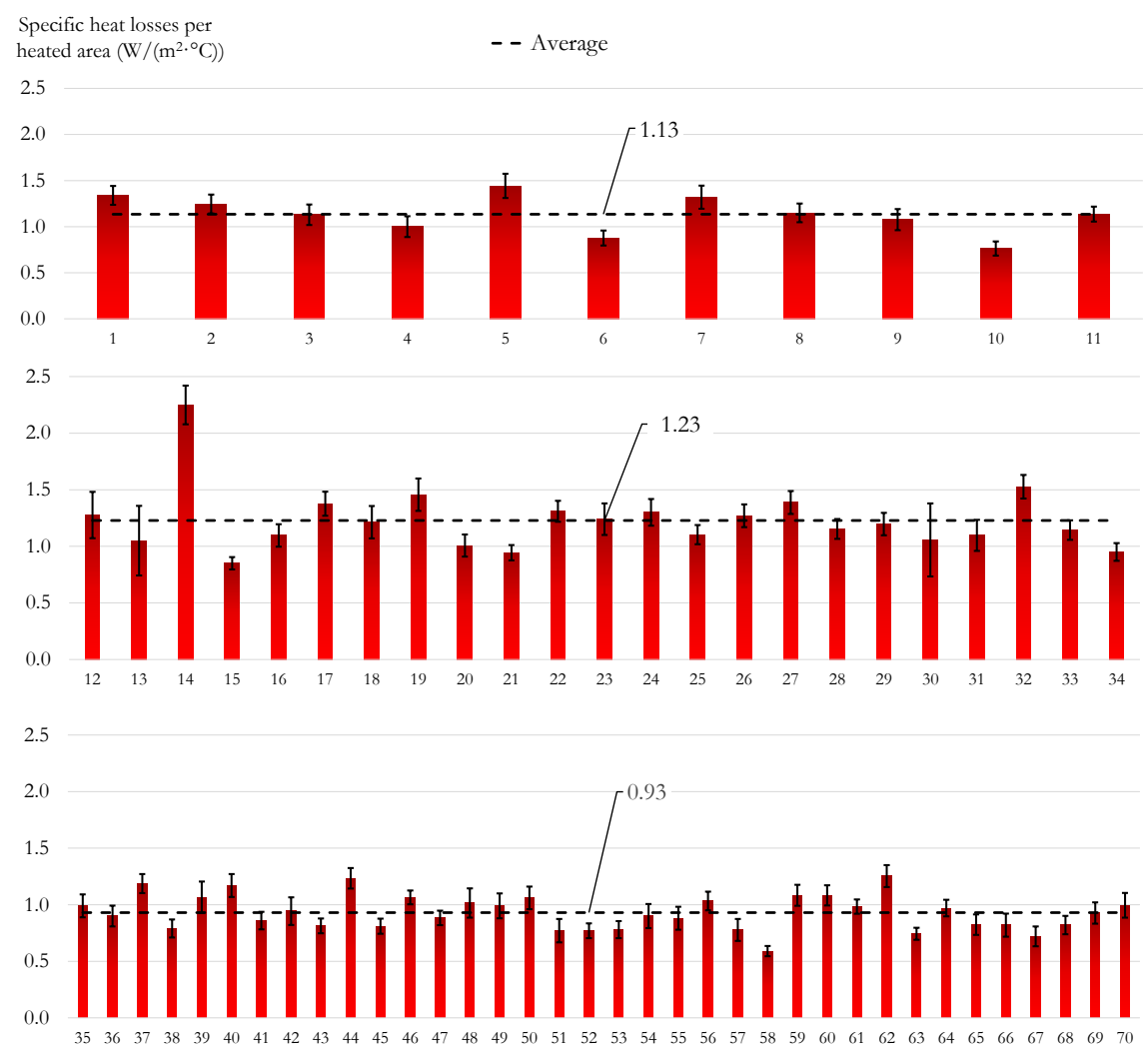

Figure 28: Specific heat losses per heated area based on numerical procedures for 2014, 2015 and 2016 [77]. Buildings constructed between 1908 and 1925 are presented at the top, buildings constructed between 1926 and 1935 in the center, and buildings constructed between 1936 and 1945 at the bottom. The average when including all buildings in each time period is visualized with a dotted line, and each error bar represents the standard deviation. 


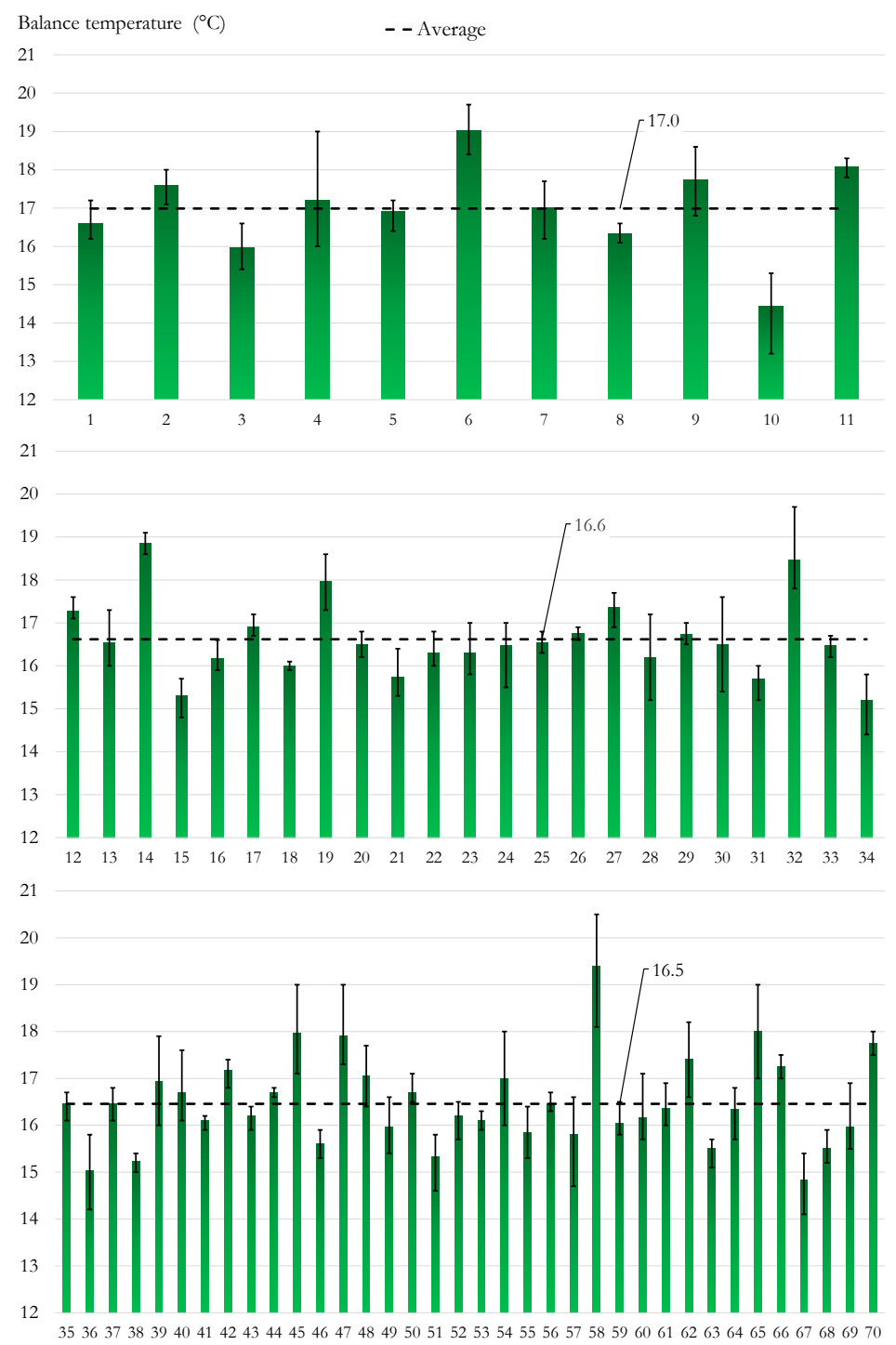

Figure 29: Balance temperatures based on numerical procedures for 2014, 2015 and 2016 [77]. Buildings constructed between 1908 and 1925 are presented at the top, buildings constructed between 1926 and 1935 in the center, and buildings constructed between 1936 and 1945 at the bottom. The average when including all buildings in each time period is visualized with a dotted line, and each error bar represents the maximum and minimum balance temperatures calculated for each building. 


\section{Conclusions}

The following chapter presents the conclusions connected to each research question based on the appended papers.

RQ1. "How can a bottom-up approach be used to analyze packages of cost-effective EEMs on a residential district built before 1945?”

By mapping and collecting data for the residential district built before 1945 in Visby, Sweden, a categorization of the district was accomplished. Consequently, this allows for analysis of representative building types. Moreover, by considering similarities in terms of building size and type of building structure, the generated building types can be divided into building clusters. Analysis of cost-effective packages of EEMs is enabled through techno-economic LCC optimization, which also allows for consideration of targets of energy use in the optimization procedures.

The generated findings show clear differences between the building types and clusters in terms of cost-effective packages of EEMs. However, the packages of EEMs are often similar for buildings within the same cluster as a result of similar building properties. The selection of cost-effective EEMs is characterized by targeting building elements with poor thermal performance, and a low investment cost. Furthermore, through the possibility of introducing targets of energy use in the techno-economic optimization procedures, the consequential impact on the cost-effective energy efficiency potential can be investigated from e.g. national building regulations as in BBR.

RQ2. "How can preservation of building heritage values be integrated in the proposed bottom-up approach when analyzing packeages of cost-effective EEMs on a residential district built before 1945?"

Two different approaches for considering building heritage values in the proposed bottom-up approach have been investigated in this thesis. The first approach consists of an assessment post-optimization of the building types in the district with regard to the suitability of the selected EEMs. This allows for analysis and prediction of the techno-economic energy efficiency potential in buildings with heritage values. Based on the preservation requirements used in this research, i.e., not allowing outside insulation of the external walls and replacement to windows with aluminum cladding, it was found that the selection of cost-effective EEMs is affected by the preservation requirements in one of twelve building types. Triple-glazed windows with aluminum cladding are selected in building type $6 \mathrm{~W}$ in order to achieve a $50 \%$ decrease in energy. This is explained by the initially fairly good thermal performance of the building, and hence the need for replacement to the window type with the lowest $U$-value. The second 
approach is based on techno-economic optimizations with regard to predefined restriction levels in terms of preservation objectives. Two restriction levels were formed using the local building scheme for Visby: a balanced level with restrictions on insulation thickness, and a restricted level, in which external wall insulation and window replacement were not allowed (otherwise same restrictions as in the balanced scenario). The results show that by combining defined restriction levels and techno-economic optimization, economically viable packages of EEMs can be generated for representative building types of a district. Moreover, the results show that the costeffective energy efficiency potential is strongly linked to initial building properties and preservation requirements. From a techno-economic perspective, there are no differences between the balanced and restricted level in terms of selected EEMs in the wood buildings since insulation of the external walls is not cost-effective. The potential decrease in LCC and specific energy use is predicted at $16-20 \%$ and $12-40 \%$, respectively. Furthermore, due to a rather high cost-effective energy efficiency potential of insulating the external walls in the stone buildings, there are significant differences in LCC and energy use between the balanced and restricted scenario. Energy renovation according to the balanced level holds a predicted decrease in LCC and specific energy use of $26-31 \%$ and $46-69 \%$, respectively. The corresponding figures for the restricted levels are $18-24 \%$ and $8-30 \%$, which illuminates clear differences between the two preservation levels for the stone buildings, especially in terms of energy use. Considering the findings of varying effects from preservation requirements on the costeffective energy efficiency potential in different building types, there is a need to differentiate optimal packages of cost-effective EEMs for various building types in the building stock built before 1945 .

RQ3. "How can local energy system analysis and optimization be combined with the bottom-up approach on a district level to analyze $\mathrm{CO}_{2}$ emissions, primary energy use and system costs on a city level??"

By using the findings generated with the proposed bottom-up approach and considering factors for $\mathrm{CO}_{2}$ emissions and primary energy use, the environmental performance of the studied district may be analyzed before and after techno-economic optimization. Moreover, through the integration of local energy system analysis and optimization in the bottom-up approach, by considering the entire heat load connected to the DH network and the decrease in heat load in the district as a result of costeffective EEMs, the $\mathrm{CO}_{2}$ emissions, primary energy use and system cost of the $\mathrm{DH}$ system can be predicted.

The results show that the environmental performance of the various building types included in the district is generally improved through cost-effective EEMs. However, 
it should be noted that the generated results are closely linked with the set assumptions of the fuels connected to the energy system boundary. The effects from improved thermal performance in the district on the $\mathrm{DH}$ system are characterized by an improved environmental performance with decreased $\mathrm{CO}_{2}$ emissions and primary energy use, and a lower system cost. The local $\mathrm{CO}_{2}$ emissions and global $\mathrm{CO}_{2}$ emissions are decreased by 71-75 tonnes/year (4\%) and 3,545-3,737 tonnes/year (41-43\%), respectively, when targeting LCC optimum and the national energy targets in BBR. The primary energy use is decreased by $5.0-5.2 \mathrm{GWh} /$ year $(9 \%)$. From an economic perspective, the system cost is decreased by $89-94$ MSEK (12-13\%) during an analysis period of 50 years. However, due to less DH sold to end users, the net income of the DH system is decreased from 2,505 MSEK to 2,302-2,311 MSEK (8\%).

RQ4. "How can the bottom-up approach be combined with a change-point model for analysis of a residential district built before 1945?"

Through the development of a unique change-point model for prediction of building thermal power characteristics, it is possible to perform an analysis of a residential district, which provides supplementary data to the proposed bottom-up approach related to the technical performance of the buildings in the district. This data can be used for differentiating buildings in the categorization. The model has been developed using selected time periods based on time-dependent variations in climate and user behavior to predict building thermal power characteristics and there is no need for data describing the user behavior in the building. The exclusive use of $\mathrm{DH}$ data, which consists of space heating, and energy use for HTW and HWC, together with the implementation of the model in the MATLAB software allows for a time-effective description of thermal power characteristics of buildings within a district. Moreover, the predicted thermal power characteristics provide additional parameters for categorizing a residential district, such as total specific heat losses and balance temperature, compared to the original categorization study in the bottom-up approach, in which only qualitative data and GIS data were used. Lastly, a computerized screening of the $\mathrm{DH}$ data of the buildings in the district for predictions of thermal power characteristics, in combination with the proposed bottom-up approach, allows for timeeffective evaluation of the technical performance of buildings when analyzing the possibilities for large-scale energy renovation of a district. 


\section{FuturE STUdiES}

This chapter presents future studies which are of interest based on the results in this thesis.

There are further interesting aspects to study based on the results presented in this thesis. The results concerning varying cost-optimal levels for different building types suggest that the current national legislation needs to be elaborated in order to achieve a more cost-effective transformation of the building stock from a building owner perspective. Hence, different packages of cost-effective EEMs need to be developed for different types of buildings in order to achieve the highest profitability during a building's life cycle. The results in this thesis suggest that consideration needs to be taken for parameters such as construction year, thermal performance and what type of floor a building is standing on, in addition to the parameters considered today.

Furthermore, urbanization resulting in larger populations living in cities and consequently more buildings connected to DH networks, as well as higher outdoor temperatures in the future as a result of global warming, are questions of interest for future studies. By including various DH systems with different dynamic behavior, fuel mix and operation, it is possible to generate a more holistic view of the interaction between cost-effective packages of EEMs in a residential district built before 1945, and the economic and environmental performance of a DH system. The effects of expansion to a CHP system are also of interest to study considering the ongoing electrification process in the building, transport and industry sector, with a higher need for electricity in the future as a result.

Future research includes development of the proposed change-point model for differentiation between transmission, ventilation and infiltration losses from the total specific heat loss terms ( $\left.Q_{\text {total }}\right)$, which can be valuable as input for building categorization. Artificial Intelligence can be used for this differentiation by searching for relevant patterns in the heating supply data, such as the correlation between heat losses and wind speed. In addition, the research can also be applied to different types of buildings, such as commercial and office buildings. In this case, it is important to consider comfort cooling since it is common in these types of buildings and will most likely be in residential buildings in the future also. To generate a socio-technical perspective, studies on indoor environment can be included. 


\section{REFERENCES}

[1] A. D. Jiboye, Significance of house-type as a determinant of residential quality in Osogbo, Southwest Nigeria, Frontiers of Architectural Research, Vol. 3, pp. 20 27, 2014/03/01/ 2014.

[2] International Energy Agency. Global Status Report for Buildings and Construction 2019. Available: https://www.iea.org/reports/global-statusreport-for-buildings-and-construction-2019

[3] European Commission. Energy performance of buildings directive. Available:

https://ec.europa.eu/energy/en/topics/energy-efficiency/energy-

performance-of-buildings/energy-performance-buildings-directive

(Last accessed: 2020, February 20).

[4] European Parliament, The Energy Efficiency Directive (2012/27/EU), 2012.

[5] Eurostat. Final energy consumption by sector. Available:

https:/ / ec.europa.eu/eurostat/web/energy/data/main-tables (Last accessed: 2020, February 22).

[6] L. Gynther, B. Lapillone, and K. Pollier. Energy Efficiency Trends and Policies in the Household and Tertiary Sectors - An Analysis Based on the ODYSSEE and MURE Databases. Available: https://www.odysseemure.eu/publications/br/energy-efficiency-trends-policies-buildings.pdf (Last accessed: 2020, February 20).

[7] European Commission, A Clean Planet for all. A European strategic long-term vision for a prosperous, modern, competitive and climate neutral economy, 2018.

[8] European Parliament, Directive 2018/844 of the European Parliament and of the Council - amending Directive 2010/31/EU on the energy performance of buildings and Directive 2012/27/EU on energy efficiency, 2018.

[9] The Swedish climate policy framework (2017:720), Ministry of the Environment, 2017.

[10] K. Dol and M. Haffner, Housing Statistics in the European Union 2010, 2010.

[11] Boverket, Energi i bebyggelsen - tekniska egenskaper och beräkningar - resultat från projektet BETSI (in Swedish), ISBN: 978-91-86559-83-0, 2010 
[12] The Swedish National Heritage Board. Data export. Available: http://www.bebyggelseregistret.raa.se/bbr2/dataexport/dataexport.raa (in Swedish) (Last accessed: 2020, February 25).

[13] The Swedish Parliament, The Swedish Planning and Building Act (2010:900), 2010.

[14] The Swedish Parliament, Historic Environment Act (1988:950), 1988.

[15] F. Ståhl, M. Lundh, and P. Ylmén, Sustainable and Careful Renovation and Energy Efficiency of Historically Valuable Buildings - A Pilot Study, ISBN 97891-86622-78-7, 2011 (in Swedish).

[16] European Energy Efficiency Platform (E3P). Energy renovation. Available: https://e3p.jrc.ec.europa.eu/articles/energy-renovation (Last accessed: 2020, January 21).

[17] Building Performance Insititute Europe, Europe's buildings under the microscope. A country-by-country review of the energy performance of buildings. ISBN: 9789491143014, 2011.

[18] M. Fabbri, M. De Groote, and O. Rapf, Building renovation passports. Customized roadmaps towards deep renovation and better homes. ISBN: 9789491143175: Building Performance Insititute Europe, 2016.

[19] The Swedish National Board of Housing, Building and Planning, Regulations and general advice (in Swedish), 2018.

[20] I. Artola, K. Rademaekers, R. Williams, and J. Yearwood, Boosting Building Renovation: What potential and value for Europe? PE 587.326, 2016.

[21] Swedish Society for Nature Conservation. Energy renovate the million program. (Last accessed: 2020, January 22).

[22] Swedish Energy Agency. Energy statistics for one- and two-dwelling buildings, multi-dwellings and non-residential premises 2018. Available: https://www.energimyndigheten.se/statistik/den-officiellastatistiken/statistikprodukter/energistatistik-for-smahus-flerbostadshus-ochlokaler/ (in Swedish) (Last accessed: 2020, February 8).

[23] Swedish Energy Agency. Energy statistics for multi-dwelling buildings 2018. Available: https://www.energimyndigheten.se/statistik/den-officiella- 
statistiken/statistikprodukter/energistatistik-for-flerbostadshus/ (in Swedish) (Last accessed: 2020, February 6).

[24] Statistics Sweden. Living in Sweden. Available: https://www.scb.se/hittastatistik/sverige-i-siffror/manniskorna-i-sverige/boende-i-sverige/ (in Swedish) (Last accessed: 2020, January 28).

[25] L. Thuvander, P. Femenias, and M. Xygkogianni, The renovation barometer 2015 (in Swedish), 2015.

[26] Wikells, Section Facts 17/18 - Techno-economic compilation (in Swedish).

[27] International Energy Agency. Data and statistics. Available:

https://www.iea.org/data-andstatistics?country $=$ WORLD\&fuel $=$ Energy $\% 20$ supply\&indicator $=$ Coal $\% 20$ pro duction $\% 20$ by $\% 20$ type (Last accessed: 2020, February 20).

[28] Eurostat. Energy consumption in households. Available:

https://ec.europa.eu/eurostat/statistics-

explained/index.php/Energy consumption in households\#Energy consump tion in households by type of end-use (Last accessed: 2020, February 20).

[29] Swedish Energy Agency, Energy in Sweden (in Swedish). Eskilstuna, Sweden, 2019.

[30] Swedish Energy Agency. Energy statistics for one-and two-dwelling buildings 2018. Available: https://www.energimyndigheten.se/statistik/den-officiellastatistiken/statistikprodukter/energistatistik-for-smahus/ (in Swedish) (Last accessed: 2020, February 6).

[31] S. Frederiksen and S. Werner, District Heating and Cooling: Lund Studentlitteratur, 2013.

[32] S. Werner, International review of district heating and cooling Energy, 2017, ttp://dx.doi.org/10.1016/j.energy.2017.04.045.

[33] N. Le Truong and L. Gustafsson, Minimum-cost district heat production systems of different sizes under different environmental and social cost scenarios, Applied Energy, Vol. 136, pp. 881-893, 2014.

[34] Swedenergy, District heating statistics, ed, 2018.

[35] L. La Fleur, Investigating cost-optimal energy renovation of a multifamily building in Sweden, Energy and Buildings, Vol. 203: 109438, 2019. 
[36] D. Griego, M. Krarti, and A. Hernández Guerrero, Optimization of energy efficiency and thermal comfort measures for residential buildings in Salamanca, Mexico, Energy and Buildings, Vol. 54, pp. 540-549, 2012.

[37] L. Liu, P. Rohdin, and B. Moshfegh, LCC assessments and environmental impacts on the energy renovation of a multi-family building from the 1890s, Energy and Buildings, Vol. 133, pp. 823-833, 2016.

[38] T. Niemelä, R. Kosonen, and J. Jokisalo, Cost-effectiveness of energy performance renovation measures in Finnish brick apartment buildings, Energy and Buildings, Vol. 137, pp. 60-75, 2017.

[39] P. Penna, A. Prada, F. Cappalletti, and A. Gasparella, Multi-objective optimization of Energy Efficiency Measures in existing buildings, Energy and Buildings, Vol. 95, pp. 57-69, 2015.

[40] Ü. Alev, L. Eskola, E. Arumägi, J. Jokisalo, A. Donarelli, K. Siren, et al., Renovation alternatives to improve energy performance of historic rural houses in the Baltic Sea region, Energy and Buildings, Vol. 77, pp. 58-66, 2014.

[41] P. Shen, W. Braham, and Y. Yi, The feasibility and importance of considering climate change impacts in building retrofit analysis, Applied Energy, Vol. 233234, pp. 254-270, 2019.

[42] European Commitee For Standardization, CSN EN 16883 - Conservation of cultural heritage - Guidelines for improving the energy performance of historic buildings, 2017.

[43] SOU 2004:94 (in Swedish), The Swedish Government, 2009.

[44] The Swedish National Heritage Board. Basic approach for defining, evaluating, prioritizing and developing the cultural heritage. Available: http://raa.divaportal.org $/ \mathrm{smash} / \mathrm{record}$.jsf?pid=diva2\%3A1234521\&dswid=-25 (in Swedish) (Last accessed: 2020, February 20).

[45] The Swedish Environmental Code (1998:808) (in Swedish), The Swedish Government, 1998.

[46] C. W. Churchman, The Systems Approach. ISBN: 0-440-38407-9, 1968.

[47] E. Abel and A. Elmroth, Building and Energy- a systematic approach. ISBN: 978-91-540-5997-3, 2007. 
[48] The Swedish National Board of Housing, Building and Planning, Handbook for energy management in accordance with the Swedish National Board of Housing Building and Planning building regulations (Vol. 2) (in Swedish), Karlskrona, 2012.

[49] L. G. Swan and V. I. Ugursal, Modeling of end-use energy consumption in the residential sector: A review of modeling techniques, Renewable and Sustainable Energy Reviews, Vol. 13, pp. 1819-1835, 2009.

[50] M. Kavgic, A. Mavrogianni, D. Mumovic, A. Summerfield, Z. Stevanovic, and M. Djurovic-Petrovic, A review of bottom-up building stock models for energy consumption in the residential sector, Building and Environment, Vol. 45, pp. 1683-1697, 2010.

[51] R. K. Yin, Case study research and applications. Design and methods. 6th Edition. Los Angeles: SAGE Publications, 2018.

[52] G. Dall'O', A. Galante, and M. Torri, A methodology for the energy performance classification of residential building stock on an urban scale, Energy and Buildings, Vol. 48, pp. 211-219, 2012.

[53] M. K. Mattinen, J. Heljo, J. Vihola, A. Kurvinen, S. Lehtoranta, and A. Nissinen, Modeling and visualization of residential sector energy consumptionand greenhouse gas emissions, Journal of Cleaner Production, Vol. 81, pp. 70-80, 2014.

[54] P. Tuominen, R. Holopainen, L. Eskola, J. Jokisalo, and M. Airaksinen, Calculation method and tool for assessing energy consumptionin the building stock, Building and Environment, Vol. 75, pp. 153-160, 2014.

[55] K. N. Streicher, P. Padey, D. Parra, M. C. Bürer, S. Schneider, and M. K. Patel, Analysis of space heating demand in the Swiss residential building stock: Element-based bottom-up model of archetype buildings, Energy and Buildings, Vol. 184, pp. 300-322, 2019.

[56] E. Mata, G. M. Benejam, A. Sasic Kalagasidis, and F. Johnsson, Modelling opportunities and costs associated with energy conservation in the Spanish building stock, Energy and Buildings, Vol. 88, pp. 347-360, 2015.

[57] E. Mata, A. Sasic Kalagasidis, and F. Johnsson, A modelling strategy for energy, carbon, and cost assessments of building stocks, Energy and Buildings, Vol. 56, pp. 100-108, 2013. 
[58] Q. Wang and S. Holmberg, A methodology to assess energy-demand savings and cost effectiveness of retrofittining in existing Swedish residential buildings, Sustainable Cities and Society, Vol. 14, pp. 254-266, 2015.

[59] L. Liu, P. Rohdin, and B. Moshfegh, Investigating cost-optimal refurbishment strategies for the medieval district of Visby in Sweden, Energy and Buildings, Vol. 158, pp. 750-760, 2018.

[60] T. Broström, A. Donarelli, and F. Berg, For the categorisation of historic buildings to determine energy saving, AGATHON International Journal of Architecture, Art and Design, Vol. 1, pp. 135-142, 2017.

[61] F. Berg, Categorising a historic building stock - an interdisciplinary approach, UU-259149, 2015.

[62] Gotland Municipality, Visby Innerstad - En Bebyggelseinventering Del 1-2 Gotland: Gotlands Museum, 2002 (in Swedish).

[63] Division of Energy Systems at Linköping University, Converter, Linköping University, Sweden, 2016.

[64] D. B. Crawley, J. W. Hand, M. 1. Kummert, and B. T. Griffith, Contrasting the capabilities of building energy performance simulation programs, Building and Environment, Vol. 43, pp. 661-673, 2008.

[65] ISO, EN ISO 13790:2008 thermal performance of buildings - calculation of energy use for space heating and cooling, 2008.

[66] E. M. Ryan and T. F. Sanquist, Validation of building energy modeling tools under idealized and realistic conditions, Energy and Buildings, Vol. 47, pp. 375$382,2012$.

[67] EQUA, Validation of IDA Indoor Climate and Energy 4.0 build 4 with respect to ANSI/ASHRAE Standard 140-2004, 2010.

[68] T. Broström, P. Eriksson, L. Liu, P. Rohdin, F. Ståhl, and B. Moshfegh, A method to assess the potential for and consequences of energy retrofits in Swedish historic buildings, The Historic Environment: Policy and Practice, Vol. 5, pp. 150-166, 2014.

[69] E. Arumägi and T. Kalamees, Analysis of energy economic renovation for historic wooden apartment buildings in cold climates, Applied Energy, Vol. 115, pp. 540-548, 2014. 
[70] S. Hammarsten, A Critical Appraisal of Energy-Signature Models, Applied Energy, Vol. 26, pp. 97-110, 1987.

[71] D. Claridge, J. Haberl, R. Sparks, R. Lopez, and K. Kissock, Monitored Commercial Building Energy Data: Reporting the Results, presented at the ASHRAE Transactions Symposium Paper, 1992.

[72] J. S. Park, S. J. Lee, K. H. Kim, K. W. Kwon, and J.-W. Jeong, Estimating thermal performance and energy saving potential of residential buildings using utility bills, Energy and Buildings, Vol. 110, pp. 23-30, 2016.

[73] J.-U. Sjögren, S. Andersson, and T. Oloffson, An approach to evaluate the energy performance of buildings based on incomplete monthly data, Energy and Buildings, Vol. 39, pp. 945-953, 2007.

[74] K. X. Perez, K. Cetin, M. Baldea, and T. F. Edgar, Development and analysis of residential change-point models from smart meter data, Energy and Buildings, Vol. 139, pp. 351-359, 2017.

[75] D. Farmer, D. Johnston, and D. Miles-Shenton, Obtaining the heat loss coefficient of a dwelling using its heating system (integrated coheating), Energy and Buildings, Vol. 117, pp. 1-10, 2016.

[76] R. Hitchin, Monthly utilisation factors for building energy calculations, Building Services Engineering Research \& Technology, Vol. 38, pp. 318-326, 2017.

[77] V. Milić, P. Rohdin, and B. Moshfegh, Further development of the change-point model - Differentiating thermal power characteristics for a residential district in a cold climate, Energy and Buildings, Vol. 231, p. 110639, 2021.

[78] European Commitee For Standardization, EN 12831-3. Energy performance of buildings - Method for calculation of the design heat load - Part 3: Domestic hot water systems heat load and characterisation of needs, 2017.

[79] P. Gluch and H. Baumann, The life cycle costing (LCC) approach: a conceptual discussion of itsusefulness for environmental decision-making, Building and Environment, Vol. 39, pp. 571-580, 2004.

[80] International Organization for Standardization, ISO 15686-5:2008, 2008.

[81] S.-I. Gustafsson and B. Karlsson G., Why is life - cycle costing important when retrofitting buildings, International Journal of Energy Research, Vol. 12, pp. 233$242,1988$. 
[82] P. Gluch, Perspectives on LCC - A Book About Long-Term Decisions and Guidance During Sustainable and Energy-Efficient Renovation of Buildings. ISSN: 1652-9162 2014 (in Swedish).

[83] V. Milić, K. Ekelöw, and B. Moshfegh, On the performance of LCC optimization software OPERA-MILP by comparison with building energy simulation software IDA ICE, Building and Environment, Vol. 128, pp. 305-319, 2018.

[84] V. Milić, K. Ekelöw, M. Andersson, and B. Moshfegh, Evaluation of energy renovation strategies for 12 historic building types using LCC optimization, Energy and Buildings, Vol. 197, pp. 156-170, 2019.

[85] A. J. Marszal and P. Heiselberg, Life cycle cost analysis of a multi-storey residential Net Zero Energy Building in Denmark, Energy, Vol. 36, pp. 56005609, 2011.

[86] A. Hasan, M. Vuolle, and K. Siren, Minimisation of life cycle cost of a detached house using combined simulation and optimisation, Building and Environment, Vol. 43, pp. 2022-2034, 2008.

[87] A. Loli and C. Bertolin, Towards Zero-Emission Refurbishment of HistoricBuildings: A Literature Review, Buildings, Vol. 22, p. 8(2), 2018.

[88] S.-I. Gustafsson, THE OPERA MODEL. Optimal Energy Retrofits in MultiFamily Residences. ISBN: 91-7870-335-2, 1988.

[89] IBM. CPLEX Optimizer. Available: https://www.ibm.com/analytics/cplexoptimizer (Last accessed: 2021, January 16).

[90] Swedish Government, A More Energy Efficient Sweden. SOU 2008:25, 2008 (in Swedish).

[91] Thermal Engineering Research Institute (Värmeforsk), Estimated emission factors for fuels, electricity, heat and transport. ISSN 1653-1248 2011 (in Swedish).

[92] Swedenergy. Environmental Assessment of District Heating. Available: https://www.energiforetagen.se/statistik/ fjarrvarmestatistik/miljovarderingav-fjarrvarme/miljovarden-fran-tidigare-ar/ (in Swedish) (Last accessed: 2020, November 27). 
[93] European Environment Agency. Overview of electricity production and use in Europe. Available: https://www.eea.europa.eu/data-andmaps/indicators/overview-of-the-electricity-production-2/assessment (Last accessed: 2020, November 27).

[94] J. Gode, F. Martinsson, L. Hagberg, A. Öman, J. Höglung, and J. Palm, Miljöfaktaboken 2011- Estimated Emission Factors for Fuels, Electricity, Heat and Transport in Sweden. Stockholm, Sweden, 2011.

[95] Chalmers University, The Energy Price and Carbon Balance Scenarios tool (ENPAC), ed, 2018.

[96] Swedenergy, Agreement in the Heating Market Committee 2018, 2018.

[97] S. Grönkvist, J. Sjödin, and M. Westermark, Models for assessing net CO2 emissions applied on on district heating technologies, International Journal of Energy Research, Vol. 27, pp. 601-613, 2003.

[98] M. Åberg and J. Widén, Development, validation and application of a fixed district heating model structure that requires small amounts of input data, Energy Conversion and Management, Vol. 75, pp. 74-85, 2013.

[99] M. Áberg, Investigating the impact of heat demand reductions on Swedish district heating production using a set of typical system models, Applied Energy, Vol. 118, pp. 246-257, 2014.

[100] L. Lundström and F. Wallin, Heat demand profiles of energy conservation measures in buildingsand their impact on a district heating system, Applied Energy, Vol. 161, pp. 290-299, 2016.

[101] T. Lidberg, T. Oloffson, and L. Trygg, System impact of energy efficient building refurbishment within a district heated region, Energy, Vol. 106, pp. 45-53, 2016.

[102] M. Åberg and D. Henning, Optimisation of a Swedish district heating system with reduced heat demand due to energy efficiency measures in residential buildings, Energy Policy, Vol. 39, pp. 7839-7852, 2011.

[103] N. Le Truong, A. Dodoo, and L. Gustavsson, Effects of heat and electricity saving measures in district-heated multistory residential buildings, Applied Energy, Vol. 118, pp. 57-67, 2014. 
[104] R. Lund, D. Djuric Ilic, and L. Trygg, Socioeconomic potential for introducing largescale heat pumps in district heating in Denmark, Journal of Cleaner Production, Vol. 139, pp. 219-229, 2016.

[105] G. Wallén, Vetenskapsteori och forskningsmetodik. ISBN 91-4436652-3: Studentlitteratur AB, 1996 (in Swedish).

[106] A. Gebremedhin, A regional and industrial co-operation in district heating systems. Dissertation No. 849, Division of Energy Systems, Linköping University, Linköping, Sweden, 2003.

[107] D. Henning, Optimisation of Local and National Energy Systems. Development and Use of the MODEST Model. Dissertations No. 559, Division of Energy Systems, Linköping University, Linköping, Sweden, 1999.

[108] D. Henning, S. Amiri, and K. Holmgren, Modelling and optimization of electricity, steam and district heating production for a local Swedish utility, European Journal of Operational Research, Vol. 175, pp. 1224-1247, 2006.

[109] G. Sundberg and D. Henning, Investments in combined heat and power plants: influence of fuel price on cost minimised operation, Energy Conversion and Management, Vol. 43, pp. 639-650, 2002.

[110] J. Sjödin and D. Henning, Calculating the marginal costs of a district-heating utility, Applied Energy, Vol. 78, pp. 1-18, 2004.

[111] K. Difs, M. Bennstam, L. Trygg, and L. Nordenstam, Energy conservation measures in buildings heated by district heating - A local energy system perspective Energy, Vol. 35, pp. 3194-3203, 2010.

[112] S. Pädam, A. Persson, O. Kvarnström, and O. Larsson, Energy efficiency inside out - what impact does energy efficiency have on indoor climate and district heating?, Energy Efficiency, Vol. 12, pp. 209-224, 2019.

[113] V. Milić, S. Amiri, and B. Moshfegh, A Systematic Approach to Predict the Economic and Environmental Effects of the Cost-Optimal Energy Renovation of a Historic Building District on the District Heating System, Energies, Vol. 13(1), 276, 2020.

[114] M. Achermann, Validation of IDA ICE, Version 2.11.06 With IEA Task 12 Envelope BESTEST, Hochschule Technik+Architektur Luzern. HLK Engineering, 2000. 
[115] BELOK, Energy efficient tap water systems in facilities (in Swedish), 2017.

[116] BEBO, Audit of heat losses from hot water circulation in residential buildingsmeasurements in 12 residential buildings (in Swedish), 2015. 



\section{Papers}

The papers associated with this thesis have been removed for copyright reasons. For more details about these see:

http://urn.kb.se/resolve?urn=urn:nbn:se:liu:diva-175144 



\section{FACULTY OF SCIENCE AND ENGINEERING}

Linköping Studies in Science and Technology, Dissertation No. 2062, 2021

Department of Management and Engineering

Linköping University

SE-58183 Linköping, Sweden

www.liu.se
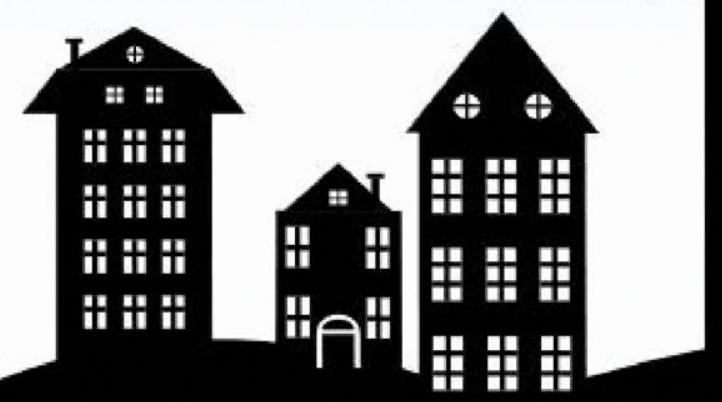

\section{II}

田早年

田计

田早蛙

田出田

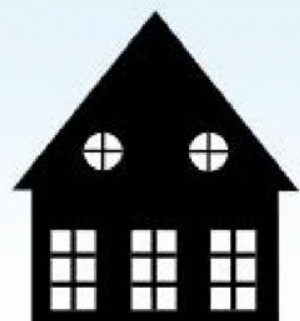

t\#\#

\#\#\#五

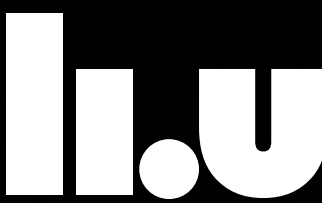

